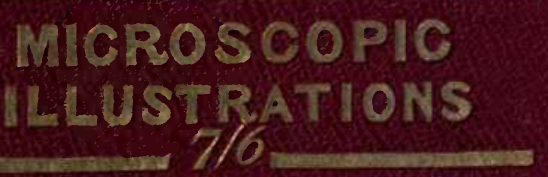




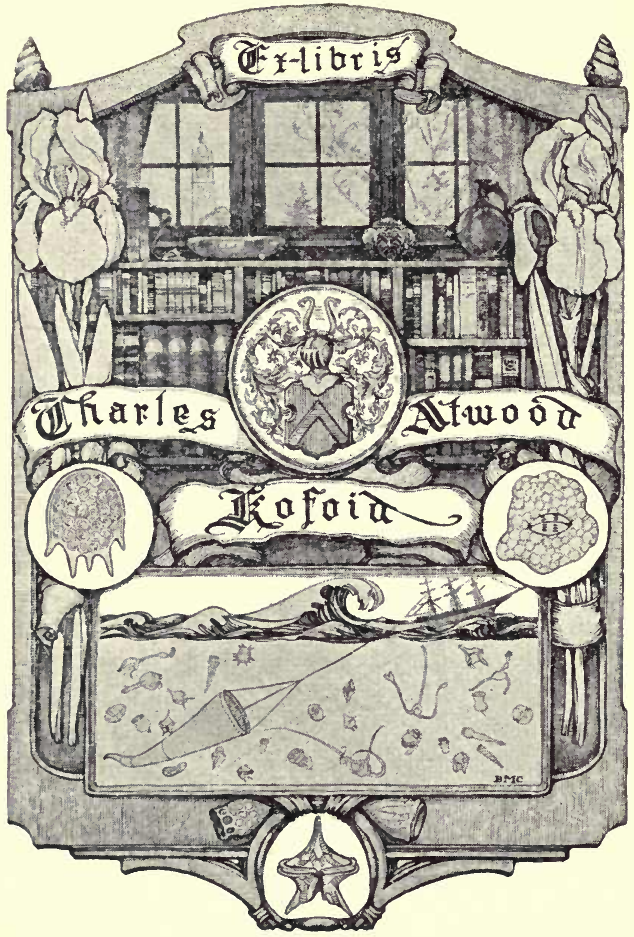


Heateet Mroygum.

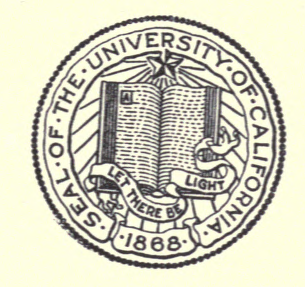

THE LIBRARY

$\mathrm{OF}$

THE UNIVERSITY

OF CALIFORNIA

PRESENTED BY

PROF. CHARLES A. KOFOID AND

MRS. PRUDENCE W. KOFOID 



\section{NEW WORKS}

oN

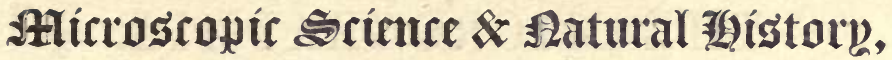

Published by WhitTaker and CO.

Just published, in 8 ro. price 8 s. (id. boards, the

NATURAL HISTORY

OF

A N I M A L C U L E S;

CONTAINING

DESCRIPTIONS OF ALL THE KNOWN SPECIES OF INFUSORIA:

WITH

INSTRUCTIONS FOR PROCURING AND VIEWING THEM.

Illustrated by upwards of 300 Magnified Figures on Steel.

TO WHICH IS APPENDED,

DR. EHRENBERG'S CLASSIFICA'TION.

By ANDREW PRITCHARD, EsQ.

Handsomely bound in cloth, 7s. $6 \mathrm{~d}$.

COLOURED IMPRESSIONS

of

ENGRAVINGS

FROM THE

NATURAL HISTORY OF ANIMALCULES.

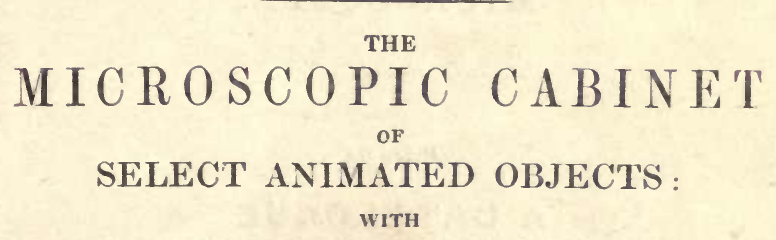

A DESCRIPTION OF THE JEWEL AND DOUBLET MICROSCOPES, TEST OBJECTS, \&c.

TO WHICH ARE SUBJOINED,

MEMOIRS ON THE VERIFICATION OF MICROSCOPIC PHENOMENA;

AND AN EXACT METHOD OF APPRECLATING THE

QUALITY OF MICROSCOPES AND ENGISCOPES.

BY C. R. GORING, M.D.

The whole illustrated by coloured Plates and Woodcuts, price 18 s. 
Lately published, price $8 \mathrm{~s}$. $6 \mathrm{~d}$.

\title{
THE MICROGRAPHIA.
}

Contents:-History and Description of Reflecting Microscopes-On Micrometers, and their Use-Monochromatic Illumination-Solar Engiscopes, and the Exhibition of Tests by them-On trying Microscopes and Engiscopes against each other, with Rules for ascertaining their comparative merits-On Eye-Pieces-Illustrations of Angular Aperture-On the most improved Construction and Management of Solar and Gas Microscopes-Cuvier's Method of dissecting Ohjects in Fluids-On a new and simple fine Adjustment for Microscopes-On making Drawings of Inanimate Microscopic Objects, by F. Bauer, Esq. F.R.S. \&c.-On a new Method of Illuminating Objects, by the Rev. J. B. Reade, M.A.

By C. R. GORING, M.D. ANd A. PRITCHARD.

Also, price One Shilling,

\section{A LIST OF 2000 MICROSCOPIC OBJECTS:}

\author{
WITH
}

REMARKS ON THE CIRCULATION IN ANIMALS AND PLANTS; THE METHOD OF VIEWING CRYSTALS BY POLARIZED LIGHT, \&c.

FORMING

A GUID E

FOR

SELECTING AND LABELLING SUBJECTS

OF

NATURAL HISTORY, BOTANY, AND MINERALOGY, FOR THE

MICROSCOPE.

Price 2s.

A C A TALOCUE

OF THE

ORDERS, FAMILIES, AND PRINCIPAL GENERA

of

\section{B R I T ISH IN SECTS,}

ARRANGED IN CONFORMITY WITH THEIR ORGANIZATION,

AND PRINTED ON ONE SIDK ONLY, TO SUIT FOR

LABELIING CABINETS. 
MICROSCOPIC ILLUSTRATIONS, fc. \&.c. 


\section{LONDON :}

Wilson \& Son, Printers,

57, Skinner Street. 


\section{MICROSCOPIC \\ I L L U S T R A T I O N S}

or

\section{LIVING OBJECTS,}

พITH

RESEARCHES CONCERNING THE METHODS OF CONSTRUCTING

MIGROSGOPES,

AND INSTRUCTIONS FOR USINC THEM.

\section{THIRD EDITION.}

TO WHICH IS ADDED,

a Suplentent an the exerification of Stitrastapic AND

AN EXACT METHOD OF TESTING MICROSCOPES.

BY C. R. GORING, M.D.

BY ANDREW PRITCHARD, M.R.I.,

HOX. MEX. 8OC. ARTS, EDIXECRGE;

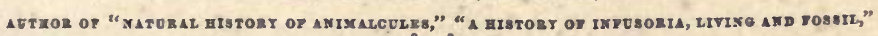
\&c. \&c.

\section{Zlontrou:}

WHITTAKER AND CO,, AVE-MARIA-LANE. 


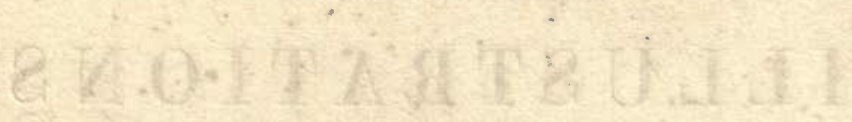




\section{6 \\ PREFACE TO THE THIRD EDITION.

In presenting to the public this edition, the Author deems it proper to remark that he has retained the same mechanical construction of the Microscope as appeared in the preceding edition. It is more especially necessary to mention this circumstance, inasmuch as of late some very elaborately constructed Microscope-stands have been made by different opticians, which, though they deserve high commendation, both on account of the ingenuity displayed in the details of their construction, and the exquisite finish of their workmanship, still, from their great costliness, their adding little to the efficiency of the optical part of the instrument, and no two makers having adopted the same form, they are not likely to come into very general use. For these reasons the original forms are here retained.

The essential principles of construction are explained in the work, and it must be borne in mind that the instructions for the use and management of Microscopes herein given apply in most cases to all, however varied in form.

The valuable memoirs of Dr. Goring, which appeared in the "Microscopic Cabinet," are given in this edition by way of supplement. This course appeared desirable as that work is out of print, and the natural history portion is now published separate, under the title of "Notes on Natural History."

The concluding paragraph relative to these Memoirs is extracted from the preface to the "Cabinet." Its accuracy has been verified by the fact, that not a single maker of Microscopes now exists (at least in this country) who fabricated Achromatic Object-glasses prior to its pub- 
lication, and the Author hopes they will induce other artists to devote their talents to this profitable branch of optical science. In making this recommendation he is aware of the feelings it will produce against him by some of the present makers and their immediate patrons, but having no interest of a private nature in these matters, it would ill become him not to promote to the utmost his favorite subject.

"The importance of certain objects in determining the qualities of Microscopes and Engiscopes is now duly acknowledged; and as no complete account of these tests at present exists, it is hoped that a full description of them will be found useful; but to render the subject complete in a scientific view, Dr. Goring has given a Memoir, 'On an Exact Method of Ascertaining the Quality of Microscopes and Engiscopes.' Of this method, which has hitherto been a secret, its value may be somewhat appreciated when it is stated that no perfect Achromatic Microscope has been produced without it; and although they have been known to the public some time, and profound mathematicians have assiduously employed their talents in the investigation of the conditions necessary for obtaining Achromatism and Aplanatism, yet no perfect instrument has been produced, excepting by the means given in this Memoir. The other Memoir by Dr. Goring, 'On the Verification of Microscopic Phenomena,' contains the sum and substance of Microscopic Science. It is condensed into short aphorisms, but I think will be found, on attentive perusal, to contain all that is essential to a practical knowledge of the subject." 
OPI N I O N S

Or

\section{SCIENTIFIC JOURNALS}

ON THE FIRST BDITION OF THE

\section{MICROSCOPIC ILLUSTRATIONS.}

"Impressed as we are with the high importance of this branch of science, and with the great value of the improvements which these gentlemen have introduced, we looked forward with the most sanguine expectations ....... and have now no hesitation in stating it as our opinion, that Dr. G. and Mr. P. have both accomplished their difficult tasks with the greatest success. The coloured engravings are executed in such a masterly manner that they will themselves bear to be seen by the microscope."

Brewster's Edinburgh Journal of Science.

"The present publication cannot fail to recommend itself generally, for it is associated with elaborate descriptions and beautiful coloured engravings of a variety of diverting and popular objects."-Journal of the Royal Institution.

" The notices of natural history in the volume before us are well arranged; the coloured engravings are executed with the most perfect fidelity; and the entire work will afford a high treat to the curious admirer of nature."-Atlas. 


\title{
OPINIONS OF THE PUBLIC PRESS
}

\author{
ON THE
}

\section{I C R O S C O P I C C A B I N E'T.}

"This is an exceedingly curious and interestlng work; the plates are marvellous."

"We earnestly recommend the Microscopic Cubinet both to the general and the scientific reader, as an original, a valuable, and an ingenious work."

London and Edinburgh Philosophical Magazine.

"We are presented," In the Microscopic Cabinet, "with engravings of the most beautiful or remarkable water-insects, and are moreover informed of their history, habits, and anatomical conformation. We have also directions as to the use of the instruments employed in these researches, and a full description of Mr. P.'s neiv microscope. * * * We cannot speak ton highly of the finished coloured engravings; they are equally remarkable for the tidelity and the beauty of their execntion. A mere inspection of these would be sufficient to create a taste for the study of a department of philosophy whlch certainly is inferior to none in the interest it is calculated to create, or the elegance of form and the harmony of adaptation which it presents to the view."

\section{New Monthly Magazine.}

"This work may be termed a practical treatise on tlue present state of Microscopes. In the descriptive portion, valuable information is imparted on the structure and habits of those most iuteresting creatures," Animalcules, Crustacea, und Insects; " and for procuring, feeding, preserving, and the best mode of examining them, useful directions are givell." Magazine of Natural History.

"This work selects a variety of living objects that have never been before described, and depicts faithfully many others that have hitherto been most iucorrectly represented. The descriptions are most elaborately written in a plain and familiar style."

Monthly Magazine.

" $\Lambda$ vast variety of practical information, popularly detailed, is diffused throughont the work; and the whole is illustrated by a number of very heautiful plates. * * * It is decidedly the most practical and satisfactory treatise on the microscope that it has hitherto been our good fortune to have met with."

"This is a very complete and interesting work." London Medical Gazette.

"Many of the descriptions of the structure and habits of animals, as observed by our Author, will be found curiously interesting. The style in which the work is got up is very creditable, and the illustrations extremely good and copious."

London Medical and Physical Journal.

“ The lovers of natural history will derive both gratification and instruction by the perusal of this work."

Register of Arts.

"This is a beautiful rolume, which must be deeply interesting to those engaged in the study of natural history. The plates are well delineated, beautifully coloured, and afforded at a reasonable rate. It is impossible to speak in too high terms of its execu. tion." London Medical and Surgical Journal.

"Some of the best executed plates and cuts that we have seen on the subject. We have no doubt that the present volume will go far to supply a desideratum; and not least as to the due appreciation of microscopes, perfection in the qualities of which is ohviously essential to the just characterization of the insect tribe."

\section{Gentleman's Magazine.}

"The greater part of this volume is taken up with descriptions of the economy and nature of aquatic insects, crustacea, and animalcules, written in a popular style, without any scientific display of terms to perplex the general reader, and is illustrated by some admirably coloured engravings, of wliose beauty and fidelity we can bear witness."

National Omnibus.

"The Microscopic Cabinet will essentially aid the cause of science." Atlas.

"This is a valuable work for scientific men, and of great assistance to the student of botany or natural listory."

Bell's old Weekly Messenger.

"The Microscopic Cabinet is a work which does almost Intinite credit to its authors, and is certainly by far the most valuable contribution which has beeu made to inicroscopic science in modern times." Mechanics' Magazine. 


\section{P R E F A C E.}

At the period of the publication of the first edition of this work in 1829, microscopes on the new principle had only just sprung into being, and some apology for a treatise upon an instrument which then apparently had little but novelty to recommend it, might have been thought requisite; since that time, however, its application to the sciences, and the pleasure derivable from it as a source of amusement, have rendered this unnecessary.

It will be found that the present arrangement of the papers is different to what it was in the first edition, that having been suited to their being published in numbers, which occasion being done away with, Dr. Goring's are now placed together, and with them the description of his instrument.

In the first chapter of this volume the reader is 
furnished with a brief sketch of the uses of the microscope, and its various improvements. This appeared to be preferable to commencing with the original Exordium, on account of the progress microscopic scrence has made in public opinion, and the enlarged view which is now taken with respect to the microscope. As, however, there are many persons who desire and expect to meet with the Exordium in the present edition of this work, it has been deemed advisable to give it entire in the Appendix, with Dr. Goring's corrections.

The three succeeding chapters are appropriated to a description of certain living microscopic objects; and containing, as they do, some remarkable particulars relating to the wonderful metamorphoses which these creatures are ordained to undergo, it is confidently hoped they will not be deficient in interest or instruction.

The remaining portion of the volume contains an account of the mechanical construction of the microscope and its apparatus; and since we have no other work devoted to this branch of the subject, affording to all persons possessing this instrument such practical instructions as are absolutely neces- 
sary for the right using and managing of it, it is fairly presumed that this will be serviceable. These instructions, it may be as well to mention, are not confined to any particular sort of microscope, but are purposely drawn up in general terms, in order that some profitable information may be gleaned from them, in the management of any microscope whatever, no matter what may be its optical construction.

From the rapidity with which one improvement has succeeded another, it is necessary, in order to come at a right conclusion as to the relative merits of the productions of different artists, to take the time at which their instruments were fabricated into consideration; for, should some of them have been made three or four years before the others, the latter will in all probability excel the former; whereas, had a comparison been instituted between the simultaneous productions of the artists, the result might have been quite the reverse.

In the explanation I have given of that remarkable instrument, the Polarizing Compound Microscope, it will be found that I have gone somewhat minutely 
into detail respecting it; and, with a view of rendering it as available as possible, have printed in the Appendix Mr. Talbot's highly interesting papers upon the polarizing properties of crystals. Although this is in itself almost a new instrument, a great deal has already been accomplished by its means, and a great variety of the hidden phenomena of nature most beautifully displayed.

The kind consideration bestowed upon the first edition by men the most distinguished in science, who had turned their attention to this subject, and the interest now so generally felt in microscopic researches, induce me to hope that the present volume--a large portion of which has been rewritten, expressly that it should contain the latest improvements-will be favourably received.

ANDREW PRITCHARD.

162, Fleet Street, London. 


\section{O N T E N T S.}

Preface

\section{CHAPTER I.}

Introductory Remarks on the Application of the Microscope to the Sciences, with an Aceount of its recent Improvements ................... 17

\section{CHAPTER II.}

On the Larva and Pupa of a Straw-coloured Plumed Culex

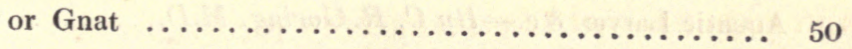

\section{CHAPTER III.}

On the Larva and Crysalis of a Day-Fly

61

\section{CHAPTER IV.}

On the Larva of a Species of British Hydrophilus ....... 70

\section{CHAPTER V.}

On the Terms employed in Microscopic ScienceWith a Description of the Vertical Microscope............... 


\section{CHAPTER VI.}

A Description of the Achromatic Microscope, together with its Apparatus, and the mode of using it :-

Round Stand Microscope-Solid Tripod-stand MicroscopeOn selecting Maynifying Powers-Candle-holder, Shade, and Condenser-Spring Double-Stage-Moveable Stages-Spring Phial-Holder-Polarizing Microscope-Apparatus for Dissecting-Simple Lenses mounted in imitation of Achromatics -Garden Clamp for the Microscope-Steadying Rods-Camera Lucida, for Drawing-Micrometer Eye-pieces-Method of Viewing Moveable Fluids in the Cavities of Crystals-Concave Specula, Silver Cups, \&c--Stops, or Diaphragms-On Viewing Transparent Objects by Daylight-On Viewing Bodies by Intermitting Light-Black Ground Illumination for Transparent Objects-On Viewing Opaque Bodies by Oblique Reflected Light-Method of determining the Forms of Minute BodiesOn Viewing the Currents in Fluids during Evaporation ......

\section{CHAPTER VII.}

Practical Remarks on Microscopes for viewing and drawing Aquatic Larvæ, \&c.—By C. R.Goring, M.D...... 146

\section{CHAPTER VIII.}

Whether there is a best possible way of constructing the Stand, or Mounting, \&c. of Microscopes (the specific purpose or purposes to which they are to be applied being first determined)-By C. R. Goring, M.D. ... 150

\section{CHAPTER IX.}

Description of Dr. Goring's Operative Aplanatic Engiscope 168 


\section{CHAPTER X.}

Manner of Observing with and Managing the Operative Aplanatic Engiscope :-

General Observations-Method of Mounting for viewing Inanimate Transparent Objects by pure intercepted DaylightMethod of Mounting for viewing Transparent Objects by Artificial Light-Mode of Mounting for viewing Diaphonous Bodies by reflected Daylight, either in a horizontal or vertical position-Way of Viewing Crystallizations of Salts and various Chemical Actions - Way of Mounting for Transparent Living Objects-Method of Mounting the Diamond and Sapphire Microscopes for Transparent Objects-Opaque Objects Method of observing Opaque Objects by Daylight, plain or condensed-Silver Cups or Specula-Mounting for Dissections, \&c.-Mounting the Diamond and Sapphire Microscopes for Opaque Objects-The Amician Catadioptric Engiscope.-By

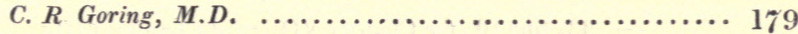

\section{APPE N D IX.}

No. 1 .

On the Optical Phenomena of certain Crystals.-By H. F. Talbot, Esq. F.R.S.

No. 2 .

Further Observations on the Optical Phenomena of Crystals. -By H. F. Talbot, Esq. F.R.S. . . . . . . . . . 219 No, 3.

Exordium.-By C. R. Goring, M.D........... 232

No. 4.

Swammerdam's Method of Dissecting and Preparing Objects for the Microscope .................... 


\section{ERRATA.}

Page 87, lines 1 and 14, for Chapter VIII. read Chapter IX.

- 93, line 10, for Chapter VII. read Chapter VIII. 


\section{CHAPTER I.}

\section{INTRODUCTORY REMARKS}

ON THE

APPLICATION OF THE MICROSCOPE TO THE SCIENCES, WITH AN ACCOUNT OF ITS RECENT IMPROVEMENTS.

" THERE IS PROBABLY NO BRANCH OF PRACTICAL SCIENCE WHICH has UNDERGONE SUCH ESSENTIAL AND RAPID IMPROVEMENTS AS THAT WHICH RELATES TO THE MICROSCOPE. IT HAS BECOME QUITE A NEW INSTRUMENT IN MODERN TIMES, AND IT PROMISES TO BE THE MEANS OF DISCLOSING THE STRUCTURE AND LAWS OF MATTER, AND OF MAKING AS IMPORTANT DISCOVERIES IN THE INFINITELY MINUTE WORLD, AS THE TELESCOPE HAS DONe IN THAT Which IS INFinitely Distant." - Sir David Brewster*.

WhrLst the mind dwells with the highest admiration on the rapid advances which are daily and hourly being made in the pursuits of science, we are recalled almost naturally to what is perhaps one of the most important considerations connected with this deeply interesting subject,-namely, how it is that we are thus enabled to make discovery after discovery into the inexhaustible treasures of Nature, and by the help of what machinery it is that we are making this astonishing progress. To investigate the genius and faculties of the human mind, the primum mobile in devising all that is great and all

* Encyclopædia Britannica, 7th edit. art. Microscope. 
that is valuable, would fall within the province of the profound metaphysician, rather than that of the practical man of science; but to elucidate the methods by which genius is aided in its high researches after truth, and in conducting those researches to their desired proficiency, although an occupation of a much humbler grade than the other, is one, nevertheless, that is by no means insignificant, or devoid of interest.

Thus, for example, an illustration of the improvements effected in the optical construction of the telescope, by which the astronomer may attain to a more perfect knowledge of the celestial bodies - by which he may discover worlds beyond worlds innumerable, and read the laws by which all those worlds are governed-cannot be deemed either unimportant or uninteresting. The invention of this beautiful instrument gave a powerful impulse to the human mind towards the study of astronomy, and every improvement since made upon it has laid open new sources of knowledge in that science, and created a greater zest for its acquisition. Even the splendid discoveries of the immortal Newton on the theory of the Moon, until verified by the observations of a Flamstead, by means of astronomical instruments, could not be received as the actual laws which govern that satellite. Even since these great discoveries, which carried the mind of man into the immensity of the heavens, and gave him a far more extended idea of the creative power than any thing could possibly have given him before, what has not the astronomer been able to effect through 
the vast perfection to which the telescope in more recent times has been brought? I need only mention the discovery of the abcrration of light; the resolution of nebulæ and of the double stars; the niotions of these binary systems, and their subservience to the same law of gravitation as governs the solar; the position and direction of the latter in space :-I might mention many others, all equally important-all marvellously grand!

And so with respect to the Microscope in aiding to extend our knowledge of the economy of this planet. Every improvement in this instrument has developed some important feature in the structure and design of the almost infinitely varied organized beings of our earth. The achromatic principle, which was at once adapted to the telescope with the most astonishing success, did not produce the same happy result on its first application to the microscope. The recent discovery of Dr. Goring, that the penetration of this instrument was dependent upon the angle of aperture, or the number of rays of light collected by the object-lens from every point on the surface of the object, was requisite for the accomplishment of this desirable purpose. By thus applying the achromatic corrections and those for sphericity to this instrument, it has now been perfected, and elevated to a grade nowise inferior to the telescope. 'The fruits of this discovery are fast pouring in upon us, and promise to yield a rich and most abundant harvest. We will allude cursorily to some of those which have been reaped already ; a few only will suffice to shew their importance, 
and to claim for the microscope a high rank among optical instruments.

The fact is, that since the modern improvements the microscope has undergone, it is being brought to the assistance, and is at the present time furthering the progress of almost every branch of natural science. To the Geologist it may be said to be a new instrument. But what has it not even now effected for him ? In his study of organic life and structure, it has unfolded to him the precise characters of divers animals and plants which inhabited and clothed our earth in ages which have long passed away. Look at the discoveries of Agassiz on the fossil creatures of the deep! By a microscopic investigation of such portions of them as have withstood the destructive power of time, namely, their scaly covering, he has been able so to group and class them, that the characters and habits of the genera belonging to each distinct era are clearly demonstrated. A microscopic examination also of the testaceous remains of sundry Entomostraceans found in slate-clay formations, now elevated much above the level of the sea, prove them to have been at some time or other imbedded in the waters. And the Naturalist may even determine by his inspection of the shell, whether the species were the inhabitants of fresh or salt water, and consequently whether the strata themselves were the indurated beds of the sea, or of some river or lake.

The most perfect animal remains which the microscope has disclosed to us, are the various loricated Infusoria 
of the division Bacillaria*. These minute creatures are so inconceivably numerous that they cover many miles of surface with several feet of thickness; as instanced in the polishing-slate and rotten-stone of Bohemia. In Tuscany whole mountains consist almost entirely of the silicified shells of these creatures; thus combining with each other in infinite numbers, to counterbalance, as it were, their individual minuteness, and to teach the unthinking this useful lesson, that Nature, in all her operations, is never employed in vain, and that, what are apparently her most insignificant productions, fall not beneath the notice of the profoundest inquirer after truth.

To the Botanist the aid of the microscpoe is indispensable. In the investigation of our fossil-flora, what does it not exhibit to us! How beautiful and delicate is the structure of the envelope of some of the fossil-fruits; those, for instance, of our London clay, when viewed under this instrument! And how important is it, that, by its assistance, we can determine with accuracy the natural orders, genera, and sometimes the very species of the trees and plants of former epochs ! How, beyond all question, is now demonstrated the vegetable origin of our coal! Preserved within a bituminous lump of coal, which has been leposited for thousands of years deep in the bowels of the earth, you may discern not only the woody fibre, its arrangement, and the disposal and form of the medullary rays, but even the most delicate of the vegetable organs, such as the spiral vessels and the beautiful 
terminations of those vessels! These are as distinctly discoverable as in the finest preparations of a recent plant. And what can be more amusing and instructive than the examination of the silicified woods, when formed into sections no thicker than the paper of a Bank-note? Thus rendered pervious to light, the organic structure of the wood becomes plainly distinguishable. And ema. nating from this, what can be a more interesting subject than the inquiry into the mode in which the silicifying process has been carried on-by which the constituent elements of the inmost and minutest portions are changed -whilst their form and situation and colour remain the same? In investigating also that extinct genus of plants, the Lepidodendra, a similar idea is raised in the mind, as to what must have been the particular state of the earth with respect to atmosphere and temperature at the period of their growth, and what the changes which have since taken place, in order to bring it to its present condition.

In our physiological inquiries into the animal and vegetable productions of the present time, the assistance of the microscope is essentially requisite. When Dr. Harvey made his grand discovery of the circulation of the blood, and first lectured upon it, in St. Bartholomew's Hospital, in 1619, he was ridiculed, and lost his practice, through maintaining what was then supposed to be so absurd and wild a theory. The idea was suggested to his mind by reflecting on the valves of the heart and veins, which were evidently so planned as to 
allow a fluid to pass but one way. All the philosophical reasoning, however, of this celebrated man could not establish, what appears to us so plain a truth, until it was evidenced in the circulation of cold-blooded animals by means of the microscope, and thus placed beyond a doubt. Discerning, as we can do, the very forms of the globules of that fluid, as they flow through the capillaries from the arteries to the veins, in obedience to the laws impressed upon them by the Almighty Creator-viewing this most sublime phenomenon, by which life itself is diffused throughout, and sustained in every part of the system-who can resist conviction of the great truth ?

Nor is it a matter of less importance in a scientific point of view, or less interesting, that by the same means we can perceive the fibrous structure of the muscles and nerves, the form and arrangement of the canals by which the internal cavities of the bones are lubricated and nourished, the glandular structure of that beautiful and complex apparatus by which the secretions* are carried on-all, and each of these, requiring but the aid of one of our improved microscopes to render them distinctly visible. Again : how admirably developed by means of the microscope are the curious and complex structures of the eyes of insects, the crystalliue lenses of those of fish, birds, \&c. $\uparrow$ and many of the other parts of the visual organs $\ddagger$. The eye-that useful and delightful

* Nouvelles Recherches sur la Structure de la Peau, par M. Breschet.

+ Philosophical Transactions, 1833.

¥ See Langenbeck on the Eye. 
portion of us which furnishes all the endless variety of objects from which we derive so great enjoymentresembles, in its peculiar formation and arrangement, an achromatic optical instrument. And if we descend to the lower classes of animals-nay, I would hardly say lower, lest some perhaps might imagine that in their small forms they do not evince as much perfection as is discoverable in beings of a higher scale, and have not all the functions which are necessary to life as full in operation as even man himself-if we enter upon an investigation of their minute structures, we can determine absolutely nothing without the microscope; and our knowledge of the very existence of many highlyorganized and active creatures is wholly dependent upon it.

Vegetable organography, upon which the modern botanist depends so much for his systematic arrangement, and with which the student is so greatly interested and amused, owes almost its very existence to the microscope. This observation will be found to apply in an especial manner both to the cellular and vascular tissues of plants. The membranous cellules of cellular tissue are sometimes not more than 1-1000th of an inch in diameter; and those of the ordinary size are about 1-200th or 1-300th. How, then, is it possible that we could become acquainted with their forms and arrangement but by the aid of the microscope? And so with respect to vascular tissue : it is absolutely indispensable toward acquiring an accurate knowledge of the structure and forms of 
these membranous tubes, and of the spiral or annular fibre which surrounds them.

A knowledge of the fructification, if I may so express myself, of that numerous and curious class of plants, the Acrogens, could not be obtained without it; nor could the existence of many of then, such as the Fungi, Lichens, Algæ, and some of the Musci, be proved. By its powers even the ashes of vegetables may be seen to contain the decisive characteristics of organic structure; and the long-debated question of the antiquarian, as to whether the "fine linen of Egypt," in the times of the Pharaohs, were of linen or cotton fibre, seeing the latter is now indigenous to that country, is for ever set at rest.

In many of the larger portions of plants, such as the cuticle of their leaves, the stomata, \&c. which require but a shallow magnifying power to display them, there is as great a difference manifested when these are viewed under an achromatic microscope, or under the old compound, as is perceptible between the most highly-finished miniature, where the most delicate features, and even the down on the skin are correctly depicted, and the mere black and white profile, where we see but the rude contour of the face. Surely, then, as works of art merely, instruments which can effect so much as this are justly entitled to a due share of consideration even from the most refined and polished minds.

In the foregoing remarks on the application of the microscope to botanical purposes, I have given the 
reader only a general outline; to enter upon any thing like details would of necessity extend an introductory chapter of this description far beyond its proper bounds. I may, nevertheless, be permitted to make use of one example by way of illustration. But how shall I select one where the materials suited to construct it are so superabundant, and where they all present so many points of interest ? It will be readily admitted that this is by no means an easy choice. I will limit my observations, however, to a single microscopic slider, and see what instruction is derivable from it. Suppose this slider to contain some sections of a recent or fossil wood; for instance, three specimens or shavings of such extreme tenuity, that if they were exposed, they would be wafted away on the slightest breeze. Let them be weighed, and they will not exceed a grain. Hand them to the chemist, and he can only prove to you that their primary constituents are oxygen, hydrogen, carbon, \&c. and in so doing he will destroy them. What, then, does an inspection of them under the microscope reveal ? It will tell you, in the first place, whether they grew up, like our forest trees, by yearly additions to the outside of their woody centres, or by internal accessions, like most of the productions of the tropics. It will tell you whether their leaves were veined or not-whether their embryos were dicotyledons or monocotyledons-whether the trees from which they were cut had branches or notand, if they had, whether these were thick and sturdy, like the boughs of the oak; or thin and flexible, like the 
branches of the fir tribe. It will tell you whether the wood might be easily cleft asunder, like deal; or would sooner break, like beech; whether it was elastic, like the pine-so admirably suited for the masts of ships; or, like the stubborn oak, would rather snap than yield to the wind. These are some of the ordinary properties developed by the microscope.

Again, in taking a more minute physiological survey, our information will be by no means less complete. For these same specimens will disclose to us, under the microscope, the form and arrangement of their woody fibres, the disposition of their barks, the beautiful structure of the tubular receptacles, by which their secretions have been carried on and their growth promoted. In short, so much will be revealed by them in this manner, that the actual distinction between a wild and a cultivated tree may be, in some cases, clearly traced. "Thus, in the cultivated cherry, the plates of the medullary rays are very thin, the adhesions of them to the bark are very slight, and hence a section of the wood of that plant exhibits a pale, smooth, homogeneous appearance; but, in the wild cherry, the medullary plates are much thicker, they adhere to the bark by deep broad spaces, and are arranged with great irregularity, so that a section of the wood of that variety has a deeper colour, and a twisted, knotty, very uneven appearance*."

Should they be specimens of endogenous woods (ver- 
tical sections of which I have at some expense and trouble lately introduced,) what a volume of instruction may be derived from them! whilst the exquisite beauty and lace-like form of the transverse cuttings will bid defiance to every attempt at describing them !

In order that this class of microscopic objects may be rendered as useful as possible, it may not be unimportant to suggest that collections of thin sections of woods should be selected according to the natural arrangement of plants. In the cases I have lately mounted, an example is given from all the principal groups; and where the genera, in any natural Order, are very dissimilar, two specimens are taken, for the purpose of instituting a comparison between them.

I need hardly mention how essential is the aid of the microscope to the Mineralogist in determining the crystalline structure of a body. In the study of crystallography, which science may be said to have been for a long time almost at a stand-still, a very extensive field of research appears to be now opening by the adaptation of polarized light to a microscopic examination of minute crystals, thus eliciting a great variety of curious and beautiful properties, entirely unknown to the world before. This subject being as yet completely in its infancy, it would be unfair to expect an elucidation of it at the present time. To convey, however, some general idea to the reader of the additional degree of interest which attaches to the phenomena of crystallization by this happy contrivance, it 
is only necessary to state, that we have now displayed to us minute crystals, with a brillancy and richness of colouring that is quite inconceivable. We see the smallest difference in their thickness marked by some exquisite change of colour; whilst the beautiful black cross in the circularly arranged crystals of zanthate of ammonia, and the cross with the coloured rings in the compound of phosphoric acid and borate of soda, \&c. \&c. excite our admiration beyond all bounds. These newly-discovered phenomena, after a patient investigation, may lead to results highly interesting, and of great importance to science.

By a simple modification of its polarizing apparatus, the microscope becomes of great value in investigating some of the physical properties of matter : it is capable of being constituted a complete polariscope, and made to exhibit the phenomena of polarization in plates of crystals cut perpendicular to their axes; for instance, the coloured rings, the black cross, the tints of unannealed glass, of amethyst, \&c.

When relaxing from the stern pursuit after the exigencies of life, where, perhaps, we may have been industriously labouring to benefit the condition of ourselves or families, what a delightful and inexhaustible source of amusement is ever open to us where a good microscope is at hand! It is not always an easy task to find innocent amusement : to find it blended with improvement is to find it indeed. We may, it is true, be entertained by the veriest trifles in life, but we shall soon grow weary of them; and even the converse of intinate 
acquaintances at times becomes vapid and dull. A recreation, to last beyond an hour, must be made to instruct as well as to amuse; it must, to a certain extent, be commensurate with what a rational and intelligent mind is in quest after, or we shall speedily be thrown upon our resources to find out a new one. A good microscope, as I have said, is a never-failing source of amusement. Were we permitted to draw a comparison between it and that grand and noble instrument, the telescope, we should be compelled to admit that it possesses very many advantages even over that instrument in this respect. We can use it at all times and seasons, and that with the greatest facility. We can invite our fricnds to pass an evening with us in being gratified with its performance, without any fear of encountering a disappointment. Not so, however, with the telescope. A few nights only throughout the year are what we may term good for astronomic purposes, and over these few we can exercise no control. Our friends may be invited-they may assemble-and the weather may prove so inauspicious as to render the finest instrument in the world of no avail. And even on the clearest night, when all our expectations are raised to the highest pitch, the wind may suddenly shift, so as to occasion the greatest interruption ; so that, perhaps, the very means we have taken to expand and elevate our notions of the infinite wisdom and power of the Divine Being, may terminate, through some mishap, in ruffling our minds, and causing an effect the very opposite to that we had designed to produce. 
The valetudinarian dare not seek his pastime from the employment of the telescope; were he to do so, his career would soon be stopped, inasmuch as his remaining out exposed to a few cold, damp nights, would at once prove fatal to him. And even those who are in the full enjoyment of health may suffer very materially by prolonging their observations with a view of attaining to some proficiency in astronomical pursuits; to say nothing of the inconvenience it occasions by breaking in upon that regularity which is so essential to the comfort and happiness of life. To the professed astronomer these remarks are not of course addressed; with him such difficulties as these do not, and ought not, to have any weight. My object was to institute something like a comparison between the telescope and the microscope as to their capability of affording rational amusement to the generality of mankind, when it is desirable to beguile a vacant hour, and where our whole time is not at our own disposal. In making out my case in favour of the microscope in this respect, I may be allowed to refer the reader to such proof as is afforded by the subjects treated of in the first three chapters of this work.

"These," says Dr. Goring, when speaking of living objects viewed under the microscope, "experience has shewn to excite the strongest emotions of pleasure and satisfaction in the great mass of observers of all ranks, whom I have always found to be most delighted by comparatively large living objects, seen with medium powers. In fact, they seem to afford the same sort of gratification with a 
menagerie of living wild beasts on the large scale; and most certainly many of them wonderfully emulate the ferocity, voracity, cunning, and cruelty of the mammalia. They prey on each other, and fight with a degree of determined obstinacy, not inferior to that of any beings whatever. They have likewise a thousand diverting pranks and humours, quite peculiar to themselves. In addition to these amiable and amusing qualities, they possess such a high degree of transparency, that their unique and beautiful internal machinery is as clearly perceptible as if they were made of glass; so that, without any dissection, we can unravel all the mysterious workings of their nature; such as the circulation of the blood, the pulsations of the heart, the peristaltic motion of the intestines, and the play of every muscular fibre. This property of transparency is not possessed by any other living beings with which I am acquainted, except the Animalcula infusoria. I may observe, that no perfect insects present so many facilities for adaptation to the microscope, or can be so easily preserved and managed; so that the larvæ, \&c. appear to me peculiarly and exclusively devoted to the consideration of microscopists*."

Having now given a brief outline of the uses to which the microscope may be applied, we will proceed to consider those practical improvements which, in modern times, the instrument itself has undergone, and which, step by step, have at length brought it to its present high state of perfection.

* Exordium, first edition, p. 6. 
Microscopes may be classed under two denuminations, simple and compound.

The simple microscope presents an object to our view under a greater angle than that which it is seen under when viewed by the naked eye; whence it is that the impression is derived of it being amplified or magnified. The amount of this amplification will be in precisely the same ratio as that when a person is seen at different distances from us : the nearer he is, the greater is the angle he will be viewed under; and so vice versá. Hence it is, that a lens which will admit of an object being placed within one inch of it, will amplify twice* as much as another the focal length of which is two inches. This quality, viz. the focal length of a lens, or its power of admitting an object within a definite distance, so that it may be distinctly visible, is obtained by giving to the surface of any transparent medium (say glass) a spherical or other curved figure. Now it will be evident that, on account of the curvature which is thus given, the rays of light which proceed from any given point in an object to the middle of the lens will pass in a more direct course through it (assuming the lens to be convex) than those which proceed from the same point to the outside or edges; and consequently the former will be less refracted or bent in their passage than the latter. All the rays, therefore, after permeation, will not proceed towards the same point in the axis of the lens, but crassing it at different distances they will enter the eye

* See Micrographia, page 63. 
confusedly, and produce a nebulous or indistinct impression of the magnified object. This defect is commonly designated spherical aberration. Another obstruction to perfect vision is occasioned by the effect produced upon the light itself, when passing from one medium into another of different density.. Light (say common white light) is a compound of coloured lights, which are not equally refrangible; that is, some of the colours are more powerfully acted upon by a refracting body than others; so that a white ray, when it enters a lens, is more or less broken up and separated into its coloured constituents, which gives a semblance of colouring to the object we are viewing. This defect is termed chromatic aberration, or dispersion.

These two great defects are to be obviated in constructing a microscope. Until within a few years, the lens of a simple microscope consisted of a single piece of glass made into a curved form, or a spherule. In order to increase its magnifying power, $i$. $e$. in order to admit an object being placed very near the lens, so that it might be viewed under a greater angle, Di Torre, Leeuwenhoek, and others, constructed lenses of spherules of exceeding minuteness-some, it is recorded, with a focal length of not more than 1-700th or 1.800th part of an inch. This method of obtaining high magnifying powers was attended with so much inconvenience in practice that it counterbalanced all the advantages which would otherwise have resulted from it. Whilst the obstructions to vision just mentioned, viz. spherical and 
chromatic aberration, were obliged to be remedied in a low power by placing a diaphragin or stop behind the lens, so as to réduce the aperture; by which means so much of the light transmitted by the lens was cut off, that the delicate structure of an object was hardly visible for want of light.

The calculations of Euler and other mathematicians were soon directed towards finding out such forms for single lenses as would occasion the minimum quantity of aberration. Still, the microscope derived but little practical advantage from their investigations; and the reason of it I apprehend was this: their formulæ were all calculated for lenses of very small angular aperture, whilst the goodness of a lens for the microscope depends upon the opposite extreme.

In 1824, in consequence of Sir D. Brewster's remarks on the diamond, I commenced making lenses of precious stones*. These, when the stones are clear, free from flaws, and from double refraction, are the most perfect single magnifiers we at present possess.

From the period just named, a new era sprang up in the history of the microscope. In 1829个, Dr. Wollaston sent forth to the world his doublet lens, which consisted of two plano-convex glasses. This invention, the result of experiment, caused a most astonishing alteration for the better in the constructing of microscopes. It suggested the idea of employing more than one glass in 
constituting a deep magnifier; and the consequence was, that we had soon devised for us a triplet, composed of three plano-convex lenses, which is by far the most perfect construction employed in simple microscopes. I may remark, however, that the use of these compound magnifiers is limited to the examining of delicate transparent objects which admit of being brought almost in contact with the lens. I may mention another improvement, though perhaps rather prematurely, viz. that the achromatic object-glass may be used as a simple microscope, and with very great advantage when the magnifying power is moderate*.

We now proceed to consider the improvements which have been made in compound microscopes. The compound, unlike the simple microscope, in which we look through the magnifier at the object itself, is furnished with a second nagnifier, designated the eye-piece, through which the sight is directed, not to the object, but to an image of it, which has been magnified by the first lens, or, as it is called, the object-glass. Now, we have noticed that the best magnifiers of simple microscopes are in fact compounds, being composed of two or three lenses; but yet they have not the double action of a compound microscope, even should it be composed of only two lenses. Dr. Goring, however, to prevent any confusion arising between the one and the other, proposed the 
name of Engiscope* for the instrument we are now considering.

In this instrument, it is of the utmost importance that the object-glass forming the image, which is to undergo a second amplification by the eye-glass before it meets the eye, should be as perfect as it can possibly be made ; because, every error occasioned by it will be magnified by the eye-glass, and thus cause very great confusion. Dr. Goring having this in view, directed the late Mr. William Tulley, in 1824, to make him a triple achromatic object-glass, for a compound microscope. With this, after many trials, during which the Doctor had contrived to enlarge the aperture of his lens, he found that he could distinguish some delicate markings on certain animal tissues, which, with equal magnifying powers having less aperture, he had not been able to discern.

Hence originated the discovery, that the penetration of a microscope is dependent upon the angle of aperture of its object-glass.

As this discovery has tended, in a great measure, to bring the microscope to a high state of perfection, I may be permitted to give a familiar explanation of the reason why an increase of aperture is so efficacious. For the details of the subject, the reader is referred to Dr. Goring's own account, in the Micrographia, Chap. VII. I am the more anxious to give this explanation, because many persons are at a loss to conceive how it is that in a compound achromatic microscope, where the light has 
to pass through several glasses, each of which impedes a portion of the rays, whilst others are lost by reflection at the surfaces, that more should remain for the purpose required than when a single glass is employed.

Every one who has considered the subject at all, will understand that by a series of glasses of different media, aberrations, \&c. may be corrected and almost entirely dismissed; but it is not so readily perceived how a compound microscope, having a series of glasses, can, with less illumination, give a brighter and more vivid picture, with more of the detail or minute structure of an object, than can be obtained with greater illumination, by a single lens. In this particular, however, consists the main advantage of an achromatic.

Let me premise that, in order to render any object visible, it is necessary that rays of light should proceed from it, either by reflection from its surface, or by transmission through it, to the eye. Again, if the number of rays be insufficient, the object cannot be seen, notwithstanding we employ a microscope for the purpose. Bearing this in mind, I will endeavour to explain how an increase of angular aperture in an object-glass, independent of any increase of its magnifying power, will admit a greater quantity of light from any given point on the surface of an object to pass through the lens, so as to render the structure of the object visible.

Let $\mathrm{A}$, and $a$, represent two objects, in all respects alike, and let us employ two microscopes, of equal magnifying powers, for the purpose of viewing them. 
Suppose that we are going to look at some spot on the surface of $\mathrm{A}$, or $a$, which we will imagine to be a delicate

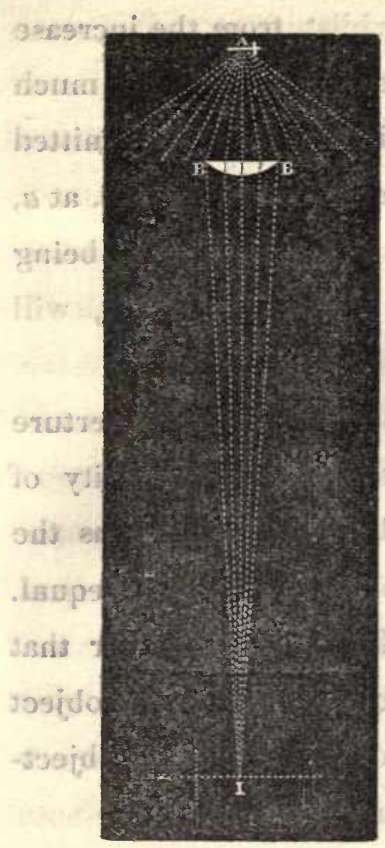

Fig. 1.

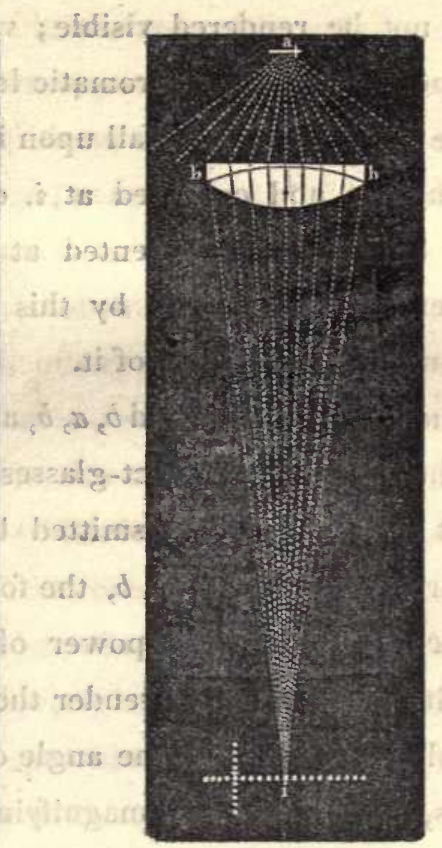

Fig. 2.

tissue. By a well-known law of light, the rays proceed in right lines, in all directions, from this spot, in the manner shewn by the dotted lines in both figures. Suppose B, B, and $b, b$, to be two object-glasses, of equal focal lengths; the former a single lens, of the best construction, such as was used in the old compound microscope, and the latter a lens of the newest form, termed an achromatic. Now, these object-glasses will form their respective images at $\mathrm{r}$, and $i$, and they will be of equal dimensions. But if the number of rays proceeding from $\mathbf{A}$, and falling upon the single lens $\mathbf{B}, \mathbf{B}$, is 
not enough, when collected at $\mathrm{I}$, sufficiently to stimulate the eye, any minute pore, striæ, or other marking at $A$, will not be rendered visible; whilst, from the increase of aperture in the achromatic lens, $b, b$, allowing much more light from $a$, to fall upon it, and to be transmitted through it and collected at $i$, every marking, \&c. at $a$, will be clearly represented at $i$; and the eye, being powerfully acted upon by this increase of light, will become highly sensible of it.

The angles $\mathbf{B}, \mathbf{A}, \mathbf{B}$, and $b, a, b$, are the angles of aperture of the respective object-glasses; and the quantity of light collected and transmitted by each will be as the squares of $\mathbf{B}, \mathbf{B}$, and $b, b$, the focal lengths being equal. Hence it is that the power of a mieroscope, or that faculty it possesses to render the structure of an object visible, depends upon the angle of aperture of its objectglass, and not upon its magnifying power alone.

But it may be supposed, perhaps, from this reasoning, that if we throw a greater quantity of light upon an object, so that more may be collected by the object-glass, we shall be the better able to define its structure; which would probably be the case if the additional light could be thrown only upon those minute parts which we wish to examine, and not upon the whole object. But as we cannot do this - as the increase of illumination cannot be made to increase the relative proportions of light which proceed from these minute parts, the intended advantage will not be derived.

Having shewn, however, that the goodness of a 
microscope is chiefly dependant upon the angle of aperture of its object-glass, (freed from the aberrations just mentioned), it is of some importance to be able to measure this angle with accuracy. When the object-glass consists of a single lens, or of two cemented together, its angle of aperture may be easily determined by the actual measurement of its acting focal length and diameter. But if it consist of two or three pairs of lenses, not in contact with each other, this mode of measurement will not give a correct result. The simplest and best method in such cases, and indeed I may say in all cases, is by means of the Microscope-gnomeometer, described at page 218 of the Microscopic Cabinet.

Considering what has been just stated, I proposed, in 1835, that achromatic object-glasses should be applied to the micrometer microscopes which were made use of for reading off the divisions whilst making the trigonometrical survey of Ireland. They have since been used by astronomers for similar purposes in the microscopes attached to transit circles; the advantage of which is, that observations can be read off much longer in the twilight of an evening without artificial illumination; thus causing less fatigue to the eye than is experienced by looking alternately at objects illuminated by different coloured lights.

Lest it should be imagined that I have dwelt somewhat too much upon the subject of angular aperture, I will adduce a case in point to shew the necessity of its being better understood than it is. I have in my possession at 
this moment a triple object-glass, evidently made in imitation of one of Mr. Tulley's achromatics. In con. structing it, however, the optician, a person of great respectability, was so unacquainted with what an achromatic is designed to effect, that he actually placed a stop behind the lenses, so that, notwithstanding the focal length does not exceed half an inch, an angle of aperture of only 7 degrees is obtained. This object-glass of course is inferior to a common lens: and hence has originated the erroneous notion that the introduction of achromatics has been no improvement to micruscopes.

Should the question arise, why a single lens, or a combination of convex ones, cannot be mounted so as to have an angle of aperture equal to that in achromatics, the answer is, that it can be done: I have often done it; and it affords an excellent method of shewing by comparison the vast superiority of the latter over the former. Long experience has taught the optician that common lenses, when mounted in this manner, occasion such great aberrations that there is no possibility of obtaining any thing approaching to a distinctness of vision. Hence has arisen the necessity of placing a small stop behind them; the effect of which being to transmit only a small pencil of the light collected by the glass, the chromatism is reduced and rendered imperceptible. So effectually, indeed, is this accomplished, that when one of our ablest philosophers was told by Dr. Goring that he proposed to make the object-glasses of microscopes achromatic, he exclaimed, "I thought they had always been so constructed." 
The first effective achromatic object-glass for a microscope was made, under the direction of Dr. Goring, by the late Mr. W. Tulley, in 1824. It consisted of three lenses, a concave inclosed within two convex ones. From its great thickness, when compared with the ordinary objectglass, it received the appellation of the thick * aplanatic object-glass for diverging rays.

It appears that the celebrated Professor Amici, of Florence, constructed some achromatics about the year 1815, but the happy discovery of test objects not being then made, nor the value of angular aperture understood, they were abandoned as useless at that period. In this country Mr. Tulley went on improving the triple form he had adopted; and notwithstanding he found it extremely difficult to work it on a small scale, and was thus obliged, in order to get magnifying power, to have recourse to a long body and a deep eye-piece, still he made the angle of aperture as large as he well could. The foci of his object-glasses were about 9-10ths of an inch, and the angular aperture 18 degrees. Subsequently he increased the angle to 38 degrees, by placing another triple achromatic before it of 6 -10ths, so that the acting focus of the combination was only 3-8ths of an inch.

The objections to this arrangement are, that it is liable to get out of adjustment-that it has twelve reflecting surfaces, the lenses not being cemented together-and that it cannot be worked of very short focus. It is considerably easier to obtain any given angle of aperture

\footnotetext{
* See a section of it, drawn in plate 3 of the Micrographia.
} 
with combinations of short foci than with shallow lenses; so much so, indeed, that 60 or 70 degrees with a focal length of 1-10th of an inch is gained with as great facility as 20 degrees with an inch focus. Thus, in proportion to the minuteness and delicacy of an object, the focus must be shortened, if we would have a suitable penetration; otherwise, the labour and time expended upon correcting the pencils of light, more especially the oblique ones, will be immense. The best proportions of angular aperture to focal length are treated of in another part of this work.

About the time of Dr. Goring's applying achromatics to the microscope, M. Sellique, in France, invented and executed a new description of object-glass, part of the arrangement of which, on account of the many advantages it possesses, is, and will probably continue to be, adhered to by opticians. Its novelty and chief merit were, that it consisted of several pairs of corrected lenses; each pair having a plano-concave of flint glass, and a double convex of plate glass, cemented with mastic varnish. The latte ${ }^{\circ}$ of these lenses was turned towards the object; by reason of which, as well as from the want of angular aperture, the combination was not so effective as it was afterwards rendered. The genius of $\mathrm{M}$. Chevalier, of Paris, soon led him to perceive some of these defects. He saw at once that the plan of combining thin pairs of lenses greatly diminished the chromatic dispersion, and he saw also that the placing the convex lens next the object must necessarily increase the aberration from sphericity. He 
therefore mounted his glasses with the flat side of the flint lens foremost, and he made the whole still more valuable by the superiority of his workmanship. It was not, however, until these object-glasses arrived in this country, and their aperture was increased by Dr. Goring, that their full effect was brought out.

In the early productions of $\mathbf{M}$. Chevalier, the foci of the different pairs of lenses composing an object-glass were of unequal lengths; the anterior pair having the shortest; and the posterior the longest focus. Some of these sets were admirably corrected; and it is much to be regretted that on account of the comparative difficulty there is in this plan of constructing them, he should have been induced to make the pairs of equal foci, by doing which the maximum of angular aperture cannot be obtained together with a fiue definition. When we consider the errors which are to be corrected in an object-glass, in order that it may produce a magnified representation of an object sufficiently perfect for it to undergo a second amplification by the eye-piece ; and when we consider further that many errors, which under ordinary circumstances are barely appreciable, become very evident as soon as some principal error is sublued, it is not surprising that the achromatic construction has been so long progressing towards its present state of perfection. To say nothing of spherical and chromatic aberration, before mentioned, it is no easy task to correct for the central and oblique pencils, so as to obtain a moderately flat field; the more especially when we consider how restricted we are to certain forms 
in our lenses, through the necessity of their being cemented together to prevent loss of light. To say nothing of the errors arising from the irrationality of the spectrum-of the difficulty there is in centering and adjusting the lenses-of the minuteness of the scale upon which the whole is constructed, insomuch that the slightest variation in the thickness of a lens (inperceptible to the eye of a workman) is quite enough to alter the state of the aberrations in finely corrected object-glasses of great angular aperture; nay, that even the thickness of the film of glass, or mica, used for the purpose of preserving an object, may do this - it is not difficult to understand that there have been great obstacles to surmount in constructing an achromatic.

The talented Professor Amici, about the period of his first attempt at achromatics, invented a reflecting microscope. This instrument not having any chromatic dispersion to contend with, and only one surface to be figured, was soon constructed with a considerable angle of aperture. Hence its performance so far excelled that of any other, that he was induced to lay aside his refracting microscope at that time.

When an account of this microscope reached this country, Dr. Goring, in 1824, suggested the idea of working its concave ellipsoidal surface with a shorter focus and a larger angle of aperture. Now, although the working of a metal is in itself more difficult than the forming a surface to a lens, yet the whole thing exhibited so many facilities over the constructing of an achromatic 
lens, that a skilful artist found but comparatively little difficulty in succeeding. For, look at the loss of time which must of necessity be incurred in making trial of an achromatic. Every time each lens has to be tried, it must be removed from its holder, the cement cleared off, and then placed in its setting; whereas a metal is always ready; and there are no refractive or dispersive powers to be ascertained, as with lenses, so that the Amician reflecting microscopes were soon brought to their most perfect condition. They have been made with an angular aperture of $5 \Sigma$ degrees, greatly surpassing all the achromatics of that time.

The improved Amician microscope soon became a decided favourite with amateurs, and had it not been that considerable tact and experience were required in bringing out "its mettle," and that its range of effective powers was limited, it would never, perhaps, have been driven out of the field by our present achromatic microscopes. I was soon convinced that of the three instruments-the Jewel-doublet, the Amician reflector, and the Achromatic-the latter would ultimately come into general use. And entertaining this view of the subject, I published, in conjunction with Dr. Goring, a very full account of the method by which an artist may test the value of his productions, and know whether or not he is proceeding in the right path; for I conceive that it is of no trivial import to have the causes of defects pointed out, when we desire to correct them. Since this publication in the Microscopic Cabinet, other artists besides the 
late Mr. Tulley have succeeded in producing achromatic object-glasses.

In the same work, the amateur is made acquainted with a class of curiously organized bodies, which require a certain degree of perfection in a microscope to render their structure visible, and thus enabled to exercise a salutary check over the workman. Since this work appeared, the achromatic microscope has been elevated to such a pitch of excellence in this country that it stands unrivalled throughout the world. We can now construct object-glasses with angles of aperture of great extent, and with the aberrations so accurately neutralized, that hardly any thing remains but the colouring from the secondary spectrum, or that which is occasioned by the irrationality of the dispersive powers of the different media employed in their construction. It is not to be expected that much more can be done; unless, indeed, other substances could be found for the making of lenses, such as will obviate those defects, which it is impossible for the workman to remedy with his present materials.

Many valuable and interesting additions to microscopic science have been made from time to time by Sir David Brewster; these should not be passed over without proper notice; but since Sir David has so ably described them himself, it is far more becoming in me to refer the reader to his works, than to enter upon an explanation of their merits in this place.

Our observations have been hitherto directed almost exclusively to the optical portion of microscopes, and 
more especially to the object-glasses of compounds ; eyepieces not having been so much attended to of late, unless, indeed, by Professor Airey and Mr Coddington. We must not, however, omit to mention Dr. Goring's plan for constructing these of corrected lenses; an improvement which has been carried into effect at Vienna.

A few words may be added on the subject of mounting these instruments for use; a consideration of so much importance, that, if it be not duly regarded, the most perfect object-glass will be comparatively of little value. I have seen many simple microscopes on stands so suitably formed, that a great deal more might be done with them, than with fine achromatics badly mounted. The necessity of having convenient stands for microscopes seems not to be much attended to, as yet, on the continent, their's being seldom suited for more than one class of observations. I would not be understood as disregarding the nicety of their workmanship; on the contrary, the beautiful finish they give to their productions is hardly to be surpassed by us. As a large portion of this work is devoted to the mechanical part of the microscope, it is unnecessary for me to enlarge upon it here; I may observe, however, that since the publication of the first edition, considerable attention has been bestowed upon this subject, and that the principles herein laid down are more or less adopted in the construction of all modern instruments. 


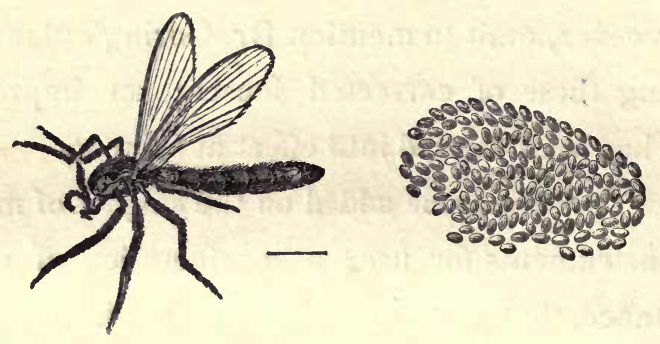

CHAPTER II.

On the Larva and Pupa of a Straw-coloured Plumed Culex or Gnat.

Tipula cristallina of De Geer.

Chironomus plumicornis of Fabricius.

Corethra plumicornis of Stephens.

Transparency is a quality so essential to the display of the internal organization of living objects, that many devoid of it are often disregarded, as of comparatively little interest. The object now before us, however, is so remarkably pervious to light, that under the microscope we are enabled to view every part of its interior structure with facility. Indeed, it is diaphanous in such a degree as to render it difficult to be discovered in the waters in which it resides, for it assimilates nearly in colour to them, during the infant part of its larva state. 
Had its pellucid nature been its only quality, as an object for the microscope, it would have been worthy of attention; but it possesses others which render it a subject of the highest admiration to all who have seen it under a good instrument.

This larva, which is produced from an egg deposited by the perfect insect, inhabits still waters, and may be found in canals and clear ponds which have a sandy or gravelly botton, but iz seldom met with in places where there is much herbage or water grass. In 1829, it was found remarkably abundant in the small ponds in Epping Forest; and in the same year, a fine large variety was met with near Killarney, in Ireland.

The most certain time to procure it is during the mouths of May and June, though it may occasionally be obtained on warm days in December and the other winter months, provided the wind is not very high-a circumstance which it is important to attend to, and which will be again adverted to in our remarks on the weather best suited for procuring aquatic insects.

The best method of obtaining this creature is by means of a collecting net, made of linen cloth, which, after

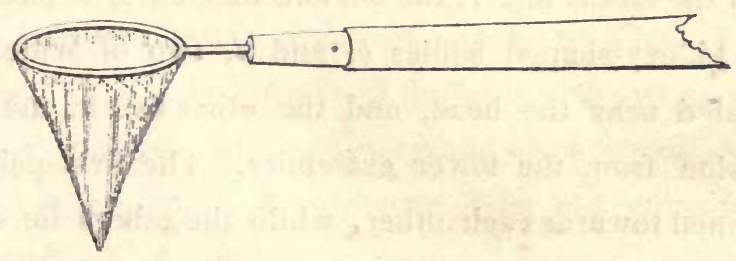

being immersed in the water, near the edge, must be taken out, and its contents removed into a glass jar. 
These must then be carefully examined by removing small quantities at a time into a white saucer, or small wide-mouthed phial. When they have been examined in this vessel with a hand-magnifier, the objects sought for should be removed to a store-jar, and the refuse thrown away; then inspect another portion, as before, until all the water taken at a draught has undergone examination.

Although nearly a quarter of an inch long in its nascent state, this larva can scarcely be observed without a hand-magnifier of abont two or three inches focus (unless the collector be short-sighted), as all its parts are nearly colourless, except two pairs of kidney-shaped bodies, which have a metallic appearance, and are nearly opaque, as shewn in the plate at $b$, and $d$, in the magnified side view, fig. 1 .

The drawing, fig. 1, represents the creature in the larva state. Fig. 2, shews the same being a day afterwards, when it had changed to the pupa state. On comparing the two drawings, however, a very remarkable and complete change of structure throughout will be clearly perceived.

In the larva, fig. 1, the obvious and curious parts are the kidney-shaped bodies $b$, and $d$, two of which are situated near the head, and the other two in the third division from the lower extremity. The first pair are inclined towards each other, while the others lie in parallel planes, as represented in the plan, or bird's-eye view, drawn of the natural size in fig. 3. Physiologists have not ascertained what may be the functions performed 
by these singular organs: it is worthy of remark, however, that a similar structure is observable in the tadpole, and figured in Sir Everard Home's Lectures on Comparative Anatomy*. The other parts of its structure, which appear equally singular and curious, are a number of globules, $a$, which are situated near the first pair of bodies, $b$. These globules have a slight oscillatory motion in different directions, and, like the reniform bodies, seem to have a metallic lustre, but are not opaque. From the exquisite polish of these globules, they reflect the forms of surrounding objects, as window-bars, \&c. which are indicated in the drawing by small squares, resembling the images formed by convex mirrors.

When the larva (as shewn of the full size in fig. 3 ) is examined from above, it exhibits the position and decussation of the various muscles lying along the back, which are observed to cross at the joints, and at points situated midway between them.

The alimentary canal appears to contain some particles of a pinkish coloured matter, and has a slight peristaltic motion: but every part of the object, as seen beneath the microscope, is so accurately noted in the drawing, that a more minute description must be deemed superfluous.

If the insect have a sufficient supply of food, it only continues for a few weeks in the larva state, when it rapidly changes to the pupa, shewn in the drawing, fig. 2. When it is desirable to preserve it for the microscope, 
this change may be retarded by keeping it in clear spring or river water. The former seldom offers sustenance to animalcules, and therefore effects this object; which is often very desirable, on account of the scarcity of this species.

The transformation of this animal from the larva to the pupa is one of the most singular and wonderful changes that can be conceived; and, under the microscope, presents to the admirer of nature a most curious and interesting spectacle. Although the whole operation be under the immediate inspection of the observer, yet so complete is the change, that its former organization can scarcely be recognized in its new state of existence.

If we now compare the different parts of the larva with the pupa, we remark a very striking change in the tail, which, in the previous state of being, was composed of twenty-two beautifully plumed branches; while, in the latter, it is converted into two fine membranous tissues, ramified with numerous vessels. This change appears the more remarkable, as not the slighest resemblance can be discovered between them, nor are the vestiges of the former tail readily found in the water. The partial disappearance of the shell-like or reniform bodies is another curious circumstance. The lower two, it may be conjectured, go to form the new tail ; for, if the number of joints be counted from the head, the new tail will be found appended to that joint which was nearest to them in the larva state, as referred to by the dotted line $d$, connecting figs. I and 2. The two small horns, $c, c$, 
which form the white-plumed antennæ of this species of gnat, when in its perfect state, are discernible in the larva, folded up under the skin near the head, at $c$, in fig. 1. The alimentary canal appears nearly to vanish in the pupa, as in that state there is no necessity for it, the insect then entirely abstaining from food; while, near this canal, the two intertwined vessels, seen in the larva, have now become more distinct, and are supplied with several anastomosing branches.

During the latter part of the day on which the drawing, fig. 2, was taken, the rudiments of the legs of the perfect insect might be seen, folded within that part which appears to be the head of the pupa; and several of the globules had vanished, those remaining longest that were situated nearest the head. It may be necessary to observe, that the head of the pupa floats just under the surface of the water ; and the insect, in this state, is nearly upright in that fluid; while the larva swims with its body in a horizontal position, or rests on its belly or sides, at the bottom of the pond or vessel in which it is kept, the fringed tail being downwards.

The circuitous manner in which the Creator appears to produce this species of gnat, and many other of His smaller creatures, is truly wonderful. Other beings are produced directly, either from the egg or the maternal womb. As, however, the Deity does nothing in vain, it may be presumed that He must have had in view some important object in the preliminary steps through which these beings have to pass-from the egg to the larva, crysalis, 
and perfect insect; and, however low these minutiæ of nature may be held in the estimation of the unthinking mass of mankind, this most elaborate proceeding renders it not improbable that they may be deemed by Him choice and exquisite productions. These mysterious operations of nature, as detected and unravelled by microscopes, are surely GRAND AND CAPITAL SUBJECTS FOR OBSERVATION. I should pity the man who scorned to be amused by inspecting these MARVELLOUS METAMORPHOSEs, and disdained to be informed of the manner in which they are effected. What a magnificent spectacle must such a transformation present in the solar or gas achromatic microscope, exhibited to a whole compary with all the accuracy and fidelity which the pictures formed by those instruments are capable of displaying!

The colour of the larva when young is a faint and scarcely perceptible yellow; but as it approaches the change, it assumes a richer and deeper colouring, and all its internal parts acquire their definite forms and tints, as exhibited in the drawing.

The natural history of this identical species of culex is unknown, not having been noticed by any British writer on entomology. The intense interest, however, which, under the microscope, it excites in the observer, will always render it an object of value. Other species of the gnat are well known; and a description of the common gnat, from the egg to the perfect insect, has been illustrated by Swammerdam, in his work entitled Biblia Natura, sive Historia Insectorum*; in which are two

* Tom. II. Tab. xxxi. et xxxii., 1737 ; also Reaumur's Hist. Insect. 
folio plates entirely devoted to it. 'This, however, is very different from the species exhibited in our drawings. Indeed, the larva and pupa of the common gnat are too opaque and uninteresting to be of much value as microscopic objects, except in their transfiguration.

A curious circumstance attends the observation of this insect : so rapid is its locomotion, that it torments the eye while attempting to delineate it, presenting alternately its head and tail to the observer. This it effects by bending itself laterally into a circular form, and suddenly whisking round in the opposite direction to that in which it had just bent itself.

In the dark ages of the world, when man considered it beneath him to be watchful of, or attentive to, the workings of Nature, and when superstition exercised an undue bias over his mind, the new phases which a creature assumed were conceived to be miraculous conversions, altogether enveloped in mystery. Now-a-days, that his zeal for investigation has led him on to a greatly extended survey of Nature, and to a more minute acquaintance with her operations than his ancestors were wont to possess-not but that the ultimate causes to which those operations are subservient remain as much a mystery as they ever were-his pride and arrogance would instigate him to get rid of every thing approaching to difficulty in the whole routine of creation. He would tell you that the metamorphoses we observe in insects, like those we have been describing, by which a living creature, an inhabitant of the water, whose life depends 
upon its being immersed in that fluid, becomes a free denizen of the air, incapacitated for a longer existence in the former element, are of easy explanation : he would tell you that the different transitions which the being has to pass through, from the larva state to the condition of the perfect fly, are but the semblance of a change ; for that if you examine it just previous to the change, you will discover the future fly folded $u$ p in the case of the larva, and ready to issue forth when the covering is removed. How badly this will serve for an explanation of the whole phenomenon, and how little it detracts from the greatness and the mystery of the change that has been wrought, is sufficiently evident to every reflecting mind: for, had the larva been examined in the early state, not the slightest indications of the future fly would have been traced. A gradual development of new forms and new organs has been carried on under this old covering, and an absorption of old forms and organs; which, however much it may seem at variance with the antiquated notions of our ancestors as to there having been an actual conversion of old matter into new, is not a whit the less marvellous. The mere bursting forth of the creature from its envelope is but a very small part of the vast transaction.

Many species of this genus of insects are, in their perfect state, possessed of a sheathed proboscis, containing instruments with which they are enabled to pierce the skin of men and cattle, injecting at the same time an acrimonious fluid into the wound. The species 
we are now describing, however, has not been examined minutely enough to determine the form of these organs. It is of a light straw colour, and has two beautiful antennæ or feelers.

The wings, also, of this gnat are of a delicate straw colour, and make very beautiful objects, when mounted under thin glass in sliders. Some species have their wings marginated, and covered with fine scales. 'These, as well as the feathers on the edges, are good objects for the microscope, and exhibit five or six longitudinal lines on each, which are so strongly marked as to be seen with any kind of light, and do not require superior penetration in the instrument, to shew them. The whole wing may be seen very beautifully under Goring's improved Amician Engiscope*, with its lowest power, which is equivalent to a lens of a quarter of an inch focus. To the larva and crysalis of insects this instrument cannot be applied satisfactorily, as it does not take in the extent of field necessary to shew the whole at once. On this account the achromatic microscope has the decided advantage, from the low power and large area which can be obtained by it. In examining this larva with the microscope, it will be best seen when the light is thrown obliquely on it; though, when low powers are used, much attention to this particular is not required.

These insects generate while hovering in the air, and the female lays her eggs in the water, selecting an unfre- 
quented spot, where she may deposit them free from danger. This is probably the cause why this larva is discovered with so much difficulty; the collector being seldom able to procure it two seasons consecutively in the same place.

The vignette at the head of this chapter was drawn from a specimen bred in a vase. Whilst in the act of producing the cluster of eggs figured on the right side, I took and preserved it in gum. The eggs were removed from the surface of the water on a slip of glass gently introduced beneath them. These measure between the one-fortieth and one-fiftieth of an inch in length.

The short line between the two figures indicates the actual length of the body of the Tipuladian Gnat. 
CHAPTER III.

On the Larva and Crysalis* of a Day Fly.

Ephemera marginata of Stephens.

When this larva issues from the egg, which it does in the decline of summer, it has at intervals an unsteady motion-in a manner, as it would seem, involuntary. During this stage it is scarcely visible to the unassisted eye, and is very pellucid. As it increases in size, the serpentine vessels attached to the sides of the animal become more apparent, and the tail assumes that rich feathered appearance, which, in conjunction with the paddles, form its pre-eminent beauty.

While the insect is very young, it is a well-suited object for the solar achromatic microscope, in which it will afford an ample fund of amusement, when represented on a screen, and dilated to the extent of about two feet in length. If the instrument be truly aplanatic, every part of the insect's internal organization may be clearly seen; and the peristaltic motion of the intestines, the circulation of the blood, and the pulsation of the dorsal vessel, can be observed without the least ronble, by any number of persons. In the latter circumstance the principal adrantage of this instrument con-

* It may, perhaps, be termed either, according to its state of growth. 
sists ; for it cannot be denied that an aplanatic compound microscope will exhibit these appearances with more distinctness, and without any risk of killing or injuring the object by exposure to the heat of the sun's rays condensed upon it.

As the creature continues growing, it assumes a variety of colouring, and becomes more opaque as its change approaches towards completion, which takes place in a few months from the time it leaves the egg. The eyes are reticulated; as represented in figure 4 , plate 11 , and are of a citron colour ; while the body exhibits a most beantiful play of different tints, and finally assumes that of a rich brown, with various shadings. The large air-vessel (trachea)* which runs along each side of the body, together with its numerous ramifications traversing the different membranous leaf-shaped paddles, are now of a dark colour, and the elytra, or wing-cases of the future insect, become daily more and more apparent.

The magnified representation of the larva (fig. 4) was taken just previous to its change to the perfect insect. Fig 5. gives the real magnitude of the creature; and fig. 6 exhibits a view of the perfect insect of the natural size.

During the infant state of this larva's existence it is very transparent, displaying, under the microscope, in a most surprising manner, the circulation of the blood.

The systems of respiration and circulation in insects differ most materially from those of the vertebrated ani-

* The coat of this vessel differs from that of most larvæ, a fact not noticed by naturalists. 
mals. In land animals the function of respiration is performed by lungs; in fish by gills : in both of which, however, the blood is propelled to the respiratory organ to be aerated. In insects, on the contrary, the air is conveyed through the body in vessels, called the tracheæ, and the blood is aerated by circulating around these vessels; whence originates the term, a diffused circulation. In place of the heart is substituted a single propelling organ, which, from its peculiar situation, has been named the dorsal vessel.

The circulation of the blood in this larva is shewn in a magnificent manner in an achromatic microscope, with a triple-cemented object-glass of an inch or half an inch siderial focus. For this purpose I would recommend the selecting of a young specimen about one or two-tenths of an inch in length, when it has just shed its skin, at which time the entire creature is exceedingly pellucid.

Around the large air-vessel which passes down each side of the body, as also along the legs, antennæ, and three-forked tail, the oat-shaped globules of blood may be seen to pass rapidly at every pulsation of the dorsal vessel. This vessel, according to Mr. Bowerbank's observations*, "extends nearly the whole length of the body, and is of great comparative magnitude. It is furnished at regular intervals with double valves about equal in number to the sections of the body." A portion of this vessel, with its valves, is represented in the annexed figure. "Both above and below each of these sets

* Entomological Magazine, vol. 1, page 240. 
of valves is a pair of singular-looking appendages, $a, a$. They are probably nervous ganglions, auxiliary to the motion of the vessel, but so exceedingly pellucid as scarcely to be defined. The action of the valves is a most interesting and beautiful sight. While in their greatest state of collapse, the point of the lower valve is seen closely compressed within the upper one. At the commencement of the expansion of the artery, the blood is seen flowing in from the lateral apertures, (as shewn by the arrows) and at the same time the stream in the artery commences its ascent. When it has nearly attained its greatest state of expansion, the sides of the lower valve are forced upwards by the increasing flow of the blood fiom the section below the valve, the lateral openings are closed, and the main current of the blood is projected through the two valves."

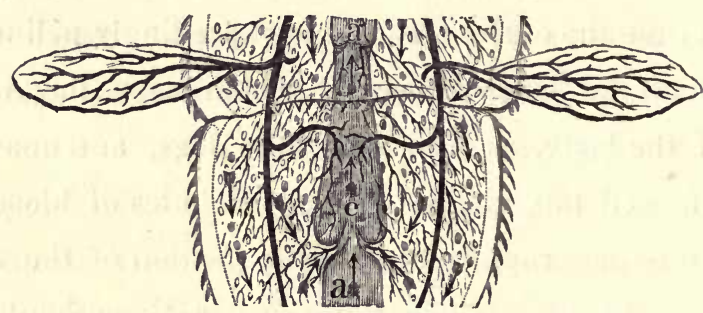

A portion of the larva of the Ephemera, greatly magnified, displaying the structure of the Circulating System.

"It is not easy to see this beautiful structure of the valves of the great dorsal vessel, for it is only when the insect is in a state of exhaustion, or has been just so much compressed as to destroy voluntary motion without entirely depriving it of life, that it is possible to subject it 
to a power sufficiently high to discern these extremely delicate and transparent tissues; and even then, to see them to the greatest advantage, recourse should be had only to such as are in the last three or four sections of the body."

When the larva is dead, the particles of the blood, of an oblong figure, may be distinctly discerned in its forked tail; and their motion is perceptible in the limbs for nearly an hour after they are separated from the body. These particles, like those of the human blood, assume a spherical form when mixed with water.

The peristaltic motion of the alimentary canal will also present, under a good instrument, a beautiful and interesting appearance.

The three-pronged tail of this insect, in its advanced age, is beautifully fringed with clusters of fine, straight, smooth hairs or bristles, several in each bunch, as represented in fig. 4. As the time for its transformation approaches, the central prong of the tail becomes more transparent, and assumes the appearance of a jointed tube, or shell-like case ; while the two exterior ones distinctly exhibit portions of the tail of the perfect insect inclosed within them, as shewn in the drawing. The same may be observed as to the legs, which are seen to contain those of the perfect fly.

This larva is produced from an egg, deposited by the perfect insect in the waters of pools or ditches, among duck-weed and the water-grasses. Its disposition is mild and inoffensive. It is incapable of destroying creatures 
of its own size, while it is itself the prey of all kinds of water-beetles and the larger larvæ.

It feeds on the larvæ of the smaller kinds of tipulæ, or crane flies, as well as on aquatic vegetables. Short pieces of grass, \&c. are frequently seen in the alimentary canal, when examined under the microscope during the spring season. For this reason, and also on account of the sharpness of its claws, it should not be kept with any of the family of the Characeæ, intended to exhibit the circulation (cyclosis) of the sap, inasmuch as it pierces the cellules whilst creeping up the stems, and thus destroys the plants.

When it is intended to collect this larva, a mild calm day should be chosen; for if there be any cold wind, it retreats into the mud at the bottom of the water. It may be easily taken with a collecting net, such as is described in the preceding chapter. This must be introduced among the grasses and water-plants to which they attach themselves. Having carefully done this on that side the pond which is most exposed to the sun's rays, and drawn it among the floating duck-weed, many hundreds may often be collected at a single draught.

These larvæ may be kept alive, for many weeks together, in a glass vase of water, with a little duck-weed floating on its surface; and will be ready to be applied to the microscope whenever required.

The rapidity with which it moves is truly astonishing. Besides its six legs, it employs the six double paddles attached diagonally to the serpentine vessels on each side of 
its body, and its tail, for the purpose of rowing and balancing itself, and two other paddles for steering, making in all fourteen. Even when the creature is at rest, if in health, all except the lowest two, or steering paddles, are in rapid motion-a circumstance which renders those beantiful ramifications of the air-vessels shewn in the drawing, figure 4 , difficult to be viewed while the larva is alive.

Independent of its locomotion, by means of its legs, paddles, and tail, it possesses a power of leaping or springing in the water, which it effects by incurvating its body backwards, and then suddenly straightening it, by which kind of motion it raises itself to the surface of the water with great celerity.

When the crysalis approximates to its perfect state, it swims more elegantly: its motions now appear entirely subservient to its will, and at the same time it leaps with greater velocity. Within a few days, however, of its change, it becomes rather sluggish, and attaches itself to the stalks of water-plants, on which it will remain for hours together, if undisturbed, only moving its paddles at intervals.

At the period of its transformation to the perfect state, some parts of the insect assume a metallic lustre, as if the space between the crysalis (which may now be called the case of the animal, every part of the latter being perceptible through it,) and the inclosed insect, were partly filled with mercury. This appearance is ultimately extended over the whole body, and is occasioned by a 
small quantity of air or gas probably evolved during the change; and which, by insinuating itself between the case and the insect, may facilitate the process. After remaining a few minutes in this state, and making occasional efforts to disentangle itself, it bursts forth from its watery dwelling; and wings its flight into the aerial regions, either leaving the entire skin behind it in the water, or carrying part of it away.

The exuviæ, or skins, which are shed previous to the creature assuming the perfect form, are very fine transparent objects for the single microscope, with a lens of the tenth of an inch focus. In this state they afford much useful information, as to the structure, formation, \&c. of which the paddles, tail, \&c. furnish no inconsiderable portion. If it be thought desirable to expedite the casting of the exuviæ, this may be effected by removing the insect from the water in which it is found into spring water. This change is most probably produced by the water mechanically altering the dimensions of the skin or case which inclosed the insect, and thereby suffering it to escape with great ease; or, perhaps, from the same cause which produces this effect in the common spider when deprived of sustenance. These skins should all be mounted in sliders, in the order in which the insect sheds them, that, by comparing them together under the microscope, we may ascertain with precision the progress made during each change.

When the crysalis is divested of its envelope, it remains apparently inert on some neighbouring plant for a few 
minutes, where it casts off from its wings the last pellicle, which is a thin and delicate membrane, formed under the elytra of the crysalis. It then appears in the imago state, with its biforked tail and wings, as represented of the full size in figure 6 .

Having become a perfect Ephemera, it hovers about in the air, the male and female generate, the latter drops her eggs in the water, and both die, existing only a few short hours, to perform all the offices destined for them to fulfil in the economy of nature.

So beautiful and perfect are the arrangements of the Creator, in order to preserve a regular succession of his creatures, that if the Ephemerre be kept from sexual intercourse, I have known them live for several days. Nor do they seem enfeebled when confined separately for a week, as I have seen them fly away with great celerity after that interval; while others, which were bred the same season, and were not kept separate, died after a few hours' existence. 


\section{CHAPTER IV.}

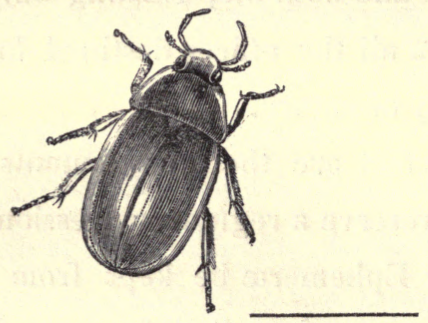

Fig. 6 .

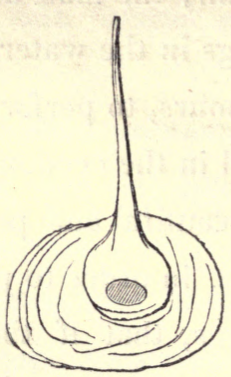

Fig. 7.

On the Larva of a Species of British Hydrophilus.

Hydrophilus caraboides.-Auctorum.

Is examining the peculiarities of the structure and habits of this larva, what most strikingly attracts our attention is its ferocious and savage disposition, and the fitness of its organs for the exercise of its ravenous propensities. It may be safely asserted that no species of larva is known to be provided with weapons of destruction so powerful, so numerous, and so well adapted to their end, as those which this creature possesses. It is on this account that it has been popularly called the WAtre DeviL. Its size is but little inferior to that of the larva of any of 
the British Coleoptera, as it measures, when arrived at maturity, an inch and a half in length, while the superior strength and courage manifested in its attacks on small fish, and other animals larger than itself, is truly surprising.

About the latter end of April, and during the month of May, small nests of these insects are often found floating among weeds and water plants, in stagnant pools, and are frequently taken in the nets of those who are searching for the early kinds of larvæ. They are in the form of balls, of a dusky white colour, and a silky texture, and have each a small stem of the same nature as the nest, but more dense. By means of this filament they are attached to the roots or stalks of weeds at the bottom of the water. (See the right hand figure at the head of this chapter.) In this situation they remain during the winter, and are thus effectually preserved from the effects of intense cold. Early in the spring, the stem or cable to which we have referred is detached from the weeds, by the winds which at that time prevail, and the nest rises to the surface of the water, and there floating, receives the genial influence of the sun. These nests may be taken and placed in a basin of water, and, as the season advances, hatched by the heat of the sun. On the larva leaving the nest, which it accomplishes by gnawing a hole in the side, the infant immediately descends to the bottom of the vessel, with its jaws extended in search of prey, and eagerly devours all the small aquatic insects that are within its reach; if, however, there is a scarcity 
of food in the immediate neighbourhood of the nest, they may be seen to attack and devour each other.

These larvæ, as well as most of those of the larger kind, are found at a greater depth of water than are the smaller ones; although, in their pursuit of small prey, they may occasionally be taken in shallow places. They require a larger net to collect them with. A net made of stout Irish linen, about a yard deep, and affixed to a hoop half a yard in diameter, will answer the purpose very well; and if it be attached to a long stick, the collector will be enabled to use it with greater facility.

In its infant state, this larva is very transparent; hence its internal structure may be clearly distinguished.

When about a quarter of an inch in length, it swims very nimbly. The colour of the head is a strong Indian yellow, with darker shadings of a bright chestnut; the eyes are now bright carmine. It is more sparingly covered with hairs, and its swimming appendages are shorter than at a more advanced period; and the head is larger, in proportion to the size of the body, than when the creature has arrived at maturity. In this respect it resembles many other creatures in its mode of growth, the head seeming to be developed and perfected before the rest of the system.

When young, it may be readily preserved in gumwater, in the manner described in the "Microscopic Cabinet," p. 229. I have several of them mounted in this way, varying in size from one-tenth to half an inch in length; and although nearly eight years have elapsed 
since they were done, they are as perfect as when they were first prepared. This method, however, will not retain them so permanently as when they are mounted in Canada balsam, between two slips of glass, in which case the specimens may also be of much larger dimensions.

The manner in which this larva treats its prey evinces an extraordinary degree of instinct. Many of the creatures on which it feeds are crustaceous about the head and back; hence they are most vulnerable at the under part of the body. This part, therefore, the larva attacks; and, to accomplish its aim, swims underneath the intended victim, and bending back its head, which is even with the surface of its back, is enabled thus to reach its prey by means of its jointed antennæ. (See $a$, fig. 30, which represents a magnified view of the larva taken while young.) Its next operation is to pierce it with the mandibles (b). Having thus secured its object, it immediately ascends to the top of the water, and, holding it above the surface, so as to prevent it struggling, shakes it as a dog would a rat. The prey of this larva is often larger than its destroyer. Its next operation is to insert the piercer and sucker $(d)$, which is capable of being thrust out or withdrawn at pleasure. When the juices of the victim are not easily procured by suction or exhaustion, the serrated pair of forceps $(c)$, is employed to tear and masticate it, and thus cause the juices to be more easily obtained. If its food be plentiful, this larva arrives at its full growth in the course of three or four months, and is then nearly opaque, and covered with hair. It can 
be kept several days without food, and by this exinanition its structure becomes considerably more transparent*, while its natural ferocity is greatly increased, so that it will attack and fight with creatures much larger than itself, and even with its own species. It may be remarked, that it studiously avoids any contest with the Nepa, or water-scorpion.

On a fine sunny day the larvæ rise to the surface of the water, and delight to bask in the sun; but if watched, they remain motionless, with their claws extended. If a stick, or any other substance, be presented to them, they will immediately seize it, and will sometimes suffer themselves to be cut into pieces before they relinquish their hold. Their bite has been considered poisonous by many persons, as it takes a greater length of time to heal than other wounds of the same extent : so that caution should be used in taking them.

Touching the anatomy of this creature, it may be observed, that the sucker, marked $d$, is contained in a crustaceous sheath, and may be considerably protruded or completely withdrawn at the pleasure of the larva: in the engraving it is shewn extended to about three quarters of its length. The eyes are compound, but of a peculiar formation, consisting of seven oval apertures, arranged like leaves upon a branch : in the drawing they are denoted by the letter $e$. The whole of the

* Dr. Goring kept the subject represented in the engraving some time without food, in order to render its interior organization more clear : it may be observed that its intestinal canal is quite empty. 
head and thorax are curiously marked with a number of lines and spots. The legs are six in number ; they are thickly set with rows of hair on their opposite sides, and each is furnished with a sharp claw. The number of swimmers on each side is seven; they are covered with hairs, and, to the specimen from which the drawing was taken, a vast number of Vorticella convallaria, , or bell polypi, were attached. These will be recognized in the magnified drawing by their bell-shaped figure. They sometimes infest this species of larva to such a degree, as considerably to impede its motions in swimming. On each side of the abdomen, which commences neal the origin of the first pair of swimmers, arise the great tracheæ, or air-vessels, distinguishable in the coloured engraving by their light blue colour; the two approach each other near the tail, where an exceedingly curious process is also distinctly exhibited. The whole surface of the body is thickly covered with hairs, and several tufts are disposed in clusters, with some regularity, down the back and sides. The flexible pulsatory organ or dorsal vessel, situated at the lower part of the body, is in perpetual motion. Its form somewhat resembles the letter $S$, inverted : it however varies a little during its vibrating motions. The use of the curious appendages at the lower extremity of the body is unknown. Its tail is biforked and crustaceous, and is marked as shewn in the plate. In figure 31 is given a representation of the larva, of its 
natural size and proportions, taken at the same period of its growth as that at which the drawing was made. As it approaches maturity, it casts its skin several times, from each of which it escapes by a rent formed down the back.

The large tracheæ, or air-vessels, which run along each side of the body, with the numerous branches emanating from them at various intervals, in their course, are composed of delicate transparent membranes, distended by means of fibres attached to, and wound about them in a spiral form, like the thread of a screw or the spring of a bell. The diameter of these vessels, one of which I dissected from a larva nearly an inch and a half in length, is one-sixteenth of an inch. When mounted between two pieces of glass, and submitted to moderate amplification, they exhibit the most beautiful and varied specimen of line-work that it is possible to imagine. The fibres of the upper and under sides intersecting each other at different angles, produce an effect which no engine-turner could surpass; it would, therefore, be useless attempting to illustrate it by a wood engraving. A branch of this vessel may also be observed running along each of the legs.

Respiration by this creature is not performed as with the larva of the ephemera, although, like it, it is an inhabitant of the water. The tracheæ in the latter is supplied with air from the membranous paddles on each side of the body, which imbibe it from the circumambient fluid. In the larva under consideration, the air is supplied by 
proper orifices situated at its tail; and the creature is obliged to ascend to the surface of the water, and elevate its tail out of it, at every inspiration. When the air thus inhaled has become unfit for respiration, it is expelled at the same orifices, and a small bubble may frequently be seen issuing from the tail, and ascending in the water. On a careful examination of the skin, which by the by affords an excellent object for the microscope, there will not appear any spiraculæ along the sides, as in perfect insects.

The respiratory system of this larva, being, when dissected out, more opaque than that of most similar creatures, is seen to great advantage when mounted in Canada balsam ; and if it be accompanied with the corresponding organs of a caterpillar, the comparison affords a beautiful example of adaptation to the different elements suited to life. In the terrestrial animal, every part being exposed to the atmosphere, mouths or orifices for inhaling the air are arranged along both sides of the body; in the aquatic larva, this system could not be made available, without the creature being compelled to quit its natural element, at every moment it had occasion to respire. To obviate this, it is furnished with two large apertures at the tail, instead of those at the sides.

I may mention that a preparation of this organ illustrates very beautifully one of the physical properties of matter, namely, the colours produced by interference, when light is made to pass between a series of fine lines.

After this creature has remained for a considerable 
time in the larva state, it buries itself in a hole, which it forms for that purpose near the edge of the water, and after passing through the crysalis state, it emerges in the form of a perfect beetle. This is effected in two years after issuing from the nest egg.

On examining the older books on Entomology, I found, in Roesal's work, (a book not noticed in Stephens' elaborate Catalogue of British Insects,) a small drawing of this larva, from which it appears to be the Hydrophilus caraboides. It is much to be regretted that modern entomologists attend so little to the aquatic larvæ of insects; for surely it will not be pretended that a description of the creature in its perfect state constitutes its history. I have often made inquiries of the first entomologists of the day as to what insect a particular larva would become, and have as often been unable to obtain the slightest information. In some cases they have doubted as to the order to which it belonged. It is true that had I been unable to procure its generic and specific names, that circumstance would not have rendered it a whit less valuable as a microscopic object; and I do not pretend to treat of them with entomological technicality.

The engraving of the perfect Beetle at the commencement of this chapter is taken, by permission, from $\mathrm{Mr}$. Curtis's British Entomology, vol. iv., plate 159. 


\section{CHAPTER V.}

On the Terms employed in Microscopic Science.

Ir has been said that every science has its own language, and we often find that words which in one science express certain ideas, do, when transferred to another, convey to our minds a sense entirely different.

Although the study of the microscope does not require a very extensive vocabulary, yet it is rendered more easy by a previous acquaintance with those terms which continually occur to the microscopist.

The following chapters are mechanical descriptions of the microscope, together with a discussion of the question as to whether there is a best possible way of constructing its mounting, or mechanical part. The importance of the latter must be evident, when we consider that although we may possess the most perfect and finest corrected and adjusted lenses, yet if their mounting or stand be defective in its construction, we shall be deprived of a great portion of their value, by being unable to make them show in an efficient manner those subjects which are within the scope of the instrument, while many classes of objects cannot be viewed by them in any way whatever.

In the present chapter, I shall merely give a succinct 
explanation of the different terms used in this and other works respecting the microscope, omitting Aplanatic; Achromatic ; Chromatic Aberration, or Dispersion ; Spherical Aberration; Engiscope and Microscope, as being explained already in the "Cabinet," p. 102.

Fig. 8.
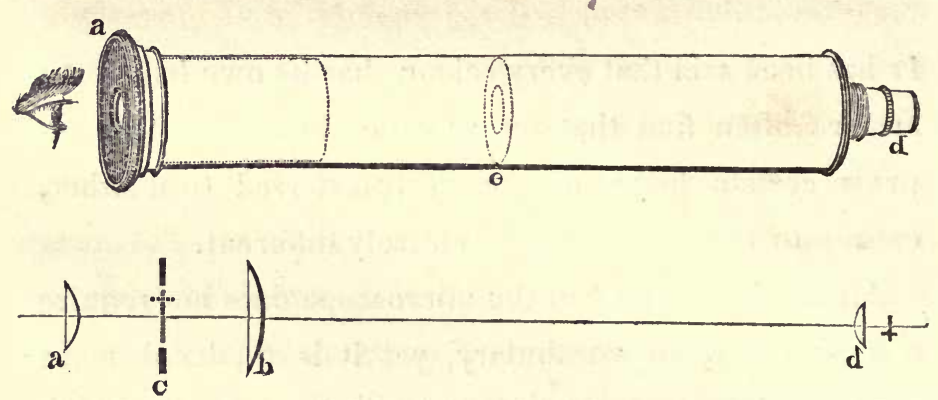

Fig. 9.

First, then, we will commence with the optical part of a compound microscope, or engiscope, the external appearance of which let fig. 8 represent. This is generally called the body of the microscope, and is either composed of a conical or a parallel tube, as here shewn. The interior of the body should be as black and as sombre as possible, and furnished with diaphragms or stops (as at $e$ ), to prevent any false light entering the eye : of course these stops must be so arranged, and of such apertures, at not to cut off or impede any portion of the rays passing through the various lenses.

The larger end of the body, $a$, is called the eye-end, into which the eye-pieces fit, either by a screw or simply by sliding them within it. The latter plan is the better, 
though it has been objected to, from the liability of their becoming loose by wear; the reverse of which, however, occurs in practice, for as the tubes become oxidized they tighten.

The eye-pieces usually consist of two lenses, as shown at $a$ and $b$, fig. 9. The first, or anterior lens, is called the eye-glass; the second, $b$, the field-glass. As I have made some eye-pieces of quartz, it would be more appropriate to call them eye-lens, or field-lens.

The diaphragm, stop, or field-bar, is shown at $c$, and should be in the focus of the eye-lens, $a$. The lens which screws into the body at $d$, is called the objectglass; it may be composed of more than one lens: they are termed collectively objectives or object-glasses, if they consist of three pairs, which is the usual form for the best deep achromatics, as shown at fig. Fig. 10. 10, where $o$ is the place for the object (that $000+$ being their combined acting focus) $-d$ is $f d_{0}$ the anterior or first pair of object-glasses$e$, the middle pair-and $f$, the third or posterior pair of objectives. As the inner surfaces of each pair are cemented together, to an ordinary observer they appear as one lens, and consequently the objective appears to be composed of only three lenses.

Over the object-lenses is often fitted a concave silver reflector, for throwing condensed light on opaque objects ; this is termed the Leiberkïh, silver cup, or speculum, and is shown at Plate 4, fig. 17.

The power of eye-pieces is determined by the focal 
length and distance asunder of their component lenses, and as they usually bear a certain relation to each other when their construction is alike, their power is sufficiently distinguished by simply expressing the focus of the eye-lens. Thus we say this is an inch eye-piece, meaning that the sidereal focal length of the eye-lens is one inch. The acting length of the body is the distance from the objectglass $d$, to the diaphragm $c$ (fig. 9), though it is usually expressed by the length of the tube (fig. 8.)

I have been thus explicit, as the magnifying power of an instrument is dependent on the focal length of the objective, the power of the eye-piece, and length of the body, taken together.

Fig. 11.

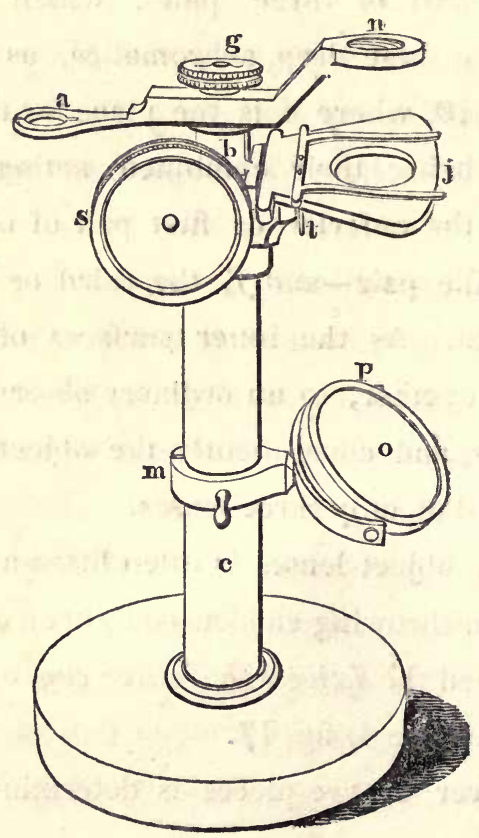


The mechanical parts of a microscope I shall illustrate by a reference to fig. 11, which exhibits the simplest construction of a microscope with which I am acquainted. It will be seen in the sequel to be the same as my achromatic engiscope, described in Chapter VI., but without its apparatus and stand, which can be added at any time by its possessor, and thus avoid the disadvantage usual in the purchase of a cheap microscope, viz. that when a better is required, the cheap one is too slight and defective in its construction to form the basis of a superior instrument, and is, therefore, of necessity thrown aside as useless.

The Vertical Microscope, fig. 4, consists of a double arm, $n, a$; the former to receive the screwed end of the compound body, $d$, fig. 8 (when employed as an engiscope), and the latter, $a$, to receive the single, doublet, or triplet magnifiers, when used only as a microscope. $b$ is a triangular bar, with a rack cut on its posterior edge, into which a pinion works, which is actuated by turning the large milled head, $s$, which raises or depresses it and the arm, $a, n$, and thus the adjustment of the focus is effected. $j$ is the stage on which the objects to be viewed are placed, and these latter are kept down by the forked piece, or finger-springs, $t$. The mirror-socket, $m$, slides upon the stem, $c$, and carries the mirror, $o$, with its frame, $p$. Above the arm, $a, n$, is a milled head, $g$, which serves to tighten it in any position in which it may be placed : $e$ is the circular foot or stand. When intended as a travelling instrument, for lightness and 
portability, the stem, $c$, screws into the top of the case, and the round foot is not required.

As the above will be sufficient to explain the terms used in the following chapter, I shall, to avoid repetition, explain the remaining terms, when describing Dr. Goring's and my own Engiscopes. 


\section{CHAPTER VI.}

$A$ description of the Achromatic Microscope, together with its Apparatus and the mode of using it.

IN a country like England, preeminently distinguished for mechanical inventions, it would be strange, indeed, if the constructing of stands for microscopes, their mountings, apparatus, \&c. had not attracted the attention of some of her artists. Since the publication of the first edition of this work, numerous contrivances of a highly ingenious description have been devised for their improvement; and though many of them are too complex ever to become of general utility, yet are they such on the whole as have tended to advance this instrument to its present effective condition. Several artists in France and Germany have also especially directed their thoughts to the microscope, and have produced some which, as specimens of workmanship, claim, no doubt, very considerable merit; but they do not appear to have had sufficiently in view the principles upon which they ought to be constructed. Those which have fallen under my notice are wholly unsuited for general purposes of observation-a circumstance which is the more surprising, because there being exhibited so much talent in the op- 
tical department, particularly in the eye-pieces, one could hardly imagine that their usefulness would be abridged through their inefficiency in other respects.

By a microscope suited for general observations, is to be understood one of such construction as will allow us to examine both opaque and transparent bodies with such facility that we may ascertain their true forms and structure. In order to compass this, both the instrument and the illumination must admit of being turned in all directions. The instrument must be further capable of carrying a wide range of magnifying powers, so that whether the object to be investigated be of moderate dimensions or a mere atom, it may come fully within its scope. It is not an uncommon case to find a microscope excellently constructed for a given power, and totally unfitted for all others. For instance, that beautiful little instrument for carrying Wollaston's doublets, can only be employed with effect for viewing very minute transparent tissues, as the scales of the Podura, \&c. It is not suited for examining the living objects described in the previous chapters, nor most animal or vegetable structures; and that splendid and extensive class of bodies, opaque objects-which require strong reflected light and moderate shallow powers to render their beautiful structures appreciable-is entirely beyond its reach. In either of the two microscopes I shall describe in this work, every class of bodies that I am acquainted with can be correctly judged of, whilst they command a very extensive range of powers. Dr. 
Goring's engiscope, described in Chap. VIIl., being on a much larger scale than that treated of in the present one, is adapted for carrying the shallowest magnifiers which can be required.

As these instruments have now become the standards by which all the better kinds are made, nodified more or less so as to conform to the different views of the artists who make them, I have judged it advisable to treat of their several parts in detail; in doing which many of the remarks I shall have occasion to make, will be found to have a general application. My own instrument, with its various modifications and additions, together with their uses, will form the subject of this chapter. In Chap. VIII. I shall give a mere explanation of Dr. Goring's aplanatic engiscope; the method of making observations with, and managing it, being penned by himself in the chapter following it.

The simplest modification of my achromatic microscope is represented at page 82 , fig. 11 . This can be used only in a vertical position; but it is admitted, I believe, to be superior to any instrument of that kind, in steadiness, simplicity, and range of powers. It will be readily conceived, that when the circular foot is unscrewed, and the stem $c$, fitted into a jointed stand, it becomes the second modification, shewn in the following engraving, fig. 12.

This microscope is represented with its stem and axis in an inclined position, which is commonly the most convenient one for the observer. Those parts of it which 
have been already described as belonging to the vertical instrument, will be very briefly referred to here. Let

Fig. 12.

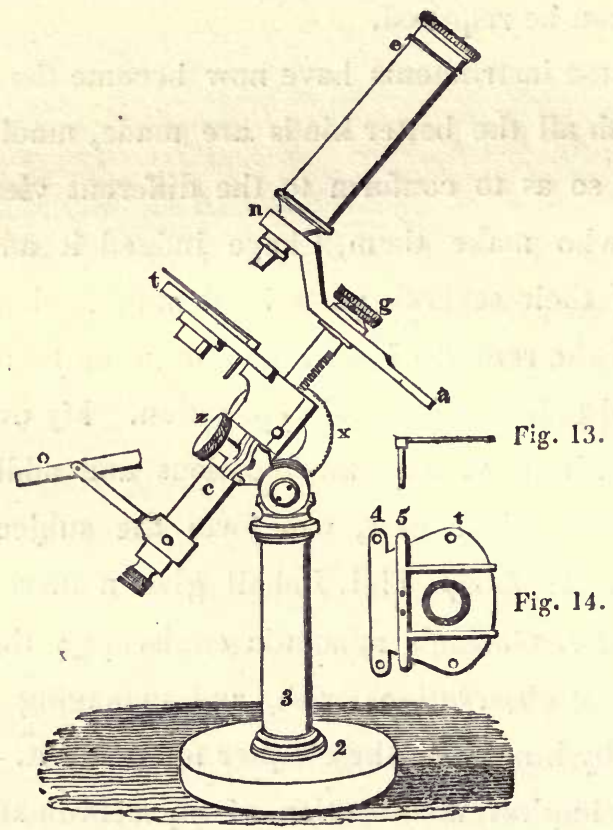

$e, n$, represent its compound body, which may be either achromatic or periscopic; its lower extremity screws into the bent arm, $n$, whilst the other arm, $a$, is suited to receive single or compound magnifiers. The stage, $t$, on which the object-sliders are to be placed, is removable at pleasure. It is shewn separate by fig. 14. The protruding ears on each side, shewn at, 4 , serve to hold by, when putting it on or removing it from the instrument. These being in a line with the two stout pins which fit into the block on the top of the stem, $c$, prevent any strain being occasioned by the operation. This 
being attended to, and the triangular bar, $b$, sufficiently raised, we may proceed with perfect safety. On the stage is fitted, in a similar manner, by means of two smaller pins, a fork-shaped plate of brass, shewn apart at fig. 13. This plate is designed to retain the slider firmly on the stage when the instrument is inclined.' The focus is adjusted by means of a rack and pinion; the letter, $x$, denoting the large milled head of the latter. The mirror-frame slides up and down the stem, $c$, thus allowing the angle of the pencil of light to be increased or diminished.

The stand of this instrument appears not to be different from those of the old-fashioned compound microscope, except in having a simple round foot, which is here adopted to save room and expense. Like them it has a joint for inclining the instrument at any required angle; but it has, besides, this novelty, which, although simple, is of great importance, viz. a capability of permitting the stem, $c$, to be turned round on its axis, so as to allow a glass vessel, or slider accommodated for animated creatures or plants, to be retained in an upright position, and their contents investigated without having recourse to stoppers or corks. When any of these vessels are used in ordinarily-constructed microscopes, they require to be placed on their sides, which, independent of disturbing the objects, admits not unfrequently into the field of view, small portions of the air included in the vessels, so as greatly to interrupt our view. When observations of this nature are to be made, the stem, $c$, should be turned 
a quarter round to the left, which brings the milled head $x$, upwards, and the arm, $n$, $a$, horizontal, where the stem, $c$, is fixed by the pinching screw, $z$. In this position a candle may be placed close behind the stage in the axis of the instrument. This will be found of great advantage in verification. Again, if the stage be removed, objects in glass vessels, which are too large to be held in the microscope, may be examined without removing them for the purpose; as also minerals, blocks of fossil woods, \&c.

The universal or ball-and-socket joint being strongly recommended in Chap. VII., it may with propriety be asked, why I have introduced a different one into my own instrument. The reason is, that while all the requisite motions are obtained by means of the joint $I$ have adopted, it allows, at the same time, the stem of the m:croscope to be over the centre of support, by which it has no tendency to fall, when the pinching screw is loosened. In the universal joint, there is always a tendency to drop (except when it is on its side), and a strain upon it. In practice, therefore, these are very liable to get out of order, where the weight of the instrument is considerable. When formed on a small scale, this objection vanishes; but when of the size adopted by Dr. Goring, until a joint can be constructed similar to that in the human arm, with a ligament in the centre, and sufficient friction to support the weight in any position, no person, I conceive, will give them the preference : at least, so it has been; for where one 
microscope has been made with Dr. Goring's joint, fifty have with mine.

Fig. 16.

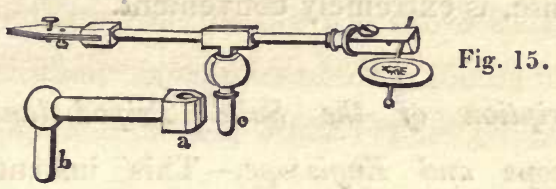

Fig. 15 represents a pair of forceps and a pin-holder, attached to a ball-and socket joint; the stem, $c$, fits into holes formed in the stage to receive it. Opaque objects, when mounted on a circular disc with a pin, are held more firmly by the pin-holder (as seen by the figure) than by the forceps. It is preferable, also, when the instrument is on a small scale, to that ingenious contrivance in Dr. Goring's Engiscope (see plate, fig. 23), as it admits of the forceps being made smaller.

The arm, fig. 16, is used for carrying the forceps when the stage is removed. The pin, $b$, fits into one of the holes in the block of the instrument; and the pin, c, fig. 15, into the hole, $a$. This arrangement for viewing opaque objects allows large silver cups to be used, for condensing the light upon them. This could not be done, if the stage did not take off, unless the aperture in it were immoderately large.

The method of viewing opaque objects by means of silver concave reflectors, is by far the simplest and the readiest; and when these are of considerable diameter and of proper curvature, we not only obtain the central illumination, but also that beautiful play of light and shade afforded by the oblique pencils.

For investigating insects, or other objects not mounted 
on discs in this manner, an additional arm for carrying a small black cup, to be placed behind the object, in lieu of the disc, is extremely convenient.

Description of the Solid Tripod-stand Achromatic Microscope and Engiscope.-This instrument, on its simplest mounting, is represented by the accompanying engraving, fig. 17. It is in all respects similar to the preceding one, except in its stand. On this account I have placed it in the position in which it is used for

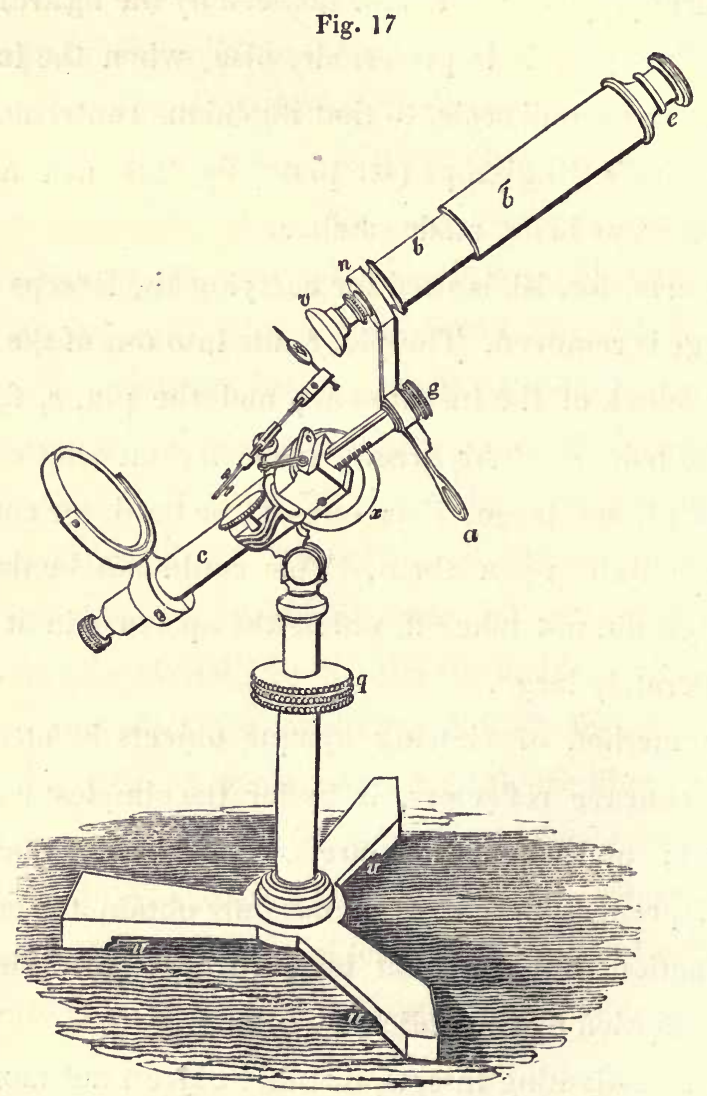


viewing opaque objects by silver cups, where $a$ is the concave speculum, orLeiberkühn.

This stand differs from the other in the following particulars. The pillar is composed of a couple of tubes, the one sliding within the other. The triple-milled ring, $q$, screws upon the top of the outer one, and serves to fix them together at any required elevation. The base, $u, u, u$, consists of one solid piece of metal, the form of which is that which several years' experience has proved to be the best. Dr. Goring, in Chap. VII., clearly demonstrates that a tripod bearing is indispensable to insure firmness. In his instrument, however, the base, instead of being solid, is composed of three pieces (see plate, fig. 7), the objection to which is, that notwithstanding a screw is used to counteract their springing, the stand is yet liable to rock. I have lately made some of his instruments with a solid base, similar to my own, which are decidedly preferable.

My tripod form has been objected to, although the solid base is now adopted in all the best instruments. It has been said to occupy more room than those having folding legs, and, therefore, to require a larger case; and again, that it should be equilateral, having its three feet of equal length. The answer to this is, -first, that no folding stand can be rendered perfectly firm, and that there is some trouble and loss of time in arranging it for use; and should it, through any hurry or mistake, be set up without properly unfolding the feet, the instrument is very liable to be injured. And, secondly, the base 
here selected can be inclosed in a case no larger than is necessary to contain all the other parts of the microscope; and, with a given weight and dimensions, the form is more steady than when the feet are of equal length. Of course, to obtain the greatest advantage, the stem, $c$, should always be over the shortest foot.

Having alluded to the packing of microscopes, it may be mentioned; that upright cases or cabinets are greatly superior to boxes for the purpose, because, the instant the door is unlocked, the instrument is ready for use; besides, sufficient space is afforded for a nest of drawers, to contain the apparatus and objects, although the latter, perhaps, are better kept in a separate cabinet.

On the selection of proper Magnifying Powers.-In a microscope constructed for single lenses, doublets, or triplets, the plain split end of the arm, $a$, is the situation designed to receive them. Upon examining the lenses, such as possess the largest aperture are of the lowest power. With these our observations should generally begin. There should be marked, on them all, their respective sidereal focal lengths. This measure will indicate very nearly the distance at which they require to be adjusted from the object. When the object to be examined is a seed or large body, commence with either of the three lowest powers. If the object is hardly perceptible with the naked eye, take those of 1-10th of an inch focus, and so proceed, step by step, to the higher powers. 
DESCRIPTION OF THE ACHROMATIC MICROSCOPE. 95

Table of Magnifying Powers.

Focal Lengths.

Inches and Parts.
Magnifying powers, estimated by a 10 -inch standard of sight.

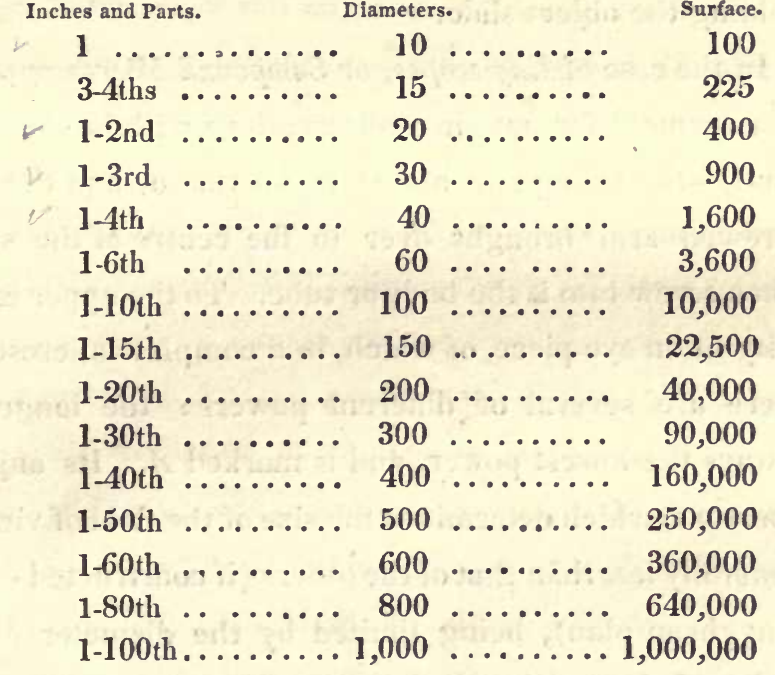

Previous to placing the magnifier into the arm just mentioned, the triangular bar should be raised, the object put upon the stage, and the light reflected from the mirror made to pass through it. All this is more readily effected before the leus is fixed in its position.

Some persons prefer having stops or diaphragms under the stage, when making observations with single lenses. In this case, the aperture of the magnifier may be greatly increased; for the stops, so situated, will have the same effect of reducing the diameter of the emergent pencil of light as a restricted aperture in the mounting of the lens would do, whilst the vision for deep powers is rendered by it more agreeable. 
Whenever high powers are used, a safety sliderholder, similar to that shewn by figs. 25 and 26 in the plate, or fig. 20 , page 106 , should be chosen for holding the object slide.

In the case of Engiscopes, or Compound Microscopes, the arrangement for making observations will be different. First,- the triangular bar is to be raised, and the bent screwed arm brought over to the centre of the stage. Then screw into it the body or tube. To the upper extremity fit an eye-piece, of which, in a complete microscope, there are several of different powers: the longest is always the lowest power, and is marked $A$. Its angular aperture, which determines the size of the field of view, is generally less than that of the others (if constructed on the Huyghean plan), being limited by the diameter of the body. It is usually a little under 30 degrees. The next eye-piece or middle power, marked $B$, and the deepest, $C$, have more than 30 degrees of angular aperture. Their amplifying powers are commonly in the proportions given given below. It is not unusual, however, to have eyepieces of intermediate powers, to suit any particular class of objects we desire to investigate.

\section{Proportional Powers of Eye-pieces.}

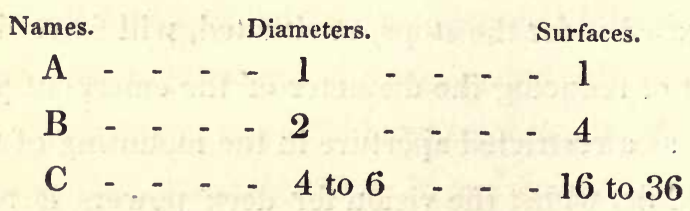

For viewing thin sections of recent or fossil woods, 
coal; jet; the fructification of ferns and mosses; fossil shells ; seeds; small insects, or parts of large ones; moluscans, or entomostraceans; the circulation in the frog, \&c. the eye-piece, $A$, is best adapted.

Again, for examining the details of any of the above objects, the eye-piece, $B$, should be substituted; as also for observing the colours of crystals illuminated by polarized light; the pollen of flowers; the dissections of insects; the vascular and cellular tissues of plants ; animalcules; Haver's canals in sections of recent, and the corpuscules, \&c. in fossil bones; the cyclosis in plants; the formation of shell; the moveable fluids in quartz and topaz; the organic remains in thin slices of flint, \&c.; the serrated lamina of the crystalline lenses of the eyes of fishes and birds, \&c. \&c.

And lastly, when it is requisite to investigate either the minutiæ of opaque objects, or the minute structures of delicate tissues, active molecules, polygastric infusoria, and the raphides in the milky juice of plants, \&c. the eye-piece, $C$, comes into use ; it being oftentimes inconvenient, when a higher power is needful, to obtain it by means of a deeper object-glass, which occasions a fresh arrangement to be made of the illumination and focus.

It must, however, always be borne in mind, that the more powerful the eye-piece is, the more will the imperfections in the object-glass become apparent, because they will be the more dilated. Hence we should observe, that less confidence ought to be placed in the observations made under a powerful eye-piece, than when the 
same amplification is obtained with a shallow one, and a deeper object-glass : the preference, therefore, when great accuracy is required, should always be given to the latter arrangement wherever it is admissible.

An engiscope may be furnished with one or more sets of object-glasses. They all have similar screws for fixing them into the lower end of the body. When a set is composed of only two or three lenses (the usual construction of shallow ones), it can give but one magnifying power. In like manner, when a set is constructed so as to take up a very large pencil of rays with the utmost definition, although composed of several pairs of lenses, it can give but one perfect power. Such sets should never be separated. In many cases, where a maximum angle of aperture, or a perfect correction, can be dispensed with, one set composed of three pairs of cemented lenses may give by separation three different magnifying powers. These sets are generally made so that their amplifications, in diameters, are in the ratio of one, two, and three; and are preferred by some observers.

Achromatic object-glasses for microscopes are of various foci, differing from two inches to 1.16 th of an inch. As a table of all the varieties would occupy more room than its worth would justify my giving, I shall specify only those which are mostly used in the table-microscope. They afford a very wide range of powers, and one or the other of them is suited for every class of objects which can be submitted for examination. It is seldom that an instrument has the whole series attached to it; and since many per- 
sons confine their attention to a particular class of objects, some little consideration is necessary for selecting those sets which are best adapted to the purpose. It is by no means an unfrequent occurrence, that applications are made to me, by those who have purchased expensive instruments, for some particular object-glass, which they do not possess, whilst they have others which to them are of little or no value.

The first column in the following table gives the sidereal focal length in inches and parts. This focal distance, in shallow object-glasses, is less than the distance an object should be placed at from the lens when arljusted for distinct vision; whereas, with the higher powers, the sidereal focal distance is greater than that between the object and the lens. It varies also with the length of the body. The second column shews the distance at which the object should be placed from the object-glass. The third column gives the mean angle of aperture, which varies a few degrees either way. The last column gives the magnifying powers in diameters, in combination with different eye-pieces. It is calculated by a 10-inch standard for sight.

Sidereal Focal Distance between the Mean Angle of Magnifying Length. Object and Lens. Aperture. Powers.

\begin{tabular}{|c|c|c|}
\hline $\begin{array}{l}\text { Inches. } \\
2 .\end{array}$ & $\begin{array}{c}\text { Inches. } \\
2,1-3 r d . . . . .10^{\circ}\end{array}$ & $\begin{array}{l}\text { Diameters. } \\
20 \text { to } 50\end{array}$ \\
\hline$\ldots \ldots \ldots$ & $1,1-8$ th $\ldots \ldots \ldots 15^{\circ}$ & 30 to 120 \\
\hline $1-2 d \ldots$ & 3.8 ths $\ldots \ldots \ldots 22^{\circ}$. & 65 to 280 \\
\hline $1-4$ th..... & 1-8th $\ldots \ldots \ldots 40^{\circ}$. & 150 to 500 \\
\hline 1-8th..... & 1-20th .. & 260 to 1100 \\
\hline 1.16th & 1.40 th $\ldots . .770^{\circ}$, & 450 to 3000 \\
\hline
\end{tabular}


The above sets may be divided into three classes-the shallow, medium, and deep; which, like the eye-pieces, I shall particularize by the letters $A, B, C$.

The shallow object-glasses, $A$, are mainly serviceable for opaque objects, which, when exhibited by means of silver specula of proper dimensions and curvature, yield a vast fund of amusement and instruction. The class of objects, enumerated under the eye-piece, $A$, is suitable for them. They display to great advantage, also, the aquatic larvæ of insects, polypi, \&c. They are serviceable as a finder for minute objects; for the general examination and selection of insects; minute fossils; coal, \&c.; the objects thus selected being afterwards submitted to the medium object-glasses, $B$.

Those denominated $B$, possessing considerable penetration, bring out the striæ and markings on the scales of insects, the various forms of the elementary tissues and fibres of vegetables, the internal structure of polypiferous zoophites; whilst a general view of those minute and delicate living creatures, the animalcula infusoria, as also the circulation in the young of the lizard, aquatic plants, \&c., is obtained by the intermediate sets. The medium-power object-glasses, when constructed with a sufficient space in front, admit of a minute examination of portions of insects preserved in Canada balsam between plates of glass of the usual thickness. This class of transparent objects, when mounted in the permanent manner I have mentioned, is certainly the most instructive and amusing of any that we possess; for although 
we cannot enjoy the sight of their motions and habits as with living specimens, yet are we in a measure recompensed for it, by the advantage of having them always at hand.

The object-glasses, $C$, are best adapted for investigating objects of the most minute and delicate description; such, for instance, as the markings on the scales of the podura; the forms and structure of minute fungi*; the globules of human blood, \&c.

A variation of magnifying power is attainable also by the body of the instrument being composed of two or more tubes (see fig. 17,) the one sliding within the other, so as to admit of an alteration of distance between the eye-piece and object-glass : the power, in this case, will vary in the direct proportion of the interval between the eye-piece and object-glass. I am fully aware that this alteration in the conjugate foci of the object-glass will affect its corrections; still, in some cases, the advantages to be derived from it will counterbalance this objection.

Having now given a description of the instrument in its simplest mounting, together with examples for selecting its object-glasses and eye-pieces, I shall proceed to consider, separately, the several additions which can be made to it, inasmuch as each one of them can be em-

* See Rev. M. J. Berkeley's admirable paper on Fungi, Annals Nat. Hist. vol. i. p. 82. 
ployed in the microscope without reference being had to any of the rest. By this means, persons engaged in particular investigations may easily judge of the peculiar apparatus which is suited for them, and select accordingly.

Secr. 1. Candle-holder, Shade, and Condenser for the Microscope. - The first addition to the mechanical portion of a microscope we may consider to be the arm, $k$, represented at fig. 21 , for carrying a candle or lamp, to supply the requisite illumination. Those persons who are in the habit of using an artificial light for the microscope, are fully aware of the difficulties there are in conducting their observations satisfactorily with it. Upon all accounts, it is advisable that the candle or lampholder should be attached to the stem of the microscope ; for by this arrangement the light may be easily kept at the required elevation, and the inconvenience arising from the foot of the candlestick coming in contact with the stand of the instrument, will be wholly avoided. Besides, you will not experience the annoyance of being continually obliged to alter the direction of the light, through unconsciously moving about the microscope.

Having given in the "Micrographia," page 219, a description of the above-mentioned apparatus, together with the shade, and shewn it by several engravings, in the following pages, at the positions, $k, l$, it is unnecessary for me to remark further upon it here. I may mention, however, that the same rod which is used for the purpose of regulating the illuminations, is made to 
carry the condenser also, and in a manner the most efficient for concentrating the light upon both opaque and transparent objects. The condenser is represented at $m$, in the same figures.

SEct. 2. Spring-double-Stage.-This stage, which is represented at $a, b, c, c$, in fig. 24 , is a vast improvement upon the ordinary stages shewn in the previous engravings, figs. 11, 12, and 17. It answers the purpose of a safety-stage for large objects, mounted on a slip of glass, or contained in a brass trough, or large live-box, which must be placed between the stage-plate, $a, b$, and the circular plate beneath it. This lower plate being kept up by the two springs, $c, c$, allows the slider, trough, or aquatic live-box, to be moved about in the manner recommended by Dr. Goring, in Chap. IX. The upper plate, $a, b$, is furnished with a forked piece similar to that shewn in figs. 13, 14, and has likewise a circular ring for reducing its aperture when necessary: This stage was contrived by me for making experiments with polarized light; for which I consider that it, or something like it, is indispensably requisite.

It fits on to the microscope in the same way as do the other stages, and like them may be furnished with dia. phragms under it.

Sect. 3. Moveable Stage.-Various contrivances have been made use of to give the stage of a microscope, when an object is placed upon it for examination, a convenient 
lateral motion. On Dr. Goring's principle, as described in the next chapter, a corresponding effect is produced by moving the optical portion of the instrument; a system which doubtless has its advantages, when either the aquatic larvæ of insects, or other large living objects, are examined; as also when any sizeable bodies are being dissected under the regular microscopes employed for that purpose. The moveable stage, however, for small objects, and for general purposes, is usually preferred.

The ordinary method of adjusting a moveable or traversing stage is by means of a couple of screws working at right angles to each other; by turning one or both of which, a plate affixed to them, and carrying with it the slider-holder containing the object, is muved in any direction. Sometimes a screw and a rack and pinion are substituted, by means of which all the movements are effected on one side; at others, levers are made to answer the purpose. But by far the most elegant invention is that of the late Mr. Tyrrel, the celebrated mechanical engraver, which, together with some improvements $I$ have made upon it, I propose to describe, as being the one most likely to be adopted generally, and preferred to all others. Its advantage consists in that with one hand and without removing it, you can give to the object a lateral movement in all directions. This is done by attaching a screw to the lower fixed plate of the stage, within whose axis passes the axis of a small pinion, the outer extremity of each terminating in a 
small milled head. These milled heads I place on the same side as the large milled head, $x$, which works in the rack of the triangular bar, so that all the motions are obtained by one hand, whilst the other is left quite at liberty.

Fig. 18.

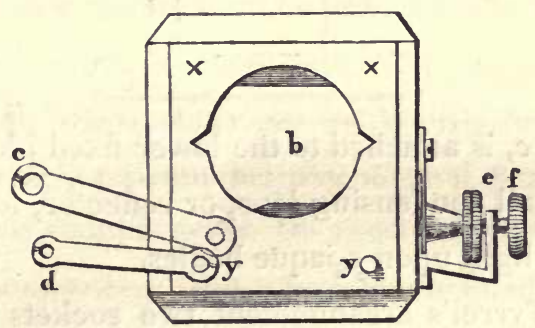

In the annexed figure, 18, a plan of this stage is given. It fits into the block of my instrument by means of two pirıs, just in the same manner as the other stages, \&c. are made to do.

$e$, and $f$, are the two milled heads for effecting the lateral motion. The former of these is connected with the screw, and will move the stage to the right or left, the latter to the pinion, and will move the stage to and fro. By turning hoth the milled heads, therefore, at the same time, a diagonal motion (by the composition of forces) will be obtained, by which the object for inspection can be brought and retained in the axis of the instrument. $y, y$, are two studs for the purpose of carrying the arm $d$, at the further extremity of which a pair of forceps (fig. 15) may be inserted for holding an insect, or any other object which may be required. The studs will support also a plate of glass when the instrument is 
in an inclined position, or the finger-springs, fig. 19, which are suited to hold large aquatic live-boxes, \&c. \&c.

Fig. 19.

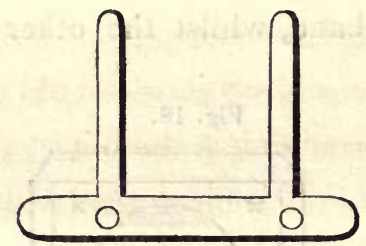

An arm, $c$, is attached to the lower fixed plate, for carrying a small condensing lens, or reflector, for throwing condensed light upon opaque bodies.

In Mr. Tyrrel's arrangement two sockets were fixed in the front at $x, x$ : the one for holding the condensing lens, and the other the forceps, instead of the studs $y, y$, and the $\operatorname{arm} c$. The objections to this plan were, that the condensing lens was moved together with the object, so that the illuminated spot did not remain under the centre of the instrument. The necessary consequence was, that a re-adjustment was to be made at every movement. Also, the situation of the sockets was such as to obstruct large plates of glass containing thin sections of fossil wood, \&c. \&c. from being laid upon the stage. These inconveniences are entirely obviated in the improved stage.

Fig. 20.

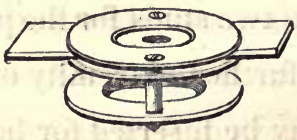

The upper plate or moveable part of the stage has a circular aperture, $b$, furnished with two angular notches, 
into which is fitted by a bayonet-joint the spring safety slider-holder, fig. 20 , or the finely-adjusting one described in the Micrographia, page 217.

The utility of these safety-slider-holders is, that if by any accident the object-glass should come in contact with the slider containing the object when it is placed between the plates, the object-glass will not be damaged; for the spring which acts upon the lower plate will yield. I most strongly recommend that a good object-glass of deep power should never be used without this or a similar contrivance. The numbers which are injured or destroyed for want of this precaution are very great. It is often quite impossible to restore them to their primitive excellence, even though the anterior lens of the combination should not be broken. It may be remarked, also, that in half the accidents of this kind which occur, the observer is wholly unconscious of what has happened, his attention being riveted to the object he is engaged with.

Sect. 4. The Spring-Phial-Holder.-This apparatus is designed to afford us all needful assistance towards investigating a certain class of objects without removing them from their natural element-fluids. The circulation or cyclosis in plants, the circulation in the tail of a fish, the structure and functions of various marine and freshwater zoophites, the habits of such entomostraceans and infusoria as attach themselves to the sides of vessels, the developinent of the young from the ova of creatures 
which deposit them on the sides of vessels, \&c. \&c., fall within the above description.

In examining any of these, this apparatus will be found to be exceedingly convenient and useful; for; by its aid, we can with perfect facility carry our researches into the contents of any open vessels, or phials, of a size proportionable to the range of the holder. In the ordinary way, a phial or vessel, unless it be very shallow indeed, must be turned upon its side, and stopped with a cork to prevent the water from running out; and even then it often happens that a portion of the air included in the vessel presents itself in the field of view, so as greatly to disconcert our plans. In using the spring-phial-holder, however, this inconvenience is avoided: and there is, besides, a more considerable advantage to be derived from it, viz. that of not disturbing the objects, by turning them about, so as to accommodate them to the microscope. Again, as open vessels can be put in the holder with as much readiness as an ordinary slider can be placed on a common stage, a series of observations on the contents of different vesels may be made in a very short space of time. In viewing by common means the cyclosis in aquatic plants, such as those of the order Characea, where every cell throughout the plant has its distinct circulation, it is necessary that a small portion of the plant should be severed from the rest, placed in a slider, and covered with a plate of mica or glass. This section will not of course remain alive for any great length of time, unless it be carefully replaced in a large vessel. With 
the phial-holder the plant may be of a size sufficient to live for months, during which it is ever ready for examination without any preparation whatever.

In a microscope of the common construction, if the magnifier or object-glass should be accidentally brought into contact with the object, when it is placed on the slip of glass used for the purpose, it is very liable to be destroyed. In this we perceive another advantage of the phial-holder; for the spring, in this case, behind the vessel, would yield, and thus prevent the injury.

Fig. 21 .

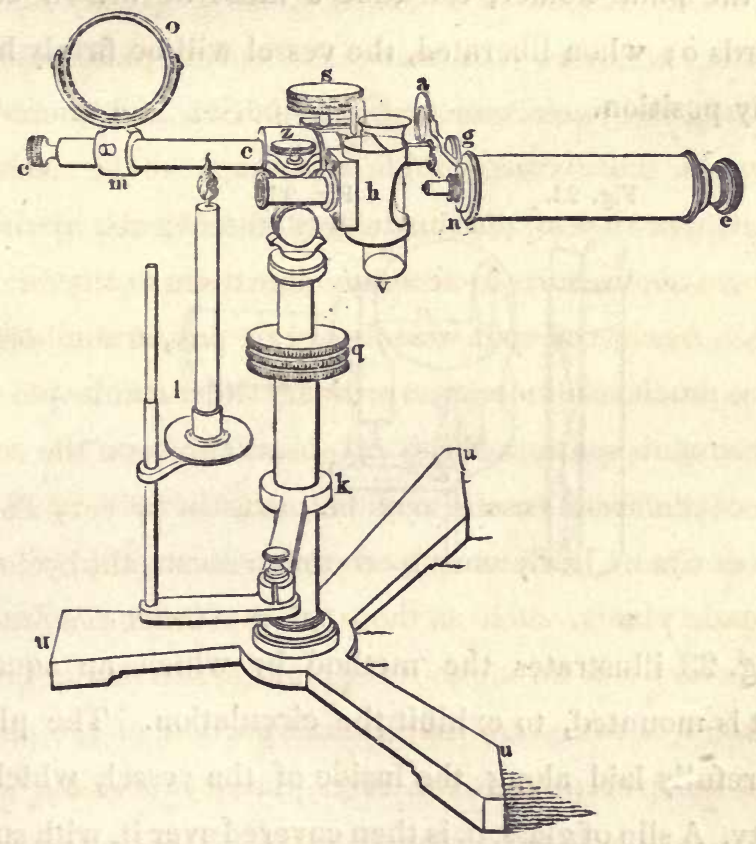

Fig. 21 represents the microscope with the body $e, n$, in a horizontal position. The stage is removed, and the 
stem $c$, turned a quarter round, where it is firmly clasped by the screw $z$. The body and arm, $a, g$, is drawn out by turning the pinion-head $s$, so as to admit of the phialholder $h$, being placed in its situation. This piece of apparatus is shewn separately on a larger scale at fig. 22, where $p, p$, are meant to represent the pins by which it is attached to the microscope. Within the tube $o$, slides another, $s$, which is propelled by a helical spring inserted within it. This latter, or sliding-tube, has a thin concave plate in front of it. When a phial, or other glass vessel, similar to that shewn at fig. 23 , is to be inserted into the phial-holder, the tube $s$ must be drawn back towards 0 ; when liberated, the vessel will be firmly held in any position.

Fig. 23.

Fig. 22 .

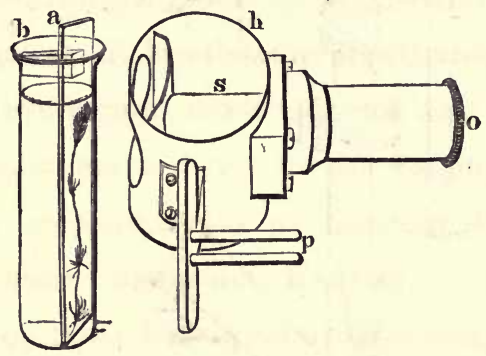

Fig. 23 illustrates the method by which an aquatic plant is mounted, to exhibit the circulation. The plant is carefully laid along the inside of the vessel, which is empty. A slip of glass, $a$, is then covered over it, with sufficient care to prevent it being injured. A small piece of cork, $b$, is fitted behind it, and the vessel, then placed in 
an upright manner, is filled with water. By this simple contrivance, for which we stand indebted to Mr. Varley, the plant is retained close against the interior surface of the vessel, so as to admit of a magnifier of short focus approaching it ; whilst in the space between the flat slip of glass and the concave surface of the vessel, it will live some months, without requiring any other attention than merely adding a little water to replace that which shall evaporate.

In reflecting upon what has been stated, it will be evident that there are two points in the constructing of our microscopes well worthy of notice, as tending to facilitate the whole of this operation, viz. that the stage be removeable, and the stem, $c$, capable of being turned round.

1. When the phial-holder is mounted on a simple stand for carrying only single magnifiers, it becomes a very useful instrument for the above purposes; as also for the examination of the progress of crystallizations and other chemical actions. In this mounting it is named the Phial-Microscope; and as a mirror is not attached to it, a lighted candle must be placed close to the end of the tube, o, fig. 22 .

Sect. 5. On the polarizing Microscope, or Apparatus made use of for viewing objects by polarized light under the Microscope.-Few subjects in experimental science have roused the attention of philosophers of the present age more than that of the polarization of light. Its 
curious action on natural and artificial bodies, eliciting, as it does, a brilliancy of colours past all conception, has created so deep an interest in the minds not only of men of science, but of all who have ever witnessed it, that a treatise upon an instrument so intimately connected with it as the microscope is, would, I am sure, be deemed altogether incomplete, if it did not embrace some particulars respecting this great phenomenon. The transmission of light through two thin plates of crystal is an operation which can be readily enough understood; but that the mere turning of one of them a quarter round should occasion a total stoppage of light, although the thickness of the plates and their inclination to each other remain the same, is so contrary to the general laws of optics and to our daily experience, that we should be at once disposed to question the fact, if we were not practically convinced of its truth. Again, supposing the plates to be in the position last named, by which, as we have said, the light is intercepted in its passage through them, and it was suggested to us to interpose between them an additional plate of a crystal, the natural conclusion would be, that this arrangement would operate to occasion a greater exclusion, if possible, than did the other, which, under ordinary circumstances, would doubtless be the case. Having done this, however, we find, to our great astonishment, that the light is now freely transmitted, and often accompanied with the most intense and splendid colouring. To arrange plates of crystals in chaste and pretty designs, so as to make these 
beautiful effects visible to the natural sight, requires both the talent of an artist and the experience of a workman. Enlist, however, but the microscope into this interesting service, and the result will be that you will be supplied at once, without a shade of difficulty, with an almost endless variety of natural forms clothed in the most brilliant tints, and that too by the ordinary crystallization of common salts. Thus, the application of a polarizing apparatus to a microscope must be considered as being highly desirable.

In a sniall pamphlet, entitled " A List of 2000 Microscopic Objects," I have given a brief description of a polarizer of my own contrivance, suggested to me through being informed that Mr. Fox Talbot had applied one to a compound microscope. To this gentleman is due the merit of having fir'st brought this arrangement before the public; as also the application to the engiscope of that beautiful invention of $\mathrm{Mr}$. Nicol-the single-image calc prism. It appears, however, that Sir D. Brewster had for years attached tourmalines to single magnifiers for the purpose of making experiments on polarization by crystals. He did this by cenienting the tourmaline to a plano-convex lens, and then illuminating the object by polarized light reflected froin a glass or japanned surface*. Professor Amici, also, has introduced the ordinary rhombs of Iceland spar into the compound microscope for a similar purpose. He has,

* Vide treatise on Microscopes, Encyclopædia Britarnica, p. 95. 
indeed, prosecuted the investigation of this subject by means of the microscope, to a much greater extent than any one else, by making it available towards exhibiting the rings in plates of crystals cut across their axes, and the exquisite tints in unannealed glass, \&c.

Fig. 25.

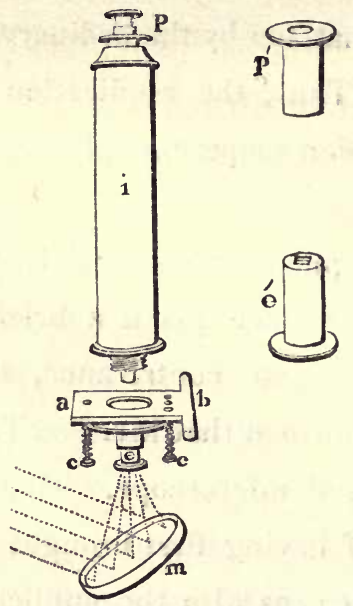

In these experiments $I$ find that achromatic objectglasses are almost essential ; for with common ones the aperture is necessarily so reduced, that a sufficient quantity of light will not be transmitted to give intensity to the colouring. The object-glasses classed under $A$, will be found most suitable; and the eye-piece, $B$, best constructed to take in the largest field admissible by the prism.

Let $i$, fig. 25, represent the body of a compound microscope, carefully placed over the centre of the springdouble-stage, $a, b$. Let a slider of crystals be placed upon the stage, $a, b$; adjust to the focus, and illuminate 
with as intense a light as can be made to pass through them. Now, insert into the socket under the stage, at $e$, a single-image prism, and then examine the crystals. They will still retain their usual colour, if any, though the light passed through them is polarized. This prism is termed the polarizer.

Next, unscrew the cap of the eye-piece, $P$, and apply another cap, containing a tourmaline, or single-image prism. This latter is shewn separately at $\boldsymbol{P}^{\prime}$. By turning one of the prisms gently round, it will be noticed that in certain positions no more light will be transmitted than just so much as passes directly through the crystal; whilst the crystal, which, before the upper prism or analyzer was added, was colourless, now displays the most brilliant colours. If a crystal be selected exhibiting a deep orange tint, and the eye be fixed upon it as the prism is turned a quarter round, the colour will gradually change to green, and the light will, at the same time, be freely transmitted through the microscope ; in other words, the field of view will become illuminated in the same manner as when a transparent object is viewed in the ordinary way. Continue turning the prism another quarter of a revolution, and the light will again be stopped, and the crystal will resume its rich orange tint. The two prisms are mounted in brass tubes, with caps. The longer one is to be used under the stage, as polarizer, and the shorter above, as analyzer.

When the analyzer is a plate of tourmaline, instead of 
Mr. Nicol's single-image calcareous prism, a more extended field of view will be obtained; notwithstanding which, the latter possesses many advantages over the former, most especially that of its being colourless.

In cases where the ingenious invention of $\mathrm{Mr}$. Nicol cannot be procured, a rhomb of Iceland spar may be well enough substituted, provided only that it has a small aperture at the under surface, and that the upper one is furnished with a sliding plate, with a corresponding aperture, so that one or other of the images can be seen at pleasure. Sir D. Brewster, who adopts this method, cements a thin plate of glass upon both surfaces of the rhomb, to take away their imperfections, and to prevent accidents occurring, or deterioration of the polish by cleaning.

The peculiar advantages resulting from the application of the rhomb of Iceland spar, I shall give in Sir David's own words. "These rhombs may be made even out of rhombs crossed with veins, which multiply the images, because the multiplied images are at too great a distance from the principal ones to be visible. This is a pecuJiar advantage, as it is often very difficult to get good pieces of spar free from this composite structure.

"This method of constructing a polarizing rhomb enables us to take advantage of the two lateral images which accompany the two principal images in crystals crossed by on evein. These lateral images, shewn at $m$, $n$, fig. 26, are distant from one another, and from the principal images, $b, c$; and as each of them consists of 
light wholly polarized in one plane, we have only to bring one of them under the aperture of the object-glass, to have an admirable polarizer, without being at the trouble of stopping out any of the other pencils.

. "The images, $m, n$, are much less bright than the principal ones, $b, c$; but this is really of no consequence, as we can obtain any degree of light we choose in the microscope, either by the condensation of artificial, or the use of solar light.

Fig 26.

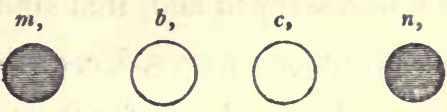

"When the vein by which these lateral images are formed is above a certain thickness, their light is white; but they are most fiequently coloured; and the observer who understands the cause of these colours may make this coloured pencil of great service in microscopical observations. If he uses a rhomb, which gives to $m$ a green of the second order, it will contain none of the extreme violet and blue rays, and none of the extreme red; so that it affords a more homogeneous pencil than if it were white light, and thus improves the performance of a microscope that is not achromatic.

"He may, in like manner, use tints which give the red extremity or the blue extremity of the spectrum, or even, when the tint is divisible by the prism into periodical bands, he may absorb the least luminous of these bands, and create a homogeneous pencil of polarized 
light, of inestimable value in particular researches, and with particular microscopes.

"But, independent of these advantages, the method of using a lateral pencil, $m$, has the great advantage of not requiring any thickness in the rhomb. A Nicol's prism, and a rhomb in which the two principal images, $b, c$, are used, must be about an inch thick, in order to be efficacious; but the distances, $m, n$, or $m, b$, are the same at all thicknesses, so that we can use rhombs for this purpose which are quite useless for any other.

"It is scarcely necessary to add, that similar rhombs in which either the principal images, $b, c$, or the lateral ones, $m, n$, are used, may be employed for the analyzer. For this purpose, a thin plate, in which $m$, or $n$, is white, is peculiarly applicable, as it enables us to see at once the whole field of the microscope*."

In all the effects produced by the foregoing arrangements, the field of view is either black or white. By employing, however, the stage represented by fig. 25, and inserting between the upper plate and the circular one a plate of crystal or unannealed glass, the back ground may, at pleasure, be made to assume a variety of colours, so that the crystals shall appear like so many coloured gems set in different tinted mountings; whilst, without this addition, they all seem to be set on black velvet.

Considerable advantage is derived, also, from my contrivance of the double stage, in the examination of $\mathrm{Mr}$. 
DESCRIPTION OF THE ACHROMATIC MICROSCOPH. 119

Talbot's “Analytic Crystals." As these experiments, however, are full of interest, I have judged it advisable to extract from the Philosophical Transactions, and give entire, in the Appendix, Mr. 'Talbot's own papers upon the subject.

If, in place of the upper prism, or analyzer, a doubleimage prism be fixed at $P$, another and very beautiful series of effects will result from the exchange. With this modification there will at the same instant be seen two images of the object arrayed in their complementary colours; and if we turn this prism round in the manner before described, an interchange of colours will take place between the images, the one assuming that of the other. If long needle-shaped crystals are procured for the purpose, the two images will be so far separated as to appear quite distinct. They will vary in their positions also, as well as in their colours and intensity, while the prism is being turned. A moon-shaped or crescent form of complementary colours will be discernible on each side of the field of view, while the latter will be white, from the union of the two complementary colours. The most gorgeous effect of all, however, is produced by this double-image prism when a plate of quartz is inserted below the crystals (say crystals of chlorate of potass) placed at $a, b$. In short, the whole experiment is so beautiful, that it is in vain to attempt any thing like a description of it.

Some crystals possess the peculiar property of exhibiting two colours, when viewed by polarized light; 
the one being elicited by the ordinary, and the other by the extraordinary ray. Hence they are termed dichromatic. To display dichroism in crystals, the lower prism, or polarizer, should alone be used; the eye-piece being allowed to remain as when objects are viewed by common light. If, whilst the dichromatic body is under examination, the polarizing prism be turned a quarter round, the colour will also be changed. In conducting these experiments, the illumination need not be so intense. In large crystals, dichroism may be readily seen without the aid of a microscope, simply by placing them between the eye and a japanned reflector inclined at the polarizing angle.

- In order to convert the microscope into a complete polariscope, I employ, instead of the mirror $n$, a polarizing reflector, formed of several parallel plates of thin glass fixed at the angle of polarization. A stage must be constructed with a large condensing lens, and made to slide upon the same stem, $c$, as is used for the mirror. A double object-glass must be attached to the body for obtaining a proper magnifying power, and the analyzer should be made of tourmaline, in order to pro. cure an expansive field of view. With this arrangement, the phenomenon of polarized light, as exhibited in unannealed glass, plates of amethyst, as also the coloured rings and black crosses in crystals cut across their optical axes, are seen in the most perfect manner. Professor Amici was the first to exhibit these curious effects by means of the microscope, although I do not know the exact construction of his apparatus. 
Sect. 6. Apparatus for dissecting.-Since the days of Lyonet and Swammerdam, until of late, very little progress has been made towards producing a microscope of a more complete description than their's, for the purpose of dissecting. It is true that two or three of this sort have been constructed, but then they have been suited for only one particular class of objects, such as the elementary tissues of plants, \&c. Dr. Goring's engiscope, with the additions hereafter mentioned as belonging to myown microscope, probably approaches the nearest of any to an efficient dissecting microscope; nevertheless, a still further advantage may be derived from having a separate stand of proper dimensions made expressly for the purpose. As one set of magnifiers will of course suffice for both stands, the expense will not be considerable. The microscope described in this chapter, with the dissecting apparatus attached to it, is, I conceive, as complete as any one of that size can be rendered; its dimensions however, are barely sufficient for the dissecting of large objects.

Having alluded to Swammerdam's microscope, it may be advisable, I think, before describing my own apparatus, to refer the reader to an account of his method of proceeding (as given in the Appendix); containing, as it does, many useful remarks. After the perusal of this, and a brief description of Lyonet's dissecting microscope, the reader will be fully prepared to understand the construction I have adopted.

Lyonet's dissecting microscope may be thus de- 
scribed :-It consisted of a circular brass table, in which was cut a circular aperture half way between the centre and the circumference. This table and aperture served the purposes of an ordinary stage, and held a watchglass, trough, \&c. to contain the object for dissection. Under the aperture was placed the mirror; and on the opposite side to that where the aperture was made, was inserted a socket, to which a number of universal joints, strung together like a row of beads, were attached. On the terminal one was placed the magnifier. Now fig. 27

Fig. 27.

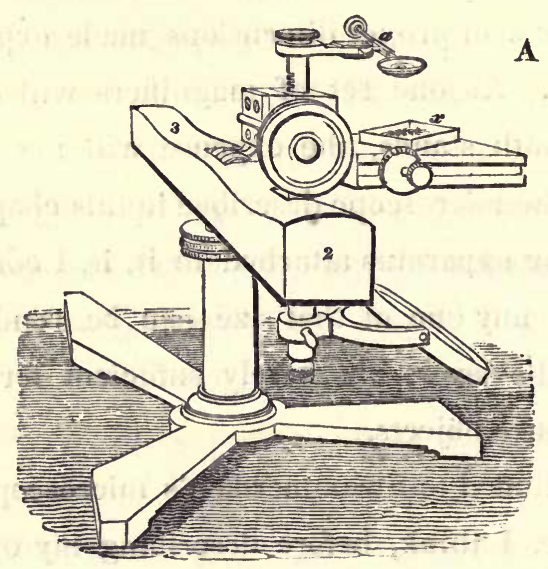

is a drawing of my instrument, placed in a vertical position, as if intended for dissecting. Nos. 2, 3, represent a wooden rest for supporting the hands; this fits on to the joint on the top of the pillar of the microscope, where it is firmly retained. Near to each end, on the upper surface of the rest, is a deepened or hollow place to pre- 
yent the hands from slipping. It will be observed, that the rest here given is perfectly straight; notwithstanding, in some cases, it will be more convenient to have it of a semicircular or curved form. There is an arm, $a$, which slides in a socket attached to an universal joint. This arm has a spring ring for carrying the magnifiers, which are inserted into it in the same manner as into the plain end of the arm, shewn in several previous figures. The dissecting trough, $x$, is placed in the moveable stage in the way described in "Micrographia," page 215. This trough, which contains the object to be operated upon, is capable of being turned about in any direction. When the object is opaque, the condensing lens, $m$, shewn in figs. 29,30 , must be brought into the position, $A$, to concentrate the light upon it.

Single or doublet magnifiers are commonly preferred to the compound microscope for dissecting, because the latter instrument inverts the image of the object. The amplifying powers, which are most generally serviceable, are those from an inch-and-a-half focus to the onetenth of an inch. When higher powers are requisite, the lenses should be made of jewels, as they allow o, more space between the object and the lens than do glass ones.

The advantages which I conceive this arrangement possesses over others, are as follow :-In the first place, the rest or support, being made of wood, does not conduct the heat away from the hands so freely as if it were of metal. 2dly. It being situated over the central sup- 
port of the instrument, and being independant of it, all straining upon the microscope is avoided, and the stage may be inclined without disturbing the hands. This will be found to have a two-fold advantage; for, by inclining the instrument, the operator is placed more at his ease ; and the superfluous matter can be easily drained away, which is necessary when large insects are being dissected. For dissecting these objects, thin pieces of soft wood, having brass rings cemented to their under sides, and being fitted into the moveable or other stage, will be found extremely convenient.

The integuments of these creatures, as soon as they are laid open, should be pinned down upon the wood, while the nervous, respiratory, or alimentary organs are being removed. The fatty matter, so very abundant in insects, must be washed away with a camel-hair pencil. By forming a ledge round the wood with a little wax, the creature may be dissected under water or diluted spirits.

The ar'm, $a$, having an universal joint, may be turned about in any direction; and should any remarkable feature present itself whilst dissecting, which it is desirable to examine without removing it, this may be readily effected by taking off the screw-nut, $g$, and substituting the usual arm of the microscope, with the achromatic body.

Sometimes the achromatic body is employed in making dissections; in this case, the image being inverted, it requires some practice in using the dissecting instru- 
ments, unless an erecting eye-piece is applied, as mentioned in the following chapters.

Sect. 7. Single Lenses mounted in imitation of Achromatic Object-glasses.-A series of single lenses mounted as object-glasses, and of the same foci and angular aperture as achromatics, will prove an excellent method of instituting a comparison between their relative values. The object-glasses are the most costly portion of an achromatic microscope, notwithstanding to ordinary observers they appear not to differ exteriorly from common lenses mounted in the manner described. Some persons are very apt to imagine that the additional price of the one above the other is owing to the achromatics superior magnifying power; but as this does not necessarily follow, these single lenses will manifest at once wherein the superiority consists.

By way of trial, screw to the body of the microscope one of the single lenses; place an object under it, and examine it with attention: then remove the single lens, and substitute an achromatic object-glass in its stead, allowing the object, eye-piece, and other portions of the instrument, to remain as before. The difference will be apparent enough in a few minutes to leave a full and lasting impression upon the mind, of the extensive improvement which has of late years taken place in this respect. I know of no better mode than this by which persons unacquainted with optical science can judge fairly of what has been effected for the microscope. 
The achromatic will be distinguishable from the single lens by its exceeding penetration, and by the total fieedom from spherical and chromatic aberration with which the light is transmitted through it. It is true that if the common lens have a diaphragm to limit its aperture, the vision will be more distinct, and the light less coloured; but then, compare the two again, and in the case of the single lens there will be a perceptible diminution of light, and the eye will soon grow weary in endeavouring to trace out the minutiæ of an object.

Sect. 8. Garden Clamp for the Microscope.-This piece of apparatus enables us to employ the microscope for the examination of flowers and plants in the garden or greenhouse. The clamp is represented by the annexed engraving, fig. 28. The end, $c$, may be screwed to a

Fig. 28.

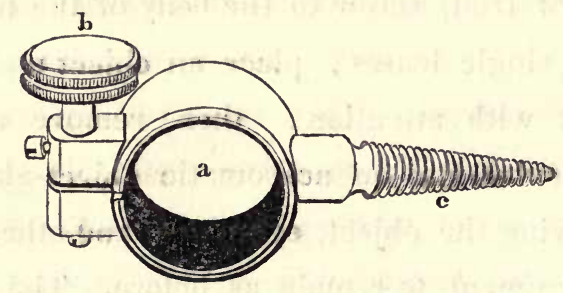

tree, door-frame, or any other convenient place. The body of the microscope is then inserted into it at $a$, and fixed there by the pinching screw, $b$. To the lower end of the body is screwed a small arm, constructed for the purpose, and carrying the forceps for holding the object. The object-glasses, $A$, with their silver specula, are the 
most serviceable for this occupation, as the adjustment is very readily made with them. The microscope, suitably equipped, may be used for examining flowers without either its stand and apparatus, or the clamp: the body, with the arm above mentioned, being merely held in the hand. A variation in the magnifying power is obtained by sliding the body in and out, and thus avoids the necessity of changing the object-glasses, which, out of doors, would be attended with some risk of loosing them.

Sect. 9. Steadying Rods.-When we have recourse to very high powers for making microscopic observations, it is of consequence that the microscope be kept as steady as possible, all motion, or tremor, being magnified to the same extent as the object itself. Under such circumstances, it is often expedient to have one or two sliding rods, whose upper extremities may be attached to the eye-end of the body, and their lower to the feet or pillar of the stand. When these rods are employed, alt their tightening screws must remain loose until the instrument is set in the proper position-the moveable stage, with its fine adjustment, put on, and the objectglass, selected and adjusted to distinct vision by means of the rack and pinion, in the usual way. When this is effected, the steadying rods may be clamped tight with the pinching screws, and all subsequent adjustment to distinct vision made by the fine adjustment, the rack and pinion being now considered immoveable. 
Although this contrivance sufficiently obviates the annoyance occasioned by tremor, yet I strongly recommend a small stout stand being had expressly for the purpose; the additional expense not being great, whilst, from its simplicity and convenience, you will be amply recompensed.

Another purpose to which the steadying rods may be applied, is that of drawing with the camera lucida. In this case, the body of the microscope should first be ranged horizontally, the steadying rods tightened with the clamping screws, and then the requisite adjustments made, the body remaining a fixture.

Secr. 10. Camera Lucida for drawing with the Microscope.-This instrument is constructed in a variety of ways, but the most serviceable is that shewn in the plate, fig. 12. As there is only one reflection, the image of the object is presented to you with its sides reversed, resembling a copper-plate engraving from which the impression is taken. The method of using this instrument is as follows :-With my microscope, the cap, or cover, which limits the pencil emerging from the eye-piece, must be unscrewed, and the ring, to which the camera is attached, substituted in its stead. This ring is furnished with a pin for the camera prism to slide upon, which may thus be made to approach or recede from the eyelens to suit the emergent pencils of light. The inclination is regulated by turning it on its axis.

For making drawings of microscopic objects, the eye- 
piece may be conveniently removed from the body of the microscope, and the end covered with a cap, having a plate of finely ground or greyed glass fitted into it. On this plate the image of the object will be formed, and distinct vision obtained by adjusting the focus in the usual manner. In this case, the eye-end of the microscope, in order to produce the desired effect, must be kept darker than the other extremity. If, instead of the plate of glass, a piece of tracing paper be employed, the image may be delineated at once. Also, the glass may have divisions marked upon it similar to those in the plate, fig. 13, and be used with drawing paper traversed with squares, on Mr. Bauer's plan, described in the Micrographia.

One great advantage which the camera lucida derives, from its connexion with the telescope or microscope, is, that the reflected image is thrown on the drawing paper, so as to appear in the same plane with it. When it is used without either of these instruments, the image is formed at the same distance below it as the object is distant from it in front; thus occasioning an error by parallax with the image and pencil, upon the slightest motion of the eye.

Beginners in drawing experience some difficulty in. obtaining a distinct view of the point of the pencil simultaneously with the magnified image. The Rev. J. B. Reade informs me, that by illuminating the ohject with strong lamp-light in the day-time, and the paper on 
which the tracing is made with day-light, this inconvenience is entirely remedied.

SECT. 11. Micrometer Eye-pieces. - The micrometer eyepiece is made to slide into the body of the microscope, like the ordinary eye-pieces. This eye-piece is designed either for drawing or measurement. When we employ it for drawing, a plate of glass, with divisions similar to those represented in the plate, fig. 13, must be used, in the manner described by Mr. Bauer. When for measurement, a slip of pearl, with divisions of 100 or 200 to an inch, answers best for all practical purposes. It must be remarked, however, that the same divisions represent different measurements according to the power of the object-glass and length of the body. When, therefore, they are once ascertained by the rules laid down in the Micrographia, page 48, they must not be altered.

For either of the above purposes, the micrometer must be placed at c, page 80 ; in the focus of the eye-lens, $a$. Now as the distance of distinct vision differs in different persons, and even in the same person, according to his state of health, the adjustment must be made so as to vary the distance between $a$ and c. This is ordinarily done by moving the lens $a$, with a screw. On consideration, however, it is evident that by this means the achromatism of the eye-piece is disturbed. I have obviated this defect with my eye-pieces by giving the adjustment to the field-bar, $c$, which carries the micrometer. 
Sect. 12. Method of viewing moveable Fluids in the Cavities of Topaz, Quartz, and other Crystals.-The existence of small cavities in crystals is of such frequent occurrence, that few persons who are in the habit of seeing crystals at all, can be unacquainted with the fact. That some of these cavities, however, contain moveable fluids, is a recent discovery, for which we stand indebted to Sir D. Brewster. As I am not aware that the method of observing these under the microscope has ever been explained, a few words upon this subject may not be considered superfluous.

Let your microscope be placed in a vertical position; apply a power of 100 or 200 diameters, and put the crystal for examination upon the stage. Bring one of these cavities into the centre of the field, and adjust to distinct vision, when the fluid will be discerned within the cavity, resembling an air-bubble. The proof that this appearance is occasioned by a fluid contained within the crystal is very readily ascertained. Take a metalheater of a proper size, having a hole in the middle to allow the light to pass through; warm it, and hold it by its handle under the aperture in the stage, close behind the glass plate upon which the crystal is situated. During this operation you will observe the fluid in the cavity expand, and, in some cases, become volatilized; and then, upon cooling again, return to its fluid condition.

Many of the cavities in gems, particularly in the 
diamond and garnet, are perfectly spherical; and, owing to the great refractive power of these stones, they have the appearance of black and opaque globules with a small bright spot of light in their centres. The proportion between the diameters of the dark annulus and the luminous spot, Sir D. Brewster has ingeniously proposed as a measure of the refractive powers of both the solid and the fluid. He has suggested, also, that these cavities being permanent, are preferable to Dr. Goring's* air bubbles in Canada balsam, for determining the aberrations of object-glasses; but a little consideration, I think, will suffice to shew that both the one and the other of these tests must give erroneous results for ordinary objects. And for this simple reason, because the light coming from the cavity to the object-glass through a portion of the gem, will be refracted by it, and enter the object-glass in a different state to what it would have done had no such medium intervened between the cavity and the lens.

In examining the organic remains embedded in flint, the object-glass requires to be corrected by this test, as the rays of light proceeding from the creatures discoverable in thin plates of that substance, have to pass through it before they enter the object-glass. The recent discovery of the crystatella + and other infusoria in flint, as also the sporules of ferns, has opened an en-

* See Micrographia, page 107.

+ Zanthydium furcata of $\mathbf{E}$. 
tirely new field to the geologist, and one which promises some very important results in throwing light upon the uriginal formation of that stone. Some beds of flints are crowded with these infusoria, whilst others are wholly without them. In viewing these creatures (crystatella) a powerful object-glass is requisite; and, as their multi-pronged spines protrude from all parts of the surface of their bodies, each part being in a different plane, there must be a new adjustment of the focus.

Some of the cavities in minerals contain "two fluids unknown to the chemist: groups of crystals, floating balls, \&c." The forms of these cavities are various. Those containing two fluids, which do not mix though in the same cavity, appear globular.

Sect. 13. Concave Specula, Silver Cups, or Leiberkühns, for illuminating opaque objects. - In viewing opaque bodies by means of concave specula, it is generally advisable to remove the stage of the instrument, and to insert the arm, fig. 16, with the furceps, fig. 15. An object-glass of a right focus must then be screwed into the body of the microscope, and the silver cup, properly fitted, made to slide over it. If candle-light, which is the simplest artificial illumination, be used, although a small argand lamp is often preferable, the light may be placed from about 3 to 6 inches behind the object.

When we have day-Jight, the concave mirror must be brought into the rear of the: object. In this case it 
should be placed as near to it as it conveniently can be, in order that the cone of rays reflected from the mirror may spread over the whole surface of the silver cup; otherwise, the maximum illumination will not be obtained.

Having brought the object into focus, the silver cup must be adjusted, without altering the adjustment of the focus of the instrument. This is done by sliding the tube belonging to the silver cup over the tube which is screwed before the object-glass. In order to obtain the maximum quantity of light, the cup must be placed so that the object is a little within its focus. As the length of this focus, however, varies with the distance at which the candle, lamp, or other illuminating source is placed from the cup (the rays being thus either parallel, diverging; or converging, ) the adjustment must be made after the position of the illuminator is determined upon. Thus, when the cup is used with a candle placed at 3 or 4 inches distance from it, the rays being divergent, the focus will be elongated, in which case the two tubes must be thrust in. Again, when we illumine by daylight reflected from a plane mirror, the focus is shortened, and the outer tube requires to be drawn out a little.

In the old constructed microscopes, the concave speculum, or silver cup, was attached to the stage of the instrument, so that a fresh adjustment was always required for every change of object. By the above mentioned plan, as soon as the cup and light arc adjusted, 
nothing further is necessary in this respect; for when the object is brought into the focus of the microscope, the illumination is sure to be correct.

Persons who have never viewed opaque objects with shallow or medium power object-glasses, and silver cups of proper diameters and curvature, are not aware of half the beautiful effects resulting from the achromatic construction. And as for objects that are suited to this method of illumination, they are almost infinite in number ; and, consequently, a greater fund of instruction and pleasure is derivable from it than can be obtained with deeper powers, where the objects which can afford amusement are much more limited.

Sect. 14. Stops or Diaphragms are used for the purpose of limiting the illuminating pencil of light, and may be described as being small tubes with apertures at each of their extremities. These are made to slide into sockets, which screw into orifices formed to receive them at the under side of each of the stages of the microscope. They are sometimes furnished with a wheel of apertures, similar to that shewn in the plate, fig. 24 ; and sometimes these sliding tubes have a small condensing lens, such as that exhibited in the Microscopic Cabinet, page 170. By having the stops or diaphragms in the form of tubes, the effect they are designed to produce may be varied, if necessary, by sliding them up and down within their sockets. Those possessing the lens, and intended to act on Dr. Wollaston's principle, require this adjust- 
ment, in order that a fine definition may be obtained with them. "The centre of the aperture must be in the common axis of the lenses" of the microscope, "and the image of the perforation formed by the condensing lens must be brought by such adjustment into the same plane as the object to be examined*."

Stops or diaphragms serve to increase the definition of the outline of delicate objects. Thus, the cilia and internal structure of animalcules become much more visible by their aid than without it, especially when we have single magnifiers only. They enable us, also, to reduce the quantity of light, when using achromatic microscopes with object-glasses of long foci; by which reduction our observations on thin transverse sections of wood, as well as on cylindrical and spherical bodies, may be more accurately made.

With high magnifying powers it is often desirable to have a lateral adjustment for the Wollaston illumination, to effect which, a movement to and fro must be given to the screw which holds the socket, on the under side of the moveable stage (page 105); whilst the body admits of a lateral adjustment, to the right or left in the other direction. By these means we may obtain either a central or eccentric pencil of light.

The reader must bear in mind, that stops have the effect of decreasing the angle of aperture of the objectglass; and therefore, in testing it, he must make proper allowance for them. 
Sect. 15. On viewing Transparent Objects by Day-light. - The best position of the instrument by day-light is that represented at fig. 29. When the object-glass is of long focus, a screen must be interposed to stop the light from falling upon the object. If this precaution be not taken, we could not obtain a correct knowledge of it, on account of the confusion occasioned by the transmitted and reflected light. They must not, therefore, be used together. A small piece of black card placed upon its edge, on the stage, will prevent the light from falling upon a transparent body.

Skcr. 16. On viewing Transparent Bodies by Intermitting Light.-It has been ingeniously suggested, in order to determine the number and arraugement of the rotatory organs of Infusoria (such as the wheel-animalcule), to illuminate them by a succession of galvanic or electric sparks. By this means, an effect is produced similar to that occasioned by the revolution of a cogged wheel when viewed in a mirror. The reflection through the cogs makes the wheel, although in rapid motion, appear stationary.

As there are several methods by which this effect can be produced, it is unnecessary to enter upon the details here, some persons preferring one way and some another. In my own experiments, I have used the sparks emitted by the electric magnetism of a wheel dipping in mercury. 
- SEct. 17. The Black Ground Illumination for Transparent Objects.-The Rev. Mr. Reade, in the Appendix to the Micrographia, has described a method of illumination for transparent objects, differing from any at present in use. It consists in illuminating the object by a very strong light placed at such an obliquity to the axis of the microscope that none of the rays can enter it, except those which impinge directly upon the object, and are thereby bent so as to pass through the object into the instrument. As the arrangement for viewing objects in this way may not readily suggest itself from a verbal description only, it has been thought advisable to illus-

Fig. 29 .

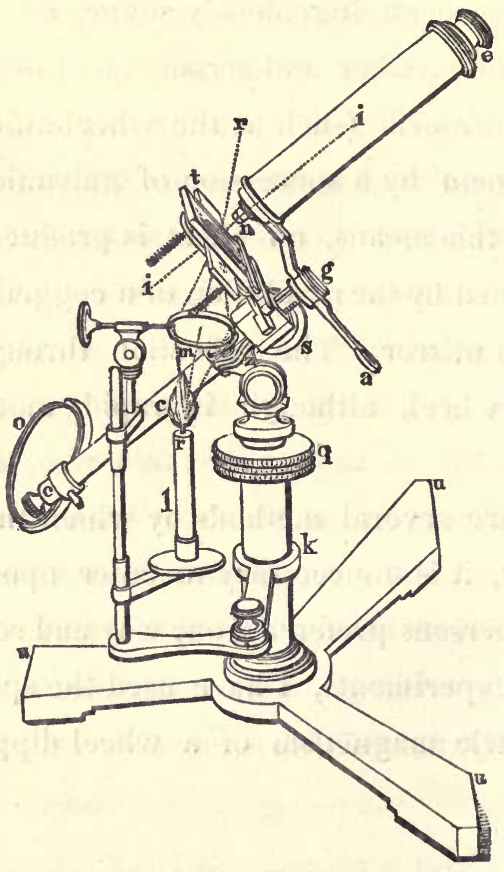


trate it more fully by means of the accompanying engravings, so that any one may make trial of it, and thence form a correct judgment of its merits. I should mention, that the effects produced are not so striking in some objects as in others, and therefore that it is worth while to make trial of several kinds.

Fig. 29 represents one of my instruments : its body, eye-piece, and object-glass, $n, i, e$; the spring doublestage, $t$; the mirror, $o$, which is turned aside ; the candleholder, $k, l$; and jointed condenser, $m$. In this arrangement it is proposed to illuminate the object by an artificial condensed light. Let the object-slider be placed between the stage and the circular plate; adjust to the focus, and place the candle, $l$, and condenser, $m$, in the positions shewn in the drawing, so that the pencil of rays, $r, r$, may form the required angle with the axis of the instrument, $i, i$. This angle will be dependent upon the angle of aperture of the object-glass; but in all cases it must exceed half that angle, in order to produce the desired effect, otherwise the field of view will be illuminated. But if a small transparent object, such as the pollen of a flower, the scale of an insect, \&c. be placed within the field of view, the rays impinging upon it will be refracted, so as to enter the microscope, and they will form an illuminated image of it upon the dark ground.

When this experiment is conducted by day-light, the instrument should be placed in the position shewn by 
fig. 30, with the condenser, $m$, to condense the light in the manner there represented.

Fig. 30 .

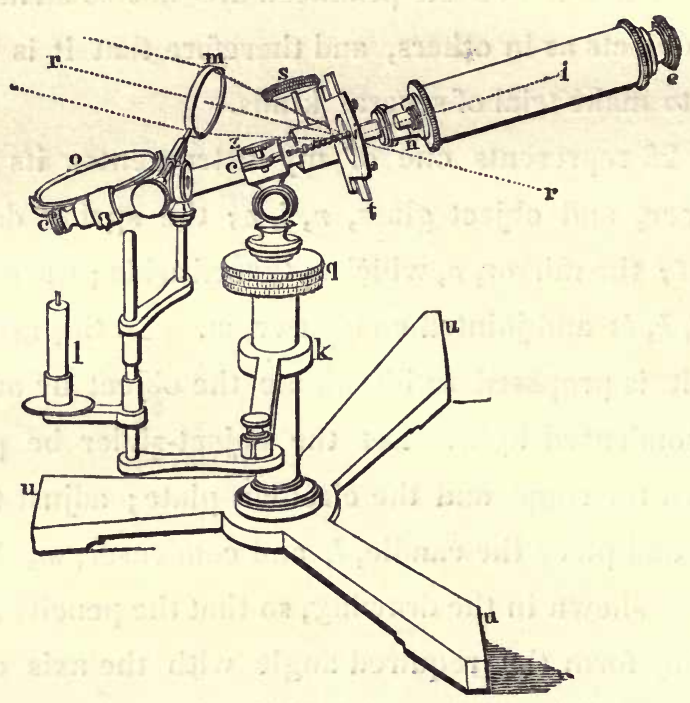

If the rays, $r, r$, make an angle with $i, i$, similar to that in the former case, the result will be the same. The most convenient plan of managing this mode of illuminating by day-light, is by means of a large concave reflector fitted upon the stem of the candle-holder; or upon a separate stand, so placed that the reflected light shall make the proper angle with the axis of the microscope. The instrument, by this means, may be placed in a vertical position, if so preferred.

The medium power object-glasses, usually marked $B$, are best suited for this method of investigation. 
SECr. 18. Method of viewing Opaque Bodies by oblique reflected Light condensed upon them by Mirrors. - It is often necessary to examine an object under object-glasses, which differ widely in their amplifying powers, or focal lengths, when great difficulty is experienced in mounting

Fig. 31.

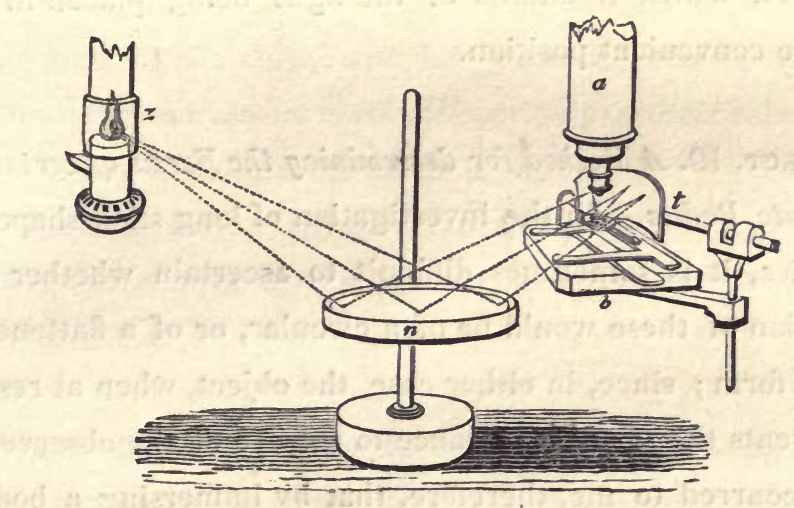

it, so as to accommodate it to them. For instancesuppose the object to be mounted on a circular disc, suitably for an object-glass of one-inch focus, it would be barely possible to illuminate it with a silver cup, adapted to an object-glass of 1-4th of an inch. Deep object-glasses necessarily require the silver cups to be small, by which means it is impracticable to give an oblique direction to the light. The method usually pursued, is to employ a silver concave reflector of the form shewn at $t$, fig. 31 ; by the aid of which light may be condensed upon the object, so as to exhibit it under objectglasses of different focal lenghs.

In order to obtain a greater condensation of light, Mr. 
Ross, who first proposed the adoption of this reflector, places a condensing lens in front of the stage. The dispersion occasioned by this lens, however, is apt to give a false colouring to the object; so that I prefer making use of a large concave mirror in the manner represented in the above (fig. 31 ), which obviates this defect, whilst it admits of the light being placed in a more convenient position.

Sect. 19. A Method for determining the Forms of certain minute Bodies.-In the investigation of long stick-shaped bodies, it is sometimes difficult to ascertain whether a section of these would be of a circular, or of a flattened oval form ; since, in either case, the object, when at rest, presents the same appearance to the eye of the observer. It occurred to me, therefore, that by immersing a body such as these in a fluid, which evaporates rapidly, the currents occasioned by the evaporation would raise and turn it upon its edges, so as to afford a view of its different sides. This plan I found to answer my expectation fully. As an example illustrative of this mode of verification may not be without its use, I have thought it worth while to present the reader with the following one :-

Take on the point of a penknife a specimen of fossil infusoria (or more correctly speaking, the silicious covering of these creatures), place it on a slip of glass, or what is perhaps more convenient, the tablet of an aquatic livebox, the cover being removed. Having equipped your microscope with a moderate power, and adjusted it to 
distinct vision, let a drop of spirits of wine, or ether, fall upon the infusoria, and observe the effect. As the evaporation proceeds, the shells of the creatures will be lifted up, presenting to the eye alternately their edges and sides, whilst they are kept in motion. When all the spirit has evaporated, excepting so much as is contained within the shells, they will lie on their sides, and the fluid within them will flow towards the opening. Thus a correct idea is obtained, not only of their external but also of their internal forms.

The evaporation will be retarded by the addition of a little water to the spirits of wine, and accelerated by the use of ether.

Sect. 20.-On viewing the Currents in Fluids during their Evaporation.-For conducting this experiment, the following method is to be pursued. Place the microscope in a vertical position; select shallow or medium-power object-glasses, which with the body shall magnify from about 40 to 100 diameters; or single lenses from a quarter to the tenth of an inch focus. Take an aquatic live-box of moderate size, and place upon the centre of it a drop of the oil of turpentine, or spirits of wine, \&c. Then cover it with the thin glass cover, taking care that the thickness of the fluid be not more than about 1-15th of an inch.

If this fluid be quite pure, the motion of its particles will not be perceptible: but Mr. Varley, who introduced the experiment to the Society of Arts, grinds a small 
portion of coal into it, which occasions the currents produced by the evaporation to be distinctly seen. The specific gravity of coal not being great, these minute portions are held in suspension during the whole experiment. The following observations on this subject are given in the Society's Transactions, vol. 50 :-

1. A drop of spirit of wine, or of naphtha, exhibits two, three, or four vortices, or centres of circulation, according to the size of the drop; and if these vortices are viewed laterally, the lines of particles will be seen forming oblique curves from top to bottom of the drop.

2. Oil of turpentine shews a rapid circulation in two continuous spirals, one to the right, the other to the left, around the drop. These meet in the opposite diameter, from which the particles are slowly carried across the diameter to the place of starting, and this continues while there is fluid enough to let it be seen.

3. If, however, the drop does not exceed one-tenth of an inch in diameter, it presents the appearance of particles continually rising up in the middle, and radiating in gentle curves to the circumference.

4. If the liquid be put into a very small phial, similar motions are perceived, the particles, when they have reached the side of the phial, going down to rise up afterwards in the centre or axis.

5. If a bubble of air be inclosed in the liquid, motions, similar to those described in No. 2, are observed in the part immediately in contact with the bubble. 
DESCRIPTION OF THE ACHROMATIC MICROSCOPE. 145

6. In a flat drop of new wine laid on the tablet or disc of the aquatic live box, but not compressed by the cover, the motion was a regular uniform circulation, the particles rising from below at one end of the drop, then passing straight across on the surface, and descending at the other end. 


\section{CHAPTER VII.}

Practical Remarks on Microscopes for viewing and drawing Aquatic Larva, \&c.

By C. R. GORING, M. D.

The instrument which I used in executing the drawings was a single microscope mounted with three achromatic lenses of the 9-10th, 6-10th, and 2-10th of an inch sidereal focus. Had I not possessed these, I should probably have used sapphires, or even equivalent common ones; for I greatly prefer a single microscope as a drawing tool, from its being so very handy and manageable, and taking up so little room on the table. All the necessary motions were given to the optical part, and not to the stage, in order that living objects should be disturbed as little as possible. I always found it make a great difference for the better when they were allowed to remain unmoved, for their natural restlessness, when exasperated by motion, renders them completely intractable; when undisturbed, they will sometimes remain quiet for half a minute together. An aquatic live-box*, of a little larger 
diameter than the length of the insect to be drawn, answers best to confine them : they may be kept quite closed up, for they do not appear to me to require air to support their existence. I was in the habit also of observing them with a compound aplanatic microscope, having a boot to slide over the objective end, so that it could be introduced into the large transparent vessel filled with water, which was their usual abode, and in which they would remain pretty quiescent, especially when well supplied with food. I must remark that Thames water is utterly poisonous to nearly the whole race of aquatic insects. I presume it is not necessary to say that every species of camera lucida, and all the contrivances which may be used for tracing inaninate objects, are altogether useless in drawing living ones. The colours of every object are given as seen with the 9-10th focus lens, having its full aperture, as they appear in mere day-light, without any artificial illumination whatever. I utterly disapprove of lamp-light for larvæ; it gives, indeed, a strong outline, but confuses and more than half obliterates the viscera, while it makes the colours very dingy and dull. The tints of these objects become fainter and fainter, and the shades darker and darker, as the magnifying power is increased. I did not find it necessary to employ any power beyond that of the simple 2-10th focus, in order to develop the whole of their structure : superior powers seem to me merely to magnify, without shewing any thing about them (except the circulation) more satisfactorily, and do not take in a sufficient portion of the object 
for a pleasing view. When we want to examine these objects merely for the purpose of amusement, it will be advisable to use compound instruments, on account of their large field of view, luxurious accommodations, and arrangements : their powers must be made equivalent to the single lenses I employed, namely, one inch, half an inch, and a quarter of an inch focus, which require their objectives to be about four, two, and one inch focus respectively, (as the weakest compound body which can be applied usually quadruples the power of the objectglass.) For the reasons stated above, all the requisite motions and adjustments must here also be given to the optical part, and not to the stage. It will also be found a very great convenience if the stage is so constructed as to admit of being altogether removed, so that any large body, such as a square vase on a large flat slider, containing the objects, can be substituted in its place, in order that there shall be no necessity to remove the insects from their usual places of abode in the said vessels, \&c. as they are very apt to receive injury and become restless by such removal. In order to effect this very desirable arrangement successfully, it will be necessary that the bar of the microscope, instead of working upon the stand with a cradle joint, should possess a capability of turning round by moving in a ball and socket, or some other similar contrivance, so that the space occupied by the stage may fold down on one side, and allow of the introduction of the jar, \&c. into it on its appropriate stand; when, all the necessary adjustments 
being possessed by the optical part, the instrument is just as perfect and manageable without its stage as with it, and may be used upon any large body whatever, which will be found a great convenience. This construction also gives great facilities for demonstrating all sorts of test objects, as well as for verifying and proving the nature of bodies inspected-(a subject which is as yet understood by few observers.)

With respect to the exhibition of larvæ, \&c. in the solar microscope, it may be observed generally, that whatever object-glass shews them well in a compound aplanatic, with the assistance of the body and eye-glasses, will shew them unassisted in the solar instrument, because the distance to which the rays are suffered to diverge does the work of the compound body in giving the necessary amplification, which it is the peculiar property of this instrument to effect to a vast extent, without altering the size of the field of view. A solar microscope may in fact be defined in its optical principle as a mere object-glass, forming an image on a skreen, instead of the space included in the field bar of a compound body.

$$
\text { C. R. G. }
$$




\section{CHAPTER VIII.}

Whether there is a best possible way of constructing the stand, or mounting, \&c. of Microscopes (the specific purpose or purposes to which they are to be applied being first determined)?

BY C, R. GORING, M, D,

I APPREHEND that the construction of all kinds of mechanical implements, tools, utensils, musical, philosophical and mathematical instruments, \&c. may be reduced to fixed principles, and that one best possible way of making them, may, and can be discovered, (when the specific and particular end and object of their fabrication is duly settled). It is otherwise with all those manufactures which are of an ornamental nature, and therefore subject to the caprice of taste and opinion; and also with every thing made for the gratification of any of our senses, or for the ease and accommodation of our personal wants. Thus it would be very absurd to pretend that there is a best possible system of cooking, or making caps and bonnets, unless we choose to assume the position, that the specific end of cooking and mantuamaking being the gratification of the whims and fancies of some particular individual, even these arts are reducible 
to fixed principles (such as they are). Every hing connected with the fine arts always resolves itself into a matter of opinion, about which it is perfectly useless to contend, because every man considers his own private judgment, however outré or singular, as of equal value at least with that of his neighbour's. The standard of taste is, then, a mere chimera, because it differs like the face, or form of the limbs, in every particular specimen of the human race; unless, indeed, it might be ascertained by taking the average of that of the whole species.

However, mankind seem to have come to a common decision concerning the utility, excellence, and superiority of many things, and to consider them as incapable, or nearly so, of any real improvement. This is the case with regard to many points, even determined by the judgment of the senses; but more so with regard to those whose value is supposed to be ascertained by the test of experience. Thus a variety of mechanical tools, \&c. may be considered as erected into standards, and not at all likely to undergo modification in future. Even musical instruments, as regards the quality of their tone and sound, seem to have arrived at a regular and determined mode of construction.

Now, if so many other things have been perfected and erected into standards, by the common consent of the human race, why should not microscopes also? Why should we not bend the whole force and power of our invention and reflection towards the fabrication of every 
thing connected with them, till every point is effected in the best possible manner? 'These instruments have undergone a complete revolution in their optical parts, and become truly dignified and respectable: assuredly their mechanical structure should correspond with the advance which has taken place in their optical constitution.

However, like other things, they are varied in their construction to serve particular purposes. 'Thus, if made merely for commerce, or to look at, or to wear in the waistcoat pocket, like a snuff-box, they must evidently be made on a plan quite different from that required for scientific observations.

I pretend not to meddle with matters concerning commerce; the trade understand them far better than I do, and shall therefore merely observe, that several individuals experienced in business have assured me, that the first thing to be considered in the construction of a microscope is its price; and the second, the size of its case, and how it is to look when packed in it, with all its little eye-traps and trinkets about it. It is frequently sold in two minutes, long before the merits of its construction can be known; therefore one kind is just as good as another, the public at large being no judges or connoisseurs in such matters.

Again, instruments may be made expressly for transparent objects, or opaque ones, or even some particular class of those bodies, for lamp-light only, or for that of the atmosphere, for drawing, for public exhibition, \&c. all of which circumstances will produce a variation in 
their fabric, while they are correctly adapted to their intended use, and, therefore, perfect in their kind. The construction which I wish to discover myself, is that of an approximation to a standard for general purposes; and I think the principles at least of such a structure may be ascertained, though the best possible way of carrying them into effect, perhaps, cannot at present-at least by myself.

In the first chapter* I have already sketched an outline of the kind of instrument which I here propose now to fill up and reduce to a determinate form, but shall first detail a few of the obstacles which all who attempt to reform the construction of microscopes may be expected to encounter. First, there is the inveterate hatred and contempt of all innovation whatever, which seems to form a part of our nature, when arrived at a certain period of life. Men long used to some particular way of doing any thing, cannot endure the idea of going to school again, and learning to act upon a new system. The very idea of the possibility of being taught any thing, galls and wounds their self-love to the quick : if this concerns a matter relative to their particular profession, or something, perhaps, on which they peculiarly pique themselves: they become altogether indignant and furious. If by any possibility they are brought to recognise the necessity of some change, they must make it themselves; what a disgraceful and lamentable poverty 
of genius would it not shew, to copy a good thing which had been invented by another man!

It cannot be denied, moreover, that there really is a great deal of trouble in getting up new philosophical instruments of all sorts. There are fresh patterns to be made, and tried, and re-made; workmen to instruct afresh, and after all, particular parts of the instrument may not fulfil the intended purpose, and must be remodelled; all of which circumstances occasion a great deal of annoyance and expense, and naturally render men averse from the adoption of new constructions; more especially as the public at large never can be imbued with a sense of the difficulties, expense, and loss of time, occasioned by what are called out of the way jobs, and consequently can never be induced to pay for them so as to remunerate the artists employed.

If it is indeed true, that conceit is given to man to console him for want of talent, and that the less of one of these qualities he may possess, the more he is likely to have of the other, what must be the consequence, should it happen that an individual, possessing seventyfive parts of conceit and twenty-five of talent in the hundred, comes in contact with something invented, or recommended, by a man who has but twenty-five of the former quality to seventy-five of the latter ? Is it likely he will adopt it? Never. He will imagine that he can produce something infinitely better, and will be still more strenuous in this opinion if he happens not to 
possess a grain of experience on the subject under deliberation.

All these considerations have had so much weight with me, that $I$ have more than once determined never to meddle with the stands and apparatus of microscopes at all, but leave men to settle them according to their own fancies; but my friends have told me, that $I$ have as good a right to consider an ounce of my own wit equal to a ton of my neighbour's as other men have, and that I ought to make the experiment, of giving a construction of my own, whether it may be adopted or not. I shall therefore state my own views on the subject, and for every particular structure recommended, shall give a reason which every man may, of course, either admit or disprove, together with the construction deduced from it. First, then, I say that the stage should be motionless, and that the optical part only should possess the requisite power of traversing and adjustment; because living objects are much more quiet when allowed to remain at rest, and therefore more easily observed : if some one who has been less plagued by them than I have, chooses to say that it makes no difference whether they are moved about or not, I will give up the point; but still insist on the propriety of making the instrument perform all its adjustments as perfectly without the stage as with it, for then we may remove the stage altogether if we please, and substitute any thing we think proper in its place, and all will go on as before. This arrange- 
ment gives us the power of examining small parts of large bodies without detaching them from their wholes.

Thus we can examine the contents of a vase of polypi, or aquatic insects, or a small part of a large specimen of a mineral, or a nosegay of flowers, with the insects which inhabit them; or with an erecting eye-piece we may apply the instrument to a turning-lathe or some piece of delicate machinery, and work upon it much more comfortably than by the help of single lenses. But for these purposes the space occupied by the stage must be left free and open; and to obtain this accommodation the bar of the microscope must swing round on its stand in any direction, on a ball and socket joint, which conjoinerl with a rotatory motion of the arm on the top of the said bar, will almost always enable us to gain the position required. An instrument which does not possess all these properties will only do half the work it ought to perform. It must be evident, also, that this construction gives the utmost facility for introducing a lamp or candle, either close behind the stage for transparent bodies, or before it for opaque ones; and this arrangement is a point of the last moment for demonstrating and verifying a variety of objects, particularly proof opaque ones, as I shall shew in due season, when I come to treat on them and on the subject of verification. No microscope which is from any cause lame or impotent, either in its optical or mechanical construction, can be fit for such purposes. 
The stage must also possess a capability of turning round on a pivot, so that by tilting the microscope we may be enabled to view the side or elevation of a body as well as its plan; for example, the curve of a small lens, when laid flat on its face, the edge of a razor, the point of a needle, \&c. without using any particular apparatus to preserve such bodies in the position in which we wish to see them. The use of such a mode of observing, in cases of dissection, must be manifest ; for in this way the side of an insect, \&c. may be viewed and worked upon without disturbing the parts laid open, in the horizontal position, and thereby occasioning much extra trouble and confusion. By turning the subject round on the stage, every elevation or side view of it may, of course, be successively obtained.

There is yet another advantage to be gained by a rotatory motion in the stage; for if we employ a diagonal objective, and tilt both the stage and the bar into a horizontal position, so that the body of the microscope shall be under the stage, we can examine crystallizations of salts without being annoyed by the steam which arises from them during consolidation, and which is almost certain to condense on the object glass when used in any other position. In the present case this is impossible; for nothing but the under surface of the glass on which the salt is placed, is presented lowards the object glass. All sorts of fluids, and the bodies contained in them, may in the same way be managed without being troublesome, 
and thus chemical actions of all sorts may be studied under a magnifying power.

Moreover, the stage must be enabled to shift down to the end of its bar, so that we may use object-glasses of long foci, and also place any large bulky body upon it without building up the whole instrument to an extravagant height, and thereby rendering it top-heavy and rickety. It must also be of such strength as not to spring under the weight of our hands when used for dissection; for if it does, it will be utterly impossible to preserve a steady focus, which will be found a dreadful nuisance with a high power, and indeed with any power. Its size must also be such as to afford a sufficient support for the hands. The distance of the hole in which the slider holder is fixed from the bar, must also be such as to allow a slider to turn completely round, otherwise we cannot get test objects into that position relative to the light in which only they can be demonstrated. ('This is especially the case with the markings on the scales of beetles and butterflies.)

I do not much approve of attaching illuminators to the stage, either for opaque or diaphanous objects. It will be found much more commodious to cause the spectrum for opaque objects to travel along with the body. Accordingly, a condenser should be attached to it. Both the mirror and condensing lens under the stage should be caused to swing round by means of a spring socket and pinching screw working on a round bar, so that they 
may be instantly removed out of the way when not wanted, without being detached from the bar.

The large illuminating mirror should (if not of very considerable dimensions) be made oval, and should work upon a swivel joint at the bottom instead of the side, otherwise it will be rendered unserviceable, for the long axis of the ellipse cannot otherwise be brought into the position necessary to give a round spectrum when placed at the requisite angle for illumination, say 45 degrees. The reason for the ellipticity of the mirror is this :-An image of it is constantly formed in the optic or visual pencil, at the eye-piece, as may be seen with a magnifier whenever bodies are viewed by the intercepted or trans. mitted light which it furnishes. Now unless this image is of equal size with the said visual pencil, an effect is produced not very dissimilar to that of mutilating the pencil in some other way, and exactly the same as to the quantity of light lost. Now a round mirror (unless it is of such size as to allow for the cutting off occasioned by its angular position,) gives an elliptic pencil. But I presume it is always advisable not to increase the bulk of any part of an optical instrument when it can be avoided; consequently the true form for the mirror is an ellipse. This form does not easily admit of the use of a concave reflector; but I disapprove of them, as they always seem to me to occasion a certain indistinctness in vision by intercepted light, and if wanted only for illuminating opaque objects, by the help of silver cups, may be dispensed with; for a much better action is produced 
by a plane mirror, co-operating with a condensing lens. Because an angular plane mirror and a condensing glass produce a round spectrum; whereas a concave mirror, when tilted, always gives an oblong one; however, in the present construction, I always suppose that when silver cups are employed, the condenser is to act by itself without any mirror at all, by which arrangement the maximum of illumination is given.

The size of the mirror is determined by its distance from the object-glass, or single magnifier used, and by the angle of aperture possessed by them. The longer the bar, and the greater the aperture of the optical part, the larger must be its dimensions to fill up the visual pencil.

The reverse of the mirror will be best occupied by $a$ surface of plaster of Paris, to reflect the light of the sun, which will be found of great use in ascertaining the true tints of transparent objects, the colours of which are shewn by this sort of light with the utmost truth and delicacy, far better than when brought out by a piece of ground glass interposed between them and the polished mirror. The double action of the mirror will be completely commanded by the most inexperienced observer, if a milled head is attached to its transverse axis, as will be shewn in its proper place.

Now these are, I think, the main and capital points to be attended to in the construction of a stand. As, however, every question is said to have two handles to it, I shall endeavour to discuss the merits of some opposite 
constructions. First, then, it has been said, that the double motion of a ball and socket joint is of a most unmanageable nature, and that a cradle joint is a true, regular, and far superior movement: this I admit, and should say, that if a telescope had, by means of a ball and socket, to follow the motion of a star, no motion could be more unappropriate and detestable; but in a microscope it happens always to be a fixture, and when clamped tight by means of a pinching-screw, is as steady as a rock.

This observation may appear very unnecessary to'my readers in general; but $I$ have met with individuals of such obtuse understandings, that they cannot be brought to comprehend that a telescope performs a part of its motion by means of its cradle joint, whereas that of $a$ microscope is the result of a traversing motion in its arm, combined with a rotatory one on the top of the bar, and therefore has nothing to do with that on the head of the stand, be it what it may, which is always a pro tempore fixture.

Again, it has been said, that by giving the motions and adjustments to the optical part, it is rendered much less steady than it might be under other circumstances; that it is like mounting a telescope on a mop-stick; that immobility is of most virtual importance for observation, \&c. I answer, that by making the work sufficiently strong and solid, and the optical part no larger or longer than is necessary, the instrument is rendered abundantly steady, and free from tremor even with its highest powers. 
At the same time I willingly admit, that if the body is made very long or large it will be almost impossible to combine the stability requisite for practical purposes with a capability of traversing and adjustment.

It has been asserted, that if after we have adjusted our light for viewing a transparent object satisfactorily, we throw the axis of the optical part out of the position which we first selected, we must begin our work of illumination over again, or lose the effect of the original one. This is true beyond certain limits, but the body of a microscope may be moved very considerably, without in the least affecting the vision of ordinary transparent objects, and to opaque bodies, of course, the observation cannot apply. Further, it is said that the employment of cones and diaphragms below the stage is of vast use in developing the nature of many transparent bodies, and in tempering the light to the shade to produce a maximum of distinctness; and that if these are employed, the most perverse and prejudiced antagonist cannot refuse to admit that any diversion of the optical part from the line of adjustment must utterly destroy, not only distinctness, but nearly all vision whatever.

To obviate these objections let there be a large roomy slider-holder, with a good steel spring, so as to pinch the plates together pretty tight; the object can then be moved about by the hands in any direction, and the body may remain a fixture, save as to the adjustment of the focus. I have always found that people like to move an object about with their hands, even when they have screw mo- 
tions for traversing, and indeed I prefer it myself, (provided the object does not yield too easily,) even with very high powers.

Lastly, it has been remarked, with great justice, that if we choose to employ any of the generation of camera lucidas for drawing objects, they can only be used with microscopes in which the body is altogether immoveable. Nothing is more certain. At the same time $I$ cannot refrain from expressing my hatred and contempt of the whole tribe, as rather impediments than helps to a real draughtsman. This much $I$ will venture to say, that if a man cannot draw without them, he cannot with them.

The slider-holder enables the present construction to operate with these nuisances, for the adjustment of the focus will not sensibly disturb that of the image on the paper, and if it should, a very little motion, backwards or forwards, given to the drawing, will re-arrange it. The only aid which I can with confidence recommend*, as of real utility, is a micrometer, composed of glass, placed in the field bar of the microscope, and divided into about 40 or 50 parts to the inch, with double divisions, or very strong lines at every fifth space. These should be rubbed over with black lead, after which they must be burnished with the edge of a piece of hard wood, so as to clean the surface of the glass without rubbing the black lead out of the divisions, (a device of the late Dr. Wollaston, and bearing the stamp of his original and 
penetrating genius); then let another piece of thin plane glass be smeared with Canada balsam, and cemented upon the divisions, which will preserve them for ever. Now if corresponding black lines, of any scale required, are placed under the paper on which we draw, we can with great facility put in our outline in the most correct proportions. Or if the paper is too opaque, a frame with black silk threads stretched upon it may be laid upon it till the sketch is completed. The contrivance can be used with my microscope as well as with any other.

Mr. Lister has constructed the stand of a microscope with a particular view to the use of the camera lucida : accordingly his body is motionless and of considerable length, so as to clear a large space on the table for the field of view. The ocular end is, moreover, firmly lashed to the legs of the stand, (which is very solid,) by means of steadying rods, forming altogether the best construction for the use of long heavy bodies, and cameræ lucidæ, which $I$ have seen.

It must be most evident that a single microscope requires exactly the same powers, properties, and capabilities as a compound one. I should, therefore, construct its stand and apparatus precisely in the same manner as that of a compound one, only it may be made on a much smaller scale : as little strength is required for carrying single magnifiers, triangular drawn tubes may be used instead of the triangular gun-metal bar of the compound (to be hereafter described). The drawing of triangular 
tubes is a novelty produced by Mr. Pritchard expressly for his diamond and sapphire instruments.

I therefore conclude that the principles, at least, of the best possible construction for the mechanical part of microscopes, may be defined. I have attempted to reduce them to practice in an instrument the patterns of which $\mathrm{I}$ have executed with my own hands, and $\mathrm{Mr}$. Pritchard has made a mechanical drawing of it, which he will describe in the next chapter, under the title of my Operative Aplanatic Engiscope. Before, however, the description proceeds, I must beg a boon of my readers and the microscopic world at large, viz. to permit me to supplant the term Compound Microscope by the word Exgiscope, which seems to me more apposite.

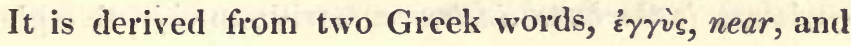

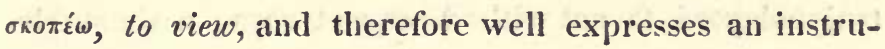
ment for viewing close objects, or for viewing objects closely, and is in strong contradistinction to the term telescope, derived, as my readers well know, from $\tau \dot{\varepsilon} \lambda o s$, an end or distant limit, and $\sigma \kappa о \pi \dot{\varepsilon} \omega$, and therefore denoting an instrument for viewing distant objects. The term

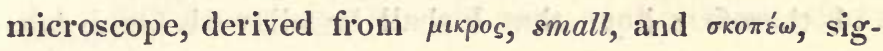
nifies an instrument for examining small objects, which is perfectly correct also, but in bad contradistinction to the telescope, which would have to be named megalascope, to oppose it (from $\mu^{\frac{1}{\varepsilon}} \gamma a \mathrm{~s}$, great, and $\sigma \kappa o \pi \varepsilon^{\prime} \omega$,) which expression would be perfectly accurate when applied to the telescope, for it views very large objects, such as the totality of a planet or the sun, \&c. Now a compound 
microscope and a telescope pass into each other by insensible degrees: a species of telescope can always be made of the former, and a kind of microscope of the latter, but both of the most execrable kind. To this last, namely, a short spy-glass, or perspective glass, with a long pull-out tube, so as to permit it to adapt itself to rays which are considerably divergent, the term Engiscope has already been applied by Martin and others, but I think most unwarrantably, for such an execrable piece of trumpery is wholly unworthy of a separate existence, or a separate name; it is just as easy to make a piece of velvet of an ass's hide as to make an object-glass which shall answer both for a telescope and a compound microscope, be its focus what it may. The only veritable engiscope is the latter instrument, with an objective-glass truly adapted to act with divergent rays; a short telescope may be made of six inches focus, and a long compound microscope with an object-glass also of six inches focus, but the construction of each must be utterly different, or they will only nominally be what they are called.

I therefore hope that I shall be allowed (as I have reformed and revolutionized both the optical and mechanical structure of microscopes) to change their names also, and shall therefore take the liberty of using the term engiscope, as aforesaid, instead of compound microscope, and retaining the expressions microscope or simple microscope, for convenience sake, to denominate what is now called a single microscope, in opposition to a compound. 
The term compound microscope will then be applied appositely to all those instruments with which we view real objects instead of images of them, constructed by combining two or more leuses together; for the optical part of what is commonly called a single microscope may be made of as many as four glasses, whereas the optical part of a compound (as it is usually termed) does not necessarily consist of more than two, viz. an object and ocular glass. Thus if we retain the old terms, how are we to define accurately a magnifier composed of two double aplanatics? Are we to christen it a single quadruple, or double doublet? or a simple compound? This will be as ludicrous as Mr. Callaghan O'Brallaghan's definition of the first bit of bread he ate in England, which it seems was a roasted potato, cooked in a brass saucepan.

It is presumed, therefore, with due deference to the opinions of better men, that the term engiscope is lawful and orthodox, and will, probably, be adopted by posterity, if not by the present generation : as to the fuss which has been made about my using an $i$ instead of a $y$, in the conversion of the Greek upsilon (both letters having the same sound, and having been used indifferently by ancient English writers), I beg to state that I did so on purpose, to make a tub to amuse the whale with, and to draw the attention of the learned to the term.

$$
\text { C. R. G. }
$$


CHAPTER IX.

Description of Dr. Goring's Operative Aplanatie* Engiscope.

Ir is necessary to premise that figures $7,8,10,11,12$, $14,17,18,19,20$, and letter $A$, are drawn one-quarter of the real size; all the rest are one-sixth, except figure 23, which is of the true size.

Figure 7 represents a geometrical elevation of the instrument, just removed from its case, the body, $a$, being screwed on, and the triangular bar, $b$, somewhat elevated above the stage, which is fixed in sitú. To begin from the foundation, - the legs are all of the same thickness, but tapered in breadth towards their extremities, in order to obtain strength where most required. In the upper one is a hole to receive the projecting pin at the end of the circular bar, $c$. Underneath the pillar, $d$, is a screw nut, $e$, which lets down, to obviate the springing of the legs. The pillar, $d$, is constructed of two pieces of very stout tube, moving stiffly in each other. At the head of this pillar is a socket, $f$, to receive the ball shewn in figure 8. This universal joint is made in the

* Aplanatic, derived from the priv. $\alpha$, and $\pi \lambda \iota \nu \eta$, error, means free from both kinds of aberration, or devoid of all errors. 
customary nanner, but the socket has a slit for the neck of the ball, only through one-quarter of a circle, to avoid weakening it unnecessarily. It is pinched by a screw, $g$, with a vice-handle. The ball, the socket of the circular bar, $h$, together with the stage-pin, $i$, are all cast in one piece, as shewn in plan, fig. 8. The stage, $j$, has a circular aperture, which has a sink and two nicks in it, together with a square hole, $k$, (as seen in fig. 9). There is likewise an arrow pointing to a nick in the socket, $h$, to shew when it is truly at right angles to the bar, $b$. It fixes on to the pin, $i$, which is clamped tight by a screw, $l$ : into the botton of this screw is inserted a piece of metal, the end of which is worked to correspond to the curve of the pin, $i$, which causes it to clamp tight with a very slight effort, and preserves the pin from injury. Within the socket, $h$, is soldered a stout tube, forming the external bar, $c$. On this circular bar slide the split sockets, $m, m, m$, carrying the condensing lens, $n$, the inferior pin, $i$, for holding the stage, and the oval mirror, $o$ : all travel up and down at pleasure, and may either be moved out of the way, by turning them onequarter round, or stripped off altogether, if thought more convenient. Their clanıing screws fix them tight in any required position. A nick is made in front of each of the sockets, and a line drawn on the front of the bar, to shew when the condenser and mirror, \&c. are truly in the axis of the aperture of the stage. The oval mirror is plane, but its reverse is formed of plaster of Paris. It revolves on a vertical axis, $p$, and on a horizontal one, $q$, 
the motions of both of which are governed by the milled head, $r$. The triangular gun-metal bar, $b$, is truncated at its edges, and is therefore strictly speaking a hexagon, this form giving greater strength in proportion to the space occupied by it than a perfect triangle would, while it still possesses the property of being locked fast when pinched on only one side : it is evident that even an equilateral hexagon would, when pinched on one side, always cause two others to bear close against a triangular containing tube. This bar slides up and down in the exterual circular one, $c$, between two plates of metal, pierced with triangular apertures to receive it: one is soldered in at the summit of the socket, $h$, the other below the milled head, $s$; and springs are placed on the same side as the rack, both above and below the pinion, to steady the bar, and give the friction necessary to prevent it from falling from its position by gravitation. If the present stand was made to operate solely with an engiscopic refracting body, it would be better to omit the rack-work of the upright bar altogether, and substitute a pinching screw for it, giving a fine movement to the body within the neck of the arm, by a screw on Ramsden's principle. In its anterior side is sunk the rack which adjusts the focus by means of the milled head, $s$, which is repeated on the opposite side. Rack-work is not perhaps the best sort of movement which might be contrived, but it is good enough, when well executed, for all practical purposes. On the top of this triangular bar is fixed the gun-metal wheel, $t$, within the teeth of which works an endless 
screw, the milled head of which, $u$, is seen in the drawing. Above the wheel is shewn the triangular pinion socket, $v$, which carries the arm, $w$, which is also of gunmetal, truncated at its edges with a sunk rack on its superior side, exactly on the principle of the other: this bar is worked by a pinion, $x$, seen in the cross elevation of this socket and bar, fig. 10. Diamond and sapphire lenses, and all sorts of simple microscopes, are attached to this arm, by being thrust into the hole at its other extremity, as drawn in the engraving.

The superiority of sapphire lenses over those of glass seems now universally recognised, and virtually, the superiority of diamonds over sapphires. (For whatever will prove the former of these propositions will most assuredly prove the latter also.) If these substances possessed no other advantages over glass, save their invulnerability and capability of being burnished into their brass settings, these properties, coupled with their extreme thinness, the natural result of their shallow curves, when properly executed, (and which allows more room for the object and for the illumination of it, if opaque, with any given power and aperture, and their superior magnifying power with a given curve, also would fully justify the patronage they have received*.

The pinion, $x$, fig. 10, has a projecting square at each end, to receive the ivory milled lever, $y$, or milled head, $z$, on either side. The whole of this socket revolves on 
the upright triangular bar, $b$, and is kept in its place by the gun-netal garter-piece, shewn at ' $a$, and has a saddlepiece well screwed on, covering it over, to prevent the loosening the pinion, by the action of the milled lever. The endless screw may be detached from the wheel, $t$, by slackening the pinching screw, $b$, which serves to keep the pinion in gear, the said endless screw being affixed to a separate piece, which turns round on the projecting and inferior part of the socket, by means of a pivot: the pinching screw, ' $b$, operating in an arc, formed to receive it. This wheel and endless screw are absolutely necessary to enable us to command the motions of the arm, when the axis of the body of the instrument is not perpendicular, or nearly so.

The body, $a$, is constructed on the smallest scale on which it can well be made without impairing its optical properties. The only true way of preventing the generation of false light is to allow so much space in the body that the rays proceeding from the object-glass shall not impinge on any part of the tube ; for no sensible light is produced until they flash against something. Into the superior part of the eye-tube, 'c, are screwed the various inverting eyeglasses, and into its inferior part, ' $d$, the erecting glasses, $A$. Upon the neck of the object end, ' $e$, are screwed the various abject-glasses, one of which is represented attached in the plate. Upon this neck also slides the illuminator, ' $f$, for opaque objects; it has a split socket and clamping screw, ' $g$, by which it is adjusted, and is composed of a plain convex lens, having an inch and a half of aperture 
and the same focus operating by lamp-light, with another isosceles convex of same power and diameter screwed to it : these curves have been found by experiment the best both for refracting the maximum of light, and for preventing any loss of it by reflection from the convex surfaces of the lenses. ' $h$ is the cap of one of the eye-pieces in dotted lines; it is supposed to be removed for the purpose of applying the camera lucida, fig. 11 , which is thrust on over the eye-tube, a side view whereof is represented at fig. 12. By far the best species of camera lucida is, I think, this (which is the invention of Professor Amici), and is composed of a simple piece of thick plate glass, with truly parallel surfaces, placed at an angle of $45^{\circ}$, and reflecting an image while we see through it, for it allows the point of the pencil, the drawing on the paper, and the image, to be seen at the same identical moment, without any dodging or effort. Care must be taken to have a sufficient thickness of glass, to prevent the visual pencil from reaching the inferior surface, otherwise there will be two images.

Fig. 13 is a micrometer, to be placed in the field-bar of one of the lowest eye-pieces. It is made of glass, with divisions of 40 or 50 parts to the inch, which are filled with black lead, well burnished in, and secured by another piece of glass being cemented over them.

Figure 14 is a square bar, sliding up and down in the square tube in the stage, $k$, fig. 9. It carries the illuminator, $f$, when it is thought advisable not to load the body with it. 
Fig. 15 represents the lengthening tube, ' $i$, with the direct boot, ' $k$, drawn over it. The lengthening piece screws on in place of the object-glass, which is again attached to its extremity. This piece, from its narrowness, will generate false light ; it must, therefore, be lined with black velvet, which is, perhaps, the best substance to stifle it when generated.

Figure 16 is the diagonal boot. It is constructed in the same manner as the other, but has a plane metallic speculum or rectangular prism of glass placed at' $l$, to reflect the rays received at right angles. It is necessary that the piece of plate-glass which is affixed to the extremity of the cones of these boots should be very perfect, and set in truly parallel.

Sir D. Brewster first conceived the project of causing an aplanatic objective to be so constructed that it should be capable of acting in water instead of air (see his Treatise on New Philosophical Instruments). I am afraid it would be very difficult to make a naked object-glass water-tight, and at the same time to adjust it perfectly; and after all $i t$ would only serve to act in water, and would be useless out of it. The present arrangement really seems to answer every practical purpose completely well, though certainly Sir David's plan is the more scientific way of doing the thing.

Figure 17 is a cup or silver speculum, which slides over the end of the object-glass.

Figure 18 is a shade to slide over the lengthening piece, 'i, figures 15 and 16 . 
DESCRIPTION OF DR. GORING'S ENGISCOPE. 175

Figure 19 is a small cone, to slide over the objectglass when acting by plain artificial light.

Figure 20 is the arm by which the optical part of the Amician Catadioptric Engiscope* is attached to the present stand: it must be considerably longer than the other, and, like it, racked to its extremity, to admit of its being taken out of the socket. By means of its swivel and pinching-screw, it allows the body to turn round, and present itself either in front or at the sides of the stage.

Figure $2 l$ is the aquatic live-box, with an extra pierced lid, ' $m$, for aerial insects and land objects, \&c. There should be about half a dozen of these, of different sizes, varying from that given in the plate, to about 2-10ths of an inch in diameter. It would be found a convenience if the larger ones had watch-glasses fixed into them with their curves applying to each other, and their concavities pointing outwards, instead of the plane glasses, as given in the drawing; for by this arrangement, when used with very low powers for exhibiting a grand mêlée of aquatic insects, \&c., taking in nearly their whole area, the edges of the field will be as distinct as its centre; the foci of these two parts of the visible superficies being always different with a flat object, and a low power, even with the best aplanatics.

The glasses, whether flat or concave, must be well cemented into their cells by painters' ground white lead or opticians' cement, that the box may be completely

* Micrographia, chap. i. 
water-tight; and the tubes themselves may be greased for the same purpose if necessary. These boxes are as useful pieces of microscopic apparatus as ever were invented.

Figure 22 represents the black ground box (an invention of $\mathrm{Mr}$. Lister), which in the present instrument also forms a stage for the single microscope, and for dissection.

At ' $n$ is seen its lid, of which a side view is given at ' 0 ; at ' $p$, its bottom with its side view also; its interior surface is lined with black silk velvet, and so is the superior surface of the lid; the sides of the cone, ' $q$, are well blacked; at ' $r$ is seen a disk, also covererl with black silk velvet, which acts along with the silver specula. Its ar'm levolves on the top of the cone, and can be removed altogether, if necessary; at its extremity is a hole, in which is inserted the cradle-joint, which carries a brass needle; a small piece of brass tube, stuffed with cork, is affixed to one of its extremities, and to the other a pair of forceps, which are represented of their full size at figure 23. These are constructed as usual, except that a hole is drilled through them at 's, to enable them forcibly to grasp the head of a common pin.

Figure 24 is the piece which carries the wheel of diaphragms ; $t$ is the plan of their under side. 'There should be about five apertures, varying from half an inch to 1-10th in diameter. This apparatus screws on to any of the aquatic boxes, also to the slider holder, figs. 25 and 26 , and the false stage or black ground, figure 22 , in place of the bottom, ' $p$. It was invented by Monsieur 
Le Baillif, at Paris ; but we have long been in the habit of using cones for the same purpose in England.

Figure 27 is a contractor, which drops into the sink formed in the aperture of the stage, when too large for carrying on dissections, or other operations of a similar nature; it has two bayonet-catches, which secure it by being turned one quarter round : into the aperture of this latter piece, a small slider-holder may be advantageously fixed (to be used with the Amician Engiscope or the simple microscope), which should likewise be made to fix to the top of the false stage, figure 22 , when its lid is removed.

Figure 25 represents a plan of the four-pillar-sliderholder, which is by far the best contrivance hitherto invented, for attaching all sorts of objects in sliders and between slips of glass, \&c. to the stage: its elevation is shewn at figure 26, with the two pins which secure it. In the plan are drawn the two cross connecting bars, ' $u, ' u$, between which and the superior plate all large opaque sliders, \&c. are placed. There is another plate below the first: between these two a common transparent slider is shewn. The helical spring is of steel of some strength, so that the sliders shall not be permitted to move about between the plates too easily. The holes at the corners of the plates which slide up and down on the pillars, must be sufficiently large to prevent any clinging or sticking.

Figure 28 shows a plan and profile of an adapter, which carries a small aquatic live box, to be used with 
the wheel of diaphragms ; it has a bayonet-catch to fix the box securely, independent of its gravity.

Figure 29 is a frame and slip of glass for crystallizations of salts.

Such is the description of an instrument which will be found a regular working tool, either for amusement or scientific investigation. It is not pretended (be it always remembered) that it is a perfect or standard instrument, but Dr. G, hopes it will be found an approximation to one.

A. P.

March 1829.

Most of the apparatus described in Chapter VI. as applicable to my microscope can be applied to this. In the instruments of this kind manufactured by me I have made the socket at $h$ to extend an inch or more above the surface of the stage : this increases the steadiness of the triangular gun-metal bar, $b$, which in practice is not required to be depressed much lower than represented in the engraving. The milled head, $s$, of the pinion is made of much larger diameter than represented; it works against the posterior angle of the triangular bar, and is placed at $h$. The fine adjustment for the focus, as also the moveable stage described at page 105 , can be attached to this stage, $j$, and the foot of the stand made of a solid tripod.

A. P.

May 1838. 


\section{CHAPTER X.}

Manner of Observing with and Managing the Operative Aplanatic Engiscope.

BY C. R. GORING, M. D.

General Observations.-Select an apartment on the ground floor, if possible, which has a northern exposure, and the casement of which (it should have only one) is not overshadowed by trees or buildings, but presents a clear view of the open sky-sky-lights are not proper for a microscopic study. In such a room I would recommend you to keep your instruments and apparatus, \&c. open, and at all times ready for observation; but take especial care to keep it locked, as if it was the case of your microscope,which, in fact, it may be termed. Have the fear of the cat before your eyes, and also of all those busy, intermeddling, officious housewives, who, under pretence of dusting, cleaning, and setting to rights, will subvert and revolutionize the whole economy of your observatory, and perhaps throw half your tackle behind the fire. Never allow the apartment to be cleaned until you have secured your apparatus. I think it myself a great convenience (and I am not singular in my opinion) to have an apartment especially devoted to my microscopes, as much as the observatory of the astronomer is to his 
transit and circles, for then there is no loss of time when you wish to go to work, and you are sure to find every thing just where you left it. I cannot be plagued by eternally packing and unpacking my implements, \&c. but this is no rule for those who like such occupation. Have caps to cover the objective and eye-glasses of your instruments, and get a little nest of drawers to stand on your table to keep talc sliders, \&c. in, with a glass cover or two (like those of watchmakers) to secure the more delicate parts of your apparatus; the rest will suffer no harm from the dust. Procure a tripod stand, like those used for small telescopes, and of such height, that when you sit down and turn the body of your instrument against the sky, like a telescope, the eye-piece may present itself in a commodious position for observation. You will also, probably, want a tripod stool to rest your engiscope upon, when placed in a vertical posture for dissecting and similar uses, as tables generally run too high for the purpose, and are always more or less unsteady. In towns the tremor occasioned by the transition of carriages is frequently a great nuisance in the upper stories of a house, more particularly if your mountings are rickety and unstable.

Now, courteous disciple, I will endeavour to instruct thee how to manage thy tackle, and will, moreover, have the extreme complaisance to suppose thee (in all microscopic matters at least) one of the awkward squad-as stupid as an owl, and as ignorant as a cart-horse. I will tell thee as well as I can all that thou art to do, and all 
that thou art not to do. I will try to make thee know the right end of thy instrument from the wrong one; how to put a fly's eye before the object-glass, and a fool's eye before the eye-piece; with many other things equally curious, important, and interesting; and if perchance I shall succeed in learning thee how to deal with the instrument under consideration, the management of all others constructed on similar principles must be perfectly obvious.

It will be necessary for me to premise somewhat concerning the optical part; though it is not my intention to treat upon it in a regular way in this chapter, as a full and particular account thereof will be given hereafter, I shall speak of it now only as an appendage to the mechanical fabric of the engiscope, and the directions relative to its use will be only of a general nature, but still sufficient for practical purposes. The optical part, then, is divided into the objective and ocular; the objective glass is situated at ' $e$ in figure 7 , and screws on to the neck of the body; it is always next the object of which it forms an image or picture, which is viewed by the ocular or eye-glass at ' $c$, always situated next the eye, (for be it remembered, that in strict language we do not view the object itself in an engiscope, but its image or picture.)

Several aplanatic object-glasses and eye-glasses accompany the instrument; their powers or foci are generally marked upon them ; but the high powers may be known from the low ones by this simple rule, viz. the largest object-glasses are the lowest in power, and 
the longest eye-pieces, having the largest glasses in them, are also the lowest powers. Now the total power of the body or optical part of the engiscope, is the result of that of its object-glass multiplied by or combined with that of the eye-piece; therefore the highest power will be given by the smallest object-glass used with the shortest eye-piece, and the lowest by the largest object-glass with the longest eye-piece. The eye-pieces mentioned above are all of the inverting kind, like those belonging to astronomical telescopes; there is, however, a pair of erecting glasses, $A$, to screw into the bottom of the pullout tube, which, with the former, make erecting eye-pieces; these are used for dissecting, \&c., and also for giving very low powers when wanted below the scale of the weakest inverting ones. The use of all these I shall shew in their proper places. Each object-glass combines with each eye-piece, whatever their number may be, according to the fancy of the observer, but the power which results fiom the combination can only be known by trial, and should be given by the maker of the instrument, in a written paper.

The object-glasses are frequently made to combine with each other. An increase of power is obtained by the elongation of the body, effected by drawing out the tube, ' $c$ : whenever the length of the body is doubled, for example, the power is also doubled (cateris paribus).

In winter it will be proper to cause the instrument to be slightly warmed at the fire before it is used, until it is of about the same warmth with the human body, other- 
wise the perspiration from the eye will be perpetually condensing on the eye-glasses, \&c. and greatly impede vision.

Always begin to examine your object with the lowest power you have, unless it is very minute; it may be lairl down as a general rule, that large objects require low powers, and small ones high powers; that the low powers show the whole or general view of an object, and the high ones only its parts in succession.

Never use high powers unless absolutely necessary; for as the power increases, so does the difficulty of finding the object, and of adjusting the focus. The colours also grow fainter and more diluted, and the shades darker and darker, until all ease and satisfaction in observation, together with all certain vision, fade away, and so very small a portion of the object is seen, that it is difficult to know what we are looking at. Recollect that a really good aplanatic object-glass shews every thing with very low powers; in fact in this property its goodness and beauty consist: do not plume yourself, therefore, upon having an instrument which shews objects with very high powers, but with very low ones.

Where, however, from the minuteness of an object, it becomes really necessary to use a high power, always select a small deep object-glass, and use it along with a shallow or long eye-piece, in preference to using an objectglass of low power, with a short or powerful eye-piece, for magnifying power is much more valuable and effective when derived from the object-glass than from the 
eye-piece (this is a subject which I shall recur to hereafter.)

When you clean the eye-glasses (a point of great importance to pure vision) do not remove more than one at a time, and be sure to replace it before you begin with another: by these means you will be sure to preserve the component glasses in their proper places: recollect that if they become intermingled, they will be useless. Keep a piece of well-dusted chamois leather, slightly impregnated with some of the finest putty or crocus powder, in a little box to wipe them with (for it is of consequence to preserve it from dust and damp), the former will scratch the glasses, and the latter prevent you from wiping them clean. As to the objectglasses, endeavour to keep them as clean as possible without wiping, and merely use a camel's hair pencil to brush them with; for wiping them hard with any thing has always a tendency to destroy their adjustment, unless they are firmly burnished into their cells.

Now I shall suppose that you want to view some transparent inanimate object mounted in a slider. There are several ways of doing this, according to the position in which you choose to preserve your instrument, whether directed upwards towards the sky, horizontally, or vertically, looking downwards, \&c. The first is the best method for direct day-light; the second, for lamp or candle-light ; the last is the worst of all for either, and should not be resorted to when the others can be used. There are, however, intermediate positions between the 
horizontal and vertical ones; say angles of 40 and 45 degrees, which are comfortable and convenient for the observer, though, 1 think, unfavourable to the action of the illuminative part of the instrument. I shall proceed to give directions, on the supposition that you wish to see in the simplest and best possible manner.

1st. Manner of mounting for viewing inanimate transparent objects by pure intercepted day-light.-When the instrument is first removed from its case, the circular bar, $c$, will be locked fast into the upper or longest leg, by means of its projecting pin; it is loosened by drawing the internal tube of the pillar a little out, for which purpose, grasp the ball and socket in one hand, and the legs in the other: by pulling in opposite directions, the inner tube will be detached, and the pillar heightened in any degree requisite for observation, at the same time the bar will be left at freedom to move in any direction by means of the ball and socket: immediately underneath the pillar is an adjusting screw, $e$, by means of which the pillar gains the support of a fourth leg, and is rendered incapable of springing; it can be used when great steadiness is required : it should but barely touch the table or stand on which the engiscope is placed.

Having then spread out the legs, and arranged the optical part according to the preceding directions, attach the slider-holder, fig. 25 , to the stage. This is done by inserting the projecting catches into the nicks, and turning it one quarter round: this fixes it fast, so that it cannot 
fall out whatever may be the position in which it is placed : pass the slider between the plates until the object appears within the aperture; slacken the pinching screws of the split sockets belonging to the mirror and condensing lens (if necessary), and turn them one quarter round, so as to be out of the way of the body, or they may be removed altogether, by sliding them off the bar; then, by means of the double action of the ball and socket, elevate the bar, until the instrument, when placed on its tripod stand, comes into the position of a telescope directed towards the heavens, at any angle you please. In fine weather, it will not be improper to let down the upper part of the casement; some microscopists have recommended us to select a white cloud, if possible, to furnish our transmitted light; I think myself that the blue light of a clear atmosphere is preferable, especially for test objects. The ball performs the office of a cradle joint, by being moved up and down in the quadrant slit of the socket. Thus, if you wish the bar to point upwards, and the ocular end of the body down. wards (as will be the case in the present instance), make the following arrangement:-Move the neck of the ball, by grasping the bar until it is about half way between the upper and lower end of the quadrant slit, (just as if it was a common cradle joint) : the body thus forms an angle of about 45 degrees, and will be in the required position (but unless the motion now to be described has been previously accomplished), in a direction directly opposite to that now required, for you will only be able to observe 
with it by looking downwards, whereas you are to look upwards. To effect the object at present in view, turn the ball completely round in the plane of the bar, until the end of the bar comes into the place of the eye-piece. The instrument is then fit for use (at least when placed on its tripod stand and directed towards the sky); remember, that by the motion of the ball as a cradle joint, conjoined with the rotatory movement natural to it, every possible position is attained. All you have now to do will be to adjust the focus, and to bring the body to bear on the part of the object you wish to see. The adjustment of the focus is accomplished by means of the milled head, $s$, and the traversing motion of the body is governed by the rack-work at $v$, coupled with the rotatory movement on the top of the bar, which is regulated by the milled-head at $z$; the method of managing this part of the instrument will be gained with the utmost facility by a little practice. In the present case it will not be very necessary, as you may move the object about at will with your hands between the plates of the slider-holder.

When you look through the instrument, be sure to place your eye quite close to the eye-piece, otherwise the whole field of view will not be visible, and note, moreover, if you see a round disk of light, at least when the object is not in the slider-holder; if you do not, it is a sign that something is wrong; perhaps the body is not placed directly before the aperture of the slider-holder, or may not be truly directed towards the light, \&c. It only remains for me to observe, that the method of using 
the instrument just described, is by far the best and simplest with which I am acquainted for all sorts of transparent objects, and should, therefore, always be used when practicable; and this observation applies to all sorts of microscopes and engiscopes. Occasionally, however, the weather is so dull and gloomy, that we see better by artificial light: I therefore now give the

2nd. Method of mounting for viewing transparent objects by artificial light.-Setting out on the supposition that the instrument has been just removed from its case, and is in the position given in the plate, proceed as follows :Place it on a table; detach the bar from the front leg, as before; move the mirror and condensing lens to one side; then turn the bar round till it assumes a horizontal position, keeping the neck of the ball at the bottom of the quadrant slit, in the position in which it is represented in the drawing : its rotatory action is the only one at present required. This arrangement will leave the space, both behind and before the stage, open for the introduction of a lamp or candle, \&c. The condensing compound lens, ' $f$, attached to the body, together with the plane-convex one, $n$, under the stage, and the mirror, must remain inert and unemployed, in this as in the preceding mode of observation, and may be removed altogether. Adjust the height of the instrument to suit that of your light and eye, by drawing the tube of the pillar in or out: place your light centrically behind the aperture of the stage, at two, four, or six inches distant from 
it, according to the strength of the illumination required, observing always to preserve a perfect round disk of light in your field of view, and every thing goes on as before, the candle or lamp supplanting the day-light. You may, if you please, tilt the instrument a little out of the horizontal plane, for convenience of observation.

3rd. Mode of mounting for viewing diaphanous bodies by reflected day-light, either in a horizontal or vertical position.-For the horizontal position every thing is arranged in the same way as when artificial light is employed; only, now the oval mirror comes into use, which must be placed truly in the axis of the body, and of the aperture in the stage. For this purpose, cause the mark on its split socket to tally with the line drawn on the bar, and then clamp the split socket tight by the screw, $m$ : then, having first removed your instrument out of the direct light proceeding from the window, by placing it in the middle of the apartment, proceed to refiect the light given by the said window into the body of your instrument, as follows. I must premise that it will be necessary that the engiscope should so present itself towards the window that its pillar and bar should not impede the light: thus, supposing the window is on your left hand, the pillar and bar must be on your right, and vice versa, so that nothing shall be between the window and the mirror. Observe, that a direct lateral position of the window is the most convenient and manageable. Then, by means of the milled head, draw the mirror round on 
its axis, at the bottom of the arm $p$, until it fironts the casement; then all that is requisite is, to turn the milled head, $r$, and along with it the mirror, round, until its light fills your field of view; which will be at an angle of about forty-five degrees, if the window is directly opposite the mirror, and your bar parallel with it. You may now, if you please, use the condensing lens, $n$, but I do not recommend it, as, along with an increase of brightness, it generates a degree of confusion and nebulosity. If employed, see that it is clamped tight into its true position on the bar. Like the mirror, it should be as close to the stage as possible.

If you wish to be exactly acquainted with the colour of transparent bodies, use the plaster of Paris side of the mirror to reflect the light of the sun, in an apartment exposed to it. With this intent, place the instrument on a table on which the sun falls, in such a manner, however, that it shall only impinge on the plaster, and leave the rest of the engiscope in shade; then proceed with it as if it were day-light. This, in my opinion, is the only way in which the light of the sun can be employed with advantage for illumination, and it brings out colours with the most perfect fidelity.

When the instrument is used in the vertical posiTron, it is, of course, in the altitude represented in the plate, and is governed precisely in the manner just described. I do not like this position at all: it should, I think, only be used with bodies which must be confined to the stage by their gravity alone, which case may some- 
times occur; but I have made most ample provision for presenting all sorts of objects in any position, without regard to their gravitation, by means of the aquatic wet and dry glass boxes, and the slider-holder, \&c. I think that the practice of poring downwards (the ordinary way of observation with microscopists of the old school,) is peculiarly detrimental to the head and eyes, having a great tendency to determine the blood to them. We never hear of astronomers, who are perpetually looking upwards, having their sight injured, like observers with microscopes, though they have to look, if possible, still more steadfustly and intently than the latter, with the highest powers. I had nearly forgot to mention a circumstance very necessary to be attended to in the management of the mirror; it is this, - to keep the milled head, $r$, invariably outwards. It is not made to travel completely round, nor is it necessary; for every possible position required for practical purposes can be attained without its traversing more than the half of a circle, by reversing the superior or inferior end of the ellipse, according to circumstances. Thus, supposing there were two windows in an apartment, one on the right, and the other on the left of the instrument, it would command either, without revolving on its inferior axis, merely by being. tilted on the right or left side.

Way of viewing Crystallizations of Salts and various Chemical Actions.-Use the mounting (No. 2); screw on the lengthening piece, ' $i$, and attach the diagonal boot 
(fig. 16) to it. By means of the wheel and endless screw let down the arm of the instrument till the body shall be considerably below the aperture of the stage; then take off the lid of one of the aquatic boxes, and fix the other part, first warmed at the fire, upon the stage; which turn round on its pivot until its surface with the box shall point downwards; then insert a drop of the salt to be viewed upon the inferior glass of the box (now, by virtue of its position, the superior one); turn the boot round on the lengthening piece until its projecting cone shall look upwards, and adjust the focus by means of the wheel and endless screw, which now performs this office, while the rack-work used under other circumstances, for the same purpose now only gives a traversing movement. Many chemical actions, between various bodies, both fluid and solid, may also be viewed in this way. Moreover, crystallizations, \&c. can be seen under any of the usual modes of mounting, by placing the salts or other bodies, between the glasses of the aquatic boxes," with the closed or pierced lids, as the occasion may demand; only, whenever there is evaporation or evolution of gas, remember to employ the pierced lids.

I think, nevertheless, that the best way of viewing salts is to use the glass slip, with its frame (fig. 29), and merely to rub the liquid salt over its surface, allowing it to drip a little at an angle of 45 , before it is placed in the slider-holder. The glass must not be warmed in this method; and the salt must be allowed to crystallize very slowly, in its own natural way. By this process, 
though somewhat tedious, none but the veritable microscopic crystals are obtained. Deliquescent salts, in damp weather, can, however, hardly be brought to consolidate in this way.

I hope the description of the method of management is now tolerably complete, as concerns transparent inanimate objects; but the method of dealing with living ones requires some illustration.

4th. Way of Mounting for Transparent Living Objects.These are not seen well by artificial light, as I have already -observed, their internal machinery being more or less confused by it, whether its rays come diverging, converging to a focus, or parallel.

It will be rather difficult to get a power low enough, with the present instrument, to obtain a general view of a number of the larger aquatic larvæ; for I do not think the present engiscope will carry an object-glass of longer focus than two inches; which, with the lowest inverting eye-piece, will be fully twice too high-(for, be it observed, the lower the power is the more of an object it will include in the field of view, and the higher the less); but, with the erecting eye-piece thrust pretty far into the body, a power will be obtained that will easily include a space of one and a half, two, or even three inches; therefore use the erecting glasses $A$, screwed on to the bottom of the internal tube of the body, and draw it in or out, until it just takes in the area of your 
Jargest aquatic live-box, and use the first or third way of mounting.

The method of using the aquatic live-box is as follows :Take off the lid, applying your finger to the hole in it, or stop it up, pro tempore, with a bit of wax; then pour in some water to the depth required, and insert your larvæ, and apply the inner part to it, observing still to keep the lid undermost: having slid it on far enough to keep the water from escaping, place the box in such a position that the hole in the lid shall point upwards; then, by squeezing the lid on further (having, of course, first removed your finger or bit of wax from the hole), you may expel all the air, and as much of the water as may be superfluous. It is now fit for use (for the pressure of the atmosphere prevents the water from coming out of the hole) by being placed in the aperture of the stage, and turned one quarter round. A single drop of water, containing animalcules, may be placed between the glasses of the smaller boxes; and, if the tubes are made air-tight by a little grease, and the hole stopped up, may be kept for weeks together without evaporating.

- If very delicate and exceedingly transparent animalcules are to be examined, use the adapter (fig. 28), with the smallest aquatic live-box mounted upon it, and secured by the bayonet-catch : let it be placed between the connecting cross-bars, ' $u$ ' $u$, and the superior plate of the slider-holder, which arrangement permits the adapter to be moved about: screw the wheel of diaphragms (fig. 24) on to the bottom of the slider-holder, and see 
that the body of the engiscope is truly concentric with the hole or diaphragm; otherwise you will have no light. Recollect, that the body of the instrument must now be stationary, and that you must move the slip about with your fingers. Whenever the diaphragms are employed, the body must be a fixture, or nearly so.

A very useful way of observing aquatic insects und larvæ is by means of the direct or diagonal boot drawn over the lengthening piece, $i$, of your object-glass, which may then be inserted into the reservoir in which they are kept. The method of mounting is as follows:- Unscrew the body from the arm, $w$, and attach fig. 15 or 16 to it, instead of its usual neck : see that the plane-glass at their ends is as far removed from the object-glass as possible (for the less water you have to look through the more distinct will be the vision); detach the stage from its pivot by slackening the screw, $l$, and clamp it tight on the lower pivot, $i$, having previously removed the condenser, $n$, altogether : then place the glass vessel on the stage, which must be truly horizontal, and clamped tight by the pinching screw, $l$ : insert the body into the reservoir, by rescrewing it, with its new appendage, on to the arm, $w$, again. If you want to observe laterally, or to take a periscopic view of the contents of the vessel, use the diagonal boot in place of the direct one; and, by turning it round on the lengthening piece, any object situated on the sides of the vessel, such as polypi or volticellæ, may be observed without disturbing them. The object-glasses apply either to the ordinary neck of the 
body, or to the lengthening piece over which the boots slide. Dissections may frequently be carried on under the surface of fluids by means of these boots, with great effect, which can hardly be accomplished in the common way.

Whenever the instrument is in a vertical position (as will, of course, be the case in the present instance,) or when it is not far off from it, the lever $y$ may be used with great advantage. In observing live subjects it is peculiarly useful, for it enables us to follow their movements much more rapidly than can be done by means of the wheel and endless screw; and the double motion of the arm being, by its assistance, governed entirely by one hand, the other is left at liberty to adjust the focus (which is, of course, perpetually changing, according to the motion of the insects observed); it is attached to the pinion on either side of the rack-work, according to circumstances, by being pushed on the square projecting pin. The wheel must then be detached from the endless screw, by slackening the clamping screw, ' $b$, and drawing the piece which carries the said endless screw backwards away from the wheel, causing it to traverse over a portion of the arc which it forms on its pivot, and fixing it afresh, so that it shall not catch the teeth of the wheel: the arm then moves freely round on the top of the bar, and is subservient to the action of the lever, the milled head of which operates upon the pinion in place of the ordinary one, and is governed by the thumb and index finger; while the others 
act upon its extremity, and give the rotatory movement which was before performed by the wheel, \&c. More: over, whenever the lengthening piece is in use for transparent objects not contained in fluids, the shade (fig. 18) may be employed. It slides down completely over the object observed, and guards it effectually from all rays of light not transmitted through it, so that it is observed purely. as a diaphanous body, and not partially also as an opaque one (as is frequently the case with transparent objects treated in the common way). This piece of apparatus is of much use in verification.

The stage may, moreover, be removed altogether; and the bar being in the horizontal position, the vase may be placed on a proper support in its stead, and observed. from without as well as from within.

5th. Method of mounting the Diamond and Sapphire Microscopes for Transparent Objects.-When the use of the engiscopic part of the instrument is thoroughly attained, nothing can be more easy than the management of these. All that is requisite is to unscrew the body. from the arm; and by detaching the teeth of the wheel from the endless screw, according to the directions already. given, to reverse the ends of the arm, so that the microscope shall come into play; whent he rotatory movement must be again secured, by bringing the endless screw in contact with the wheel, and clamping it tight: thus the instrument becomes converted into a simple microscope of the first quality, which is to be used exactly as the. 
engiscope was: I can give no better directions concernirrg it. The sapphire and diamond lenses have their own peculiar settings in a species of dish or cup, which is attached to the arm by being thrust into the hole at its extremity. The superior cohesion of the precious stones admits of their being burnished into a cell, which is again fixed into the setting. This arrangement allows the len'ses to be shifted about without difficulty, or risk of losing them. If they are plano-convex, as they should be, another advantage results, which is, that they may be used either.with their flat or convex side towards the object, according as great distinctness, or a large field of view, may be required (for you cannot have these qualities combined). Remember, therefore, if you want a large field of view, and do not, at the same time, require a large aperture, united with great distinctness, to place the lens with its flat side next the eye. If, on the contrary, you must have a very large aperture, conjoined with the utmost possible degree of distinctness, then place the convex side next your eye. The aplanatic lenses should also have settings on which they can be screwed at pleasure, to be used as simple microscopes. If, at any time, when bodies are merely laid upon the stage, and confined to it only by their gravity (the stand being used vertically, as in dissections, for example), the face should come into too close contact with the stage, the apparatus (fig. 21) must be used, which is inserted into the aperture, like the live-boxes and slider-holder : the object being laid upon it, due space will be alforded for the nose, and the breath will be less likely 
to steam the leuses. The arm, $w$, is made to turn round in any position most convenient to the observer. The adapter (fig. 28), which is to be used between the bars of the slider-holder, to carry a small aquatic live-box, or the like, affords another species of convenience of a similar nature, and serves to elevate the face of the observer above the stage.

Opaque Objects.-Opaque objects seldom require such high powers, or such large apertures, as transparent ones. Their colours are best brought out by daylight, natural or condensed; but artificial light, perhaps, shews them best in all other respects.

They should always be viewed upon a black ground of some description. The more sombre, and dingy, and faint, their tints are, the greater need there is of a black ground to stifle all heterogeneous light.

As they only reflect or radiate light, a much stronger illumination is requisite for them than for diaphanous bodies, which almost always transmit a great deal more light than opaque ones are capable of reflecting. Moreover, they seldom present flat surfaces, as most pellucid bodies can be made to do. This, when the power is considerable, causes one part of the object to be indistinct, while another is seen accurately : this must always be allowed for. A very perfect instrument can only have one point in focus at once, and, consequently, can only shew one point distinctly at once, all the rest not on the plane of the focus being confused. 
The direct light of the sun is utterly improper for exhibiting opaque bodies, being polarized and decomposed by them, so as to give rise to all sorts of optical deceptions: neither can it be modified or dulled by refraction through rubbed glass, or any sort of semipellucid substances, and thus rendered fit for use : by reflection from white unpolished surfaces it may, but it is then no stronger than the light of the atmosphere.

6th. Method of observing Opaque Objects by Day-light, plain or condensed.-Employ the mounting (No.2) recommended for transparent objects by artificial light.

If your object is contained in a slider, insert it into the holder in the usual manner: turn your back diagonally towards the window, and place the engiscope on a table, in a convenient position for observation in that direction, so that the light of the window may fall full upon your object, without being intercepted by your head: the nearer you are to the window the better, provided its direct light does not get into your eyes. - You then proceed to the adjustment of the focus, \&c. as before described. If your power is considerable, or the day dull, you will require a condensed light: to obtain it, attach the condenser, ' $f$, to the neck of the body, by means of its clamping screw and split socket, ' $g$; unscrew the double convex lens from the other, and remember to use only the plano-convex, with its plane side presented towards the light, and its convex side towards the object: slide it up or down upon the neck of the body; and adjust, 
also, by the help of the joint, $v$, until you get a good spectrum of light upon your slider. (It will be well, in the first instance, to form an image of the window upon your object, and then to push the illumination a little closer to it, so as to obliterate the image.) You will in this way get the maximum of brightness :-The crown of the convex side of the bull's eye, or condenser, when properly adjusted, will be about an inch, or an inch and a quarter, from the object.

If you think it more commodious, you may attach the condenser to the stage, instead of the body-(only, in this case, if you move the optical part, you will lose your light). To effect this, remove the setting of the lens altogether from the split socket, by unscrewing the joint, $v$, and fix it afresh, by means of its screw, into the square bar, fig. 14, which insert into the square hole in the stage. The adjustment is effected now by pushing the illuminator up and down in the stage, combined with the motion of its joint, $v$, as before. I think, however, it will be found advisable only to attach the condenser to the stage when artificial light is employed; for, in this latter case, the weight of an additional lens is applied to the condenser, which might overload the body, if dependent from it.

If you wish to view opaque terrestrial living objects, put them into the suitable live-boxes, with the pierced covers, to admit air. These said boxes, with one or the other of their lids, may be used to hold nearly any object. 
7th. Method of observing Opaque Objects by Artificial: Light, either plain, condensed, or reverberated, by Silver Cups.-Use the mounting (No. 2), as before: close the shutters of your apartment, if you mean to observe in this way in the day-time: procure a telescope candlestick, $\mathrm{or}^{\circ}$ one which has an arm moving up and down upon a bar, so that it can be adjusted to any height as a candle burns down-(the sliding-tube of the pillar will, in some measure, serve this purpose, if you have not a proper candle-. stick), and get a wax taper, or, what is better, a piece of old rushlight, to afford your illumination. Don't laugh! but do as I bid you : and, moreover, a pair of scissars, to trim it. A piece of rushlight (please your worship) well trimmed, gives a remarkably steady light, without flaring or fickering, and is just as intense as that afforded by oil, or tallow, or gas itself, burnt in any other way. The intensity of the light is the thing wanted, not the quantity. Perhaps a wax rushlight might be an improvement. Now this rushlight, adjusted to the proper height, is to be placed before your stage, and as near to your object and object-glass as may be, without burning them : but you must take especial care that its direct light does not get into the body of the engiscope, or it will utterly destroy all distinct vision : on this account it must be always placed a little on one side of the objective : and if the focus of the said object-glass is longer than half an inch, it will be highly advisable to use a conical shade (fig. 19), drawn over it, reaching almost to the object itself; which will, moreover, always be some 
OBSERVING WITI AND MANAGING ENGISCOPE. 203.

security against burning it, or injuring the objectglass itself. The object, if below a certain size, will of course be seen upon a ground of some sort, and this must be a black one : if on a slider, it must be gummed upon black paper ; or, if mounted upon a cork cylinder, having a pin thrust through it, the surface of the cylinder must be blacked with lampblack and glue, before the object is applied to it : but if it is of a nature to be held by the nippers, Mr. Lister's black ground (fig. 22) must be employed to bring it out in true relief; for it is far blacker than any other, and stifles all heterogencous light much more perfectly. This is attached to the stage in the same way as the live-box or slider-holder; and is, in fact, the same piece of apparatus which constitutes the false stage for the simple microscopes, and for dissecting; with the top and bottom, ' $n$, ' $p$, applied in their proper places, to close it up. In the present case, its dark abyss is to form the ground against which the object is examined. At the other end of the needle is a piece of cork, contained in a bit of brass tube. This is to receive the pin by which insects are retained in their drawers in entomological cabinets, which can thus be taken out and examined without injury; more especially if the pins have been thrust through them diagonally, which is a great convenience when applied to the microscopes, as it allows their backs and bellies to be freely presented to the action of the object-glass. The nippers, seen of their natural size at fig. 23, are drilled through at $s$, so as to lay hold of the head of a pin, and 
retain it firmly, so that it can be twisted about in any direction, without risk of detaching it. This will be found a most useful contrivance for holding the cork cylinders, and all objects whatsoever mounted on pins. The swivel which carries the nippers, \&c. is thrust into the arm, and in that manner userl, as shewn in the plate. - The mode of observation by plain artificial light corresponds with that by plain daylight. It is one of the simplest and best ways of viewing opaque objects; and the contrast of the strong divergent lights and shadows cast by the rushlight, brings out, and enables us to comprehend, the foreshortenings and perspective of the complicated details frequent in irregular opaque subjects, and thus to verify their true nature, construction, and relative position, much better than, I think, any other: sort of illum ination.

Never forget that, when observing with the candle before the stage, you must hold your breath, or have a handkerchief tied over your mouth: a single puff is all that is necessary to cause the flame of the light to play over the object and destroy it (and thus in fits of absence have I destroyed many valuable ones). What renders a rushlight so useful is, that it will not, of itself, flare over your object : it can, moreover, on account of its smallness, be got closer to an object with impunity than any other artificial light; and thus, in fact, gives the most intense-sort of plain illumination; for the intensity of light decreases according to the square of its distance from the object. 
When observing faint, sombre, and dull opaque objects, especially if high powers are used, a vast increment of apparent brightness is obtained, if all light is excluded from the eye, save that of the visual pencil. Thus, it will be found a great assistance if a large blackened pasteboard shade, nearly a foot in diameter, is made to fasten upon the eye-piece, and thus completely to exclude the direct light of the candle, \&c. ; or still better, if a black hood, like those used by astronomers, is made to cover up the face completely, but with an aperture for the body of the instrument. Such an arrangement also saves us the trouble of shutting one eye; and the enlargement produced in the aperture of the iris, by keeping the eyes in the dark, enables the faintest rays to affect the retina.

Condensed Artificial Light is procured by the action of the double illuminator, ' $f$; whenever it is used by lamp or candle-light, the double convex must be screwed on, still preserving the convex side of the plano, or bull's eye, next the object. The split socket must be clamped tight in such a position on the neck of the body, that it shall present the face of the illuminator in a lateral position relative to it, so that the rays of the candle, \&c. shall fall conveniently upon it; its distance from which should be about an inch and a half, and its distance from the object should also be about an inch, which will give the maximum of illumination, with a large spectrum, so as to illume a considerable space. I think, whenever 
this condenser is used, the flame of an Argand lamp should be employed, shaded, however, by an external copper tube, with an aperture in its inferior part just large enough to expose the flame, placed over the usual glass one. This will give increased effect and splendour to the object, by preserving the apartment in gloom, and thus allowing the iris to expand itself.

I do not think a more intense light is got with an Argand lamp than with a rushlight, but certainly a far greater quantity of it.

Silver Cups, or Specula, afford a very brilliant and intense light, almost without shadow, because it plays vertically upon the summit of an object, like the sun of tropical climates. This is the only species of illumination which will bring out many opaque objects properly (a fly's foot, or human hair, for example); but for others, requiring shade for their verification, it is altogether improper. (The markings on the scales of butterflies, \&c. are a good illustration of this position.)

Each object-glass must have a cup attached to it capable of adjustment, by being mored up and down upon the tube in which the object-glass is set, so as to cause the focus of the latter to coincide with that of the cup, (the maximum of brightness cannot otherwise be easily attained). The object must always be held by the nippers or mounted on a cork cylinder, when it is to be illuminated by cups : when the nippers only are employed, the disk, ' $r$, must be placed between them and the illuminating 
tens, \&c. so as to prevent any false light from getting into the object-glass, and also to furnish a black ground.

Remove the bottom of the black box, ' $p$, and fix the condenser, $n$, in such a position, by means of its tightening screw, that its convexity shall be inserted into the bottom of the said black box, which will be found its best position either for day-light or candle-light. The engiscope must then be placed on the tripod-stand mounting, No. 1 , and directed against the sky, (the best way, perhaps, of using the cups, with day-light), or it may be used in an horizontal or vertical position, and the light reflected by the oval mirror; but when artificial light is preferred, use the mounting No. 2, and place an Argand lamp about an inch and a half from the condenser, $n$, taking care that its flame is concentric with it, and a most intense illumination will be procured, even with powers equal to the 1-60th of an inch focus. Cups, when properly managed, give a brighter light than can be procured by any other means. They may be used without the assistance of the condenser, but, of course, in this way give a much more feeble light.

Please to remember that the condenser under the stage, and that represented attached to the body, are expressly and exclusively devoted to opaque objects.

8th. Mounting for Dissections, \&c.-Dissections are generally performed on opaque subjects, though it may be sometimes necessary to dissect transparent ones also. 
The erecting eye-piece must, of course, always be employed, by sliding it up and down in the body; with various objectives the power may be made gradually to advance from a mere nothing up to the 1-20th of an inch (which I conceive to be the utmost which can be used), and still allow sufficient space between the object and the object-glass for the anatomist to manage his implements, and to procure the necessary illumination.

Mount the engiscope in the vertical position, and see that the bar is locked fast in its front leg, to give the utmost degree of stability; place it on the tripod stool, before recommended, with the front of the stage before you, and the pillar next to the window-(a diagonal position for yourself and the instrument relative to it, will be most convenient, to allow the light to fall freely on your subject.) Use the single condenser, $n$, to furnish your light, if necessary; it may be moved round the neck of the body, to suit your convenience. You may also employ the lengthening piece, ' $i$, if you please, which will allow you to fix the stage on the pivot and sliding socket, $i$, and give a lower position for it. If you use the latter, see that it is clamped very fast, that it may not give way with the weight of your hands.

If you do not find it advisable to employ the false stage, fig. 22, which procures a separate rest for the little fingers, while the thumb and index finger operate, drop the piece, fig. 27 , into the aperture of the stage, and fix it by turning it one quarter round. Then place the piece of cork or wood, \&c. on which you dissect in the 
smaller aperture of this, and proceed. I should recommend you to get the leaves of two Pembroke or other tables placed on each side of you, to rest your elbows upon at pleasure, and likewise to procure several pieces of board, about one and a half inch thick, to place under the instrument, to depress or elevate it without the help of the slide in the pillar (which, when called into effect, always unlocks the bar.)

Your operations can always be carried on under the surface of liquids, by the lielp of the direct or diagonal boots.

When you wish to get at the side of your subject without disturbing its surface, mount in the position, No. 2, and turn your stage round on the pivot, $i$, until it comes to be in the plane of the bar : every lateral view can then be obtained at pleasure, by turning the object round, and you can operate in this position as well as in the vertical one. You may also, by help of the ball and socket, tilt the body at any required angle, and still adjust the stage to the horizontal position, as before, taking care to pinch it fast by means of the screw, $l$, before you begin to work again.

There are no tools for dissection equal to very fine scissars,-they always cut without dragging or tearing; there is, however, the greatest difficulty in procuring them. The Sheffield workmen are the only ones capable of making them sufficiently delicate. Miniature scissars have been made only half an inch in length quite perfect; now, a pair constructed with blades like these, but in 
other respects like those for some operations on the eyes, (i.e. without bows), having one arm inserted in a long handle, and the other left short, playing against a feeble spring to keep it open, is the sort of tool required. It is held like $a$ pin, and cuts by the pressure of the index finger on the short arm. You may, of course, dissect with simple microscopes of low powers as well as with the engiscope, but the present stand is not so well adapted for them as a separate one would be:

9th. Mounting the Diamond and Sapphire Microscopes for opaque objects. - It is one of the vices of simple mieroscopes that they can only shew opaque objects with cups-at least if their powers exceed one quarter of an inch. The lower foci shew opaque objects admirably with day-light, the stand being in the vertical position. When used for plain day-light in a horizontal one, all that is necessary is to assume such an attiturle relative to the window that the head shall not intercept its light. For example, if you sit with the bar horizontal and parallel with the window, the light will naturally fall between the stage and the magnifier upon the object. When cuips are employed, they act precisely like those attached to the engiscope, and magnifiers thus mounted are managed in the same way.

10th. The Amician Catadioptric Engiscope is attached fo the present stand by means of the arm, fig. 20, and is manager precisely on the same principle as the refracting 
aplanatics. The body turns round upon a swivel, by means of the pinching screw, to suit the convenience of the observer; and the only real peculiarity in observing with the reflecting engiscope is, that the optical part is always at right angles to that of the refracting one in any given mode of mounting or observation-just as the eyetube of the Newtonian telescope is relatively to that of a refractor, cateris paribus; but this instrument, as well as the simple and compound microscopes, are probably best on their appropriate stands, of -which full and particular descriptions will be given hereafter*. It is only for the sake of those who should like to have the three instruments jumbled together, that they are adapted to the same stand in the present case.

Courteous reader, I have endeavoured to supply the place of a vivâ voce lecture on the instrument, and to infuse into thee such knowledge as I possess, touching the management of the aplanatic engiscope, \&c. The directions given will, I hope, be found more explicit, clear, and intelligible, as well as more full, particular, and diffuse, than any others hitherto given in print. Valeant quantum valere possunt. By their assistance thou shalt be enabled to enter into a course of researches very nearly as profitable to thyself and fellow creatures as if thou wert engaged in the sublime and important occupation of determining whether the small star of $\varepsilon$ Bootis, is of a greenish bluc, or bluish green; or whether some nebula is very gradually or very suddenly much brighter in the middle. 



\title{
A P P E N D I X.
}

\author{
$\overline{\overline{ }}$ \\ No. 1. \\ On the Optical Phenomena of certain Crystals. \\ By H. F. TALBOT, EsQ. F.R.S.*
}

Soмe time ago I had the honour to communicate to the Royal Society an account of my invention of the polarizing microscope. This instrument possesses so great a power of developing the internal structure of transparent bodies, even in their minutest visible particles, that I feel confident the employment of it will lead to many new and interesting results. At present I mean to confine myself to the description of a phenomenon which shews strikingly the beautiful order and regularity with which nature disposes the fabric of some of her minutest visible works.

The object I speak of is a kind of minute crystallization which may be obtained in peculiar circumstances, and $\mathbf{I}$ doubt not in many different ways; but the manner in which it has presented itself to my observation is as follows :-

A crystal of borax is placed in a drop of phosphoric

* From Phil. Trans. Part I. for $1 £ 37$. 
acid, somewhat diluted, upon a plate of glass, and then moderately heated until the crystal dissolves in the acid. It is then set aside to crystallize. It is well to prepare a number of these plates at once, varying the relative proportion of the acid and salt, in order that the desired kind of crystallization may be found in one or other of them; for there is a considerable variety in the crystalline forms obtained by this method, some of which indeed are very singular. But when that kind of crystallization takes place which it is more particularly my intention to speak of, the field of view of the microscope is seen covered with minute circular spots, each of which is like a tuft of silk radiating from a centre, and is composed of a close assemblage of delicate acicular crystals forming a star. But besides these, are seen interspersed among them a number of circular transparent bodies, which are evidently modifications of the former, being, in fact, tufts or stars of acicular crystals, in such close assemblage as to be in optical contact with each other, and to produce the appearance of a single individual. Now let us suppose a group of these circles to be under examination with the polarizing microscope, and when the polarizers are crossed we observe the following phenomenon:-The field of view being lark, the little circles become luminous, and we see upon each of them a well defined and dark closs, dividing the crystal into four equal parts. All these crosses are placed similarly, and are parallel to each other, and their direction remains unaltered when the crystals are turned round in their own plane by 
revolving the plate of glass upon which they stand. This beautiful appearance can be seen with a moderate mag. nifying power. I measured the diameter of some of the larger crystals, which I found to be from 1-300th to 1-600th of an inch. But there are many much smaller, and indeed they may be seen decreasing in size, until nothing remains visible of their structure but the four luminous quadrants, appearing like four minute dots of coloured light placed close together.

I proceeded to examine the circles with a high magnifying power, and under favourable circumstances of illumination, and $I$ observed in them a very admirable structure.

Each circle has upon it one or more coloured rings arranged concentrically, but the number as well as the colour of these rings is different in different individuals.

The innermost ring is deeply coloured or black, and incloses a central space of white light, which is traversed by the arms of the cross intersecting in the centre. This part of the cross, which stands within the innermost ring, is beautifully well defined, and perfectly black. The general appearance resembles the figure 98, in Brewster's Optics, which is a representation of the rings seen in uniaxal crystals. It especially resembles it in the circumstance above mentioned, viz. the more defined outline of the part of the cross which is within the innermost ring.

We have hitherto supposed the polarizer's to be crossed; but if we place them in a parallel position we shall sce 
a phenomenon complementary to the above. The circle now presents four patches of coloured light, one in each quadrant; and we generally see near the centre four black or obscure spots, which correspond to the arms of the cross in the other position.

Such is an outline of the microscopic appearances presented by these little crystals, which are probably the minutest bodies in which so complicated an optical structure has hitherto been witnessed. I find that the smaller circles are, the more perfect is their form, and the brighter their colours.

These crystals, as I have already observed, probably consist of spicula diverging from a point, but which are in the closest possible contact, and in a state of complete mechanical cohesion. It seems to follow as a consequence from such a structure, that their density must increase from their circumference towards their centre. Now it is worthy of remark, that Sir David Brewster has discovered very similar phenomena by polarized light in the crystalline lenses of certain fishes, which are known by direct experiment to increase in density towards the centre. Indeed the figure which be has given of the lens of the codfish in the Philosophical Transactions for 1816 (Plate XII. fig. 1,) is so like the appearance of one of the crystals which I have described, that it might be supposed to have been intended for a representation of it.

Having pointed out this resemblance, I may also mention another class of facts to which I think those I have described possess a considerable analogy. I mean the 
optical figures which Brewster has discovered in spheres of glass whose density was rendered variable by heating them.

He says* that " if we take a cold sphere of glass and immerse it in a trough of hot oil, placed in a polarizing apparatus, we shall observe a black cross with four sectors of polarized light. If the sphere is turned round, it will exhibit in every position the very same figure. If we now suppose the trongh to be filled with such spheres, they will exhibit the same phenomena in whatever direction the polarized light is transmitted through them, and even if they were in a state of motion. A fluid composed of such spherical particles would exhibit the same polarizing structure in every possible direction, and even if it were in a rapid state of gyration. If the particles possessed the structure that produces circular polarization, the fluid would develop the phenomena exhibited by oil of turpentine, \&c."

And again + , "The structure of the particles of a circularly polarizing fluid must be exactly the same along every one of its diameters; that is, the structure must be symmetrical round the centre of the particle, or analogous to that which takes place in common polarization when a sphere of glass has its density regularly increasing or regularly diminishing towards its centre."

I have quoted these remarkable passages at length, because it appears to me that what is there advanced

* Library of Useful Knowledge, art. "Polarization of Light," p. 51.

+ Ibid. p. 45. 
merely as a hypothesis, acquires a considerable degree of probability from the facts which $I$ have stated, since I have succeeded in rendering actually visible circular particles of excessive minuteness, in each of which the microscope detects the very structure imagined by Brewster, viz. the black cross and four sectors of light. So that it appears not improbable that the circular polarizing properties of fluids may be owing to the presence of multitudes of particles similar to these, which they hold in solution. 


\section{No. 2 .}

Further Observations on the Optical Phenomena of Crystals.

By H. F. TALBOT, EsQ. F.R.S.*

Skct. 1.-In my former paper on this subject I have described the remarkable circular mode of crystallization which sometimes occurs when borax crystallizes from a solution in phosphoric acid.

I have stated that when examined by the polarizing microscope, a black cross and four sectors of light are seen upon each crystal; and upon that kind which is most easily and frequently obtained, there are seen in addition one or more rings of rivid colour. Some deviations, however, from this usual form occur occasionally; one of which, being extremely beautiful as a microscopic ubject, deserves a separate mention. This variety of crystalline circles differs from the one first described in the following particulars.

1. The circles are much larger, attaining the diameter of one-tenth of an inch; whereas those first observed did not exceed one-two-hundredth of an inch in diameter.

2. They are flat, whereas the former ones were convex, and frequently, I believe, of a spherical form. 
3. In consequence of which probably, they are seen to exhibit no coloured rings, but only a cross.

4. The cross is brightly coloured, red, green, blue, \&c. upon a white ground (the polarizers being supposed to be parallel to each other). 'This has a beantiful appearance, especially when several circles seen at once have crosses of different colours.

5. When the polarizers are placed at right angles, the phenomenon complementary to the above is seen. For in. stance, the circle which presented a red cross upon a white ground now presents a black cross upon a green ground,

6. In an intermediate position of the polarizers, the circle just mentioned presents a red cross alternating with a green one, thus dividing the circle into eight sectors of coloured light.

Other circles present other colours, but they all follow the same analogy, and the crosses upon all the crystals are in a parallel position.

7. These crystals last longer than the former ones. I have found some of these retain their structure for two montlıs; the former kind seldom last in perfection more than a day.

8. It sometimes happens that their circumference is imperfect, and presents a notched or jagged outline. These have a very beautiful appearance, and have been alnost universally compared by those who have looked at them to highly-coloured flowers with four petals; the cross upon them being so dark as to have the appearance of being a division between the petals. 
All the circles, when viewed by common light, appear transparent, white, and very uniform. If they are composed of acicular crystals diverging from a point, these latter must be exceedingly slender and numerous, and in perfect optical contact, since a high magnifying power does not render them separately visible.

SEcr. 2.-With respect to the chemical nature of these crystals, it appears to me evident that they consist of boracic acid. They are obtained by dissolving borax in phosphoric acid; and it may be inferred that this latter substance unites with the alkali, and isolates the boracic acid. In order to see if this supposition were correct, I dissolved boracic acid in alcohol, and I found that a drop of this solution evaporated on a plate of glass fiequently yielded an abundant crop of the crystalline spherules. But these are generally exceedingly small, requiring a high power to display in them the cross and four sectors of light, and they speedily grow opaque; for which reason they are not so well suited for observation as those prepared by the former method. They establish the fact, however, that this mode of crystallizing is a property of the boracic acid. It is highly improbable that it should be peculiar to that substance, but I have not yet met with it in any other.

SECT. 3. Explanation of some of the Optical appearances. -1. When any doubly refracting crystal is examined with the polarizing microscope, (the polarizers being 
transverse to each other, and the field of view corrsequently dark,) if it be turned round in one plane, it is seen to grow four times luminous and four times dark in the course of one revolution. This I have found to be universally the case with all the substances which $I$ have tried, and it also is in accordance with theory.

2. In the case of an acicular crystal one of the optical axes always coincided with the axis of figure, or length of the crystal; so that if a crystal of this sort appears unilluminated, all the others that are either parallel to it or perpendicular to it are likewise dark.

3. It results from the above, that a circle composed of acicular crystals diverging from a point must present the appearance of a black cross, and that the crosses on all the circles will be parallel.

4. With respect to the rings of colour, they are a consequence of the variable thickness of the crystalline circle at different distances from its centre. Their being visible, and indeed very conspicuous, upon a body of such small diameter, arises from the very energetic action of boracic acid upon polarized light.

SEct. 4. I have remarked that the circular crystallization of boracic acid is frequently entirely superseded by other modes of crystalline formation; which circumstance appears to be chiefly owing to the presence or absence of combined water. Some of these variations deserve to be particularly specified.

1. Instead of circles there often occurs a formation 
of crystals resembling two opposite sectors of a circle combined. This form may be traced in different crystals, from its commencement when the angle of the sector is small, through all degrees of increase, until at length the opposite sectors unite and form a complete circle.

2. The crystals are frequently of a very irregular elongated shape, which does not approximate either to a prismatic or a cylindrical form. This stem, as it may be termed, subdivides itself at both extremities into an immense multitude of diverging fibres, giving it the appearance of a bundle of elastic filaments firmly held to. gether in the central part, but with its extremities left at liberty to diverge*.

3. Another variety resembles in the same way irregular stems or branches, which, however, instead of being subdivided, are abruptly truncated at both extremities perpendicularly to the general line of their direction.

4. Sometimes, on the contrary, the ramification is much more developed, and then resembles two plumes united by a common stem.

5. Crystals of regular geometric form. These appear to require the presence of combined water.

Whichever of these formations occurs, it is for the

* This appearance is not very uncommon in the crystallization of other substances, though I believe it has not yet been described. The divergence of the filaments suggests the idea of electrical repulsion as being at least its primary cause. 
most part seen in all the crystals at once, to the exclusion of any of the other forms.

Sect. 5. These crystals generally undergo a spontaneous change in the course of one or two days after they have been formed. Those (No. 4) resembling plumes usually break up and resolve themselves into small rhombs and other geometric forms. The elongated crystals (Nos. 2, 3) undergo a remarkable change. They become traversed with innumerable fissures transverse to their length, and thus break up into thin plates, which either cohere loosely or separate entirely.

Sect.6. All these forms are very pleasing objects for the polarizing microscope. 'This arises from the very high depolarizing power of boracic acid, which enabies its thinnest plates to exhibit colours of great variety and brilliancy, and causes even its dust or smallest particles to appear luminous. The more energetically any substance acts upon polarized light, the closer and more crowded are the band and lines of colour which appear upon its crystals. These isochromatic lines, of which there are frequently many alternations, denote lines of equal thickness in the crystal. In the case of boracic acid, when anhydrous or nearly so, these lines are more crowded than in any other crystal that I have yet examined, insomuch that to exhibit them distinctly is as fine a test of the performance of a microscope as to resolve the more diffi- 
cult lines on the scales of a butterfly's wing, or any other of the known test-objects. And in many cases the microscope only indicates the existence of a still more delicate structure, which, at least in its present state, it has not power distinctly to exhibit.

Sect. 7. On Analytic Crystals. - I now come to describe a property of crystals which I met with while employed in pursuing the above investigation. This is, the power which certain crystals have of analyzing polarized light in a manner analogous to the tourmaline; for which reason I shall propose for them the name of Analytic Crystals.

If I am not mistaken, this property has been hitherto confined to the tourmaline and a few other natural minerals : and it has not been known that their effects could be imitated, much less surpassed, by crystals artificially made. I trust, therefore, that it will be of some interest to describe a method of procuring such crystals.

In the following experiments it will be understood that the analyzing plate of the microscope (or the polarizer next the eye) is removed.

1. A good example of this kind of crystal is obtained by dissolving the sulphate of chromium and potash in tartaric acid by the aid of heat. A drop of this solution placed on a plate of glass soon yields by evaporation filmy crystals, which very frequently have the characteristic property of tourmaline: that is to say, that if 
polarized light is transmitted through them, in one position they suffer it to pass freely, but if they are turned round 90 degrees, they arrest and absorb it entirely.

When the experiment has been successfully conducted, the crystals will not in this position allow the smallest portion of light to pass.

If now we consider the extreme thinness of these crystalline films, it will appear how energetic must be their action upon light; since, although white and transparent, they are able to produce an absorption equalling that of the best tourmalines, notwithstanding that the effect of the latter is aided by their natural dark colour.

But if these crystals are analogous to the tourmaline, they must have the power which that substance has of analyzing the light that has been transmitted through other crystals.

Accordingly, if we place in the path of the polarized ray a plate of sulphate of lime of a proper thickness, the crystal which before absorbed the light and appeared black, becomes splendidly coloured with that colour which the sulphate of lime produces, and which a tourmaline would shew if it were employed as an analyzing plate.

On reversing the polarization of the ray (or turning round the crystal), the complementary tint appears. The same results occur if the crystal is employed in the first place to polarize the light, and tourmaline or calcareous spar is used to analyze it, so that the analogy or rather identity of effect with the tourmaline is complete. 
I will now mention some other crystals which possess the analyzing property, but not in such a high degree.

2. Boracic acid.-If dissolved in boiling water, it yields in cooling irregular crystals which have considerable analytic power. A crystal which in one position is so translucent as to be hardly distinguishable from the water in which it floats, is in the transverse position very strongly defined. It does not become dark all over, but only in its outline.

If now we employ it to analyze the tints of sulphate of lime, its outline becomes beautifully coloured. Nothing can exceed the delicacy of colouring which a number of these crystals exhibit when viewed together; those which lie in one direction appearing, for instance, green; those in a transverse direction, red. The appearance is very unlike any other optical phenomenon that $I$ know of, in consequence of two colours being seen in strong contrast, and without any intermediate tints ; and also from the outline only of the objects being coloured, while their interior remains without colour. It is only when the crystals have a fibrous or striated structure that the tint extends over all their surface.

The boracic acid has the same analytic property, and precisely the same appearance, when it crystallizes from a solution of borax in phosphoric acid. The plumose crystals of it (No. 4, suprà) are very delicately coloured with the two opposite tints.

I obtained a very beautiful result by placing a drop of phosphoric acid upon a group of circular crystals. This 
caused a fresh deposition of boracic acid upon them as nuclei, which assumed the form of very delicate cilia, spreading in all directions as from a centre. These fringed circles shewed the analytic property in an admirable mauner, exhibiting four quadrants coloured alternately with complementary colours of great vivacity.

3. Another instance which is worthy of mention is the oxalate of potash and chromium, a salt whose optical properties have been investigated by Sir David Brewster*. If some gum arabic is added to a solution of this salt, and a diop of it put between two plates of glass, it abandons its usual mode of crystallization for another, which resembles a microscopic vegetation composed of minute prisms growing one ont of another, and variously arranged in sprigs and branchlets; while in other places it assumes an undulating capillary form, much resembling in miniature the tufts or locks of a species of Conferva which is seen growing in pools of water or in the sea. Now these objects are possessed of a high analytic power, insomuch that, when a plate of sulphate of lime is placed beneath them, they assume a colour of great intensity and splendour, which is changed for the complementary tint when the polarization of the incident ray is reversed.

4. Nitre-If nitre and gum arabic are dissolved together in hot water, a drop of the solution put on a glass plate yields very good analytic crystals. These have a 
branched or plumose appearance, and assume beautiful colours in polarized light when a plate of sulphate of lime is placed beneath them. The microscope shews the colour to reside principally in the ontline, but to the naked eye the whole film appear's coloured. As these films may be obtained of large size, the phenomenon can be well seen by the unassisted eye.

A very interesting experinent, and one which throws much light upon the cause of these appearances, is to transmit a beam of polarized light very obliquely through a small prism of nitre immersed in gum, and viewed with the microscope. Its outline then generally exhibits two colours instead of one; for, while the edge of the prism which is on that side from whence the ray of light comes, is, for instance, of a red colour, the opposite edge will appear green. Reverse the polarization of the light, and these colours are exchanged one for the other. This observation enables us to explain the origin of the phenomenon in a satisfactory manner, and to shew why it only occurs in crystals possessing strong double refraction, like nitre, in which the refractive indices of the two rays are materially different.

When a ray of common light is incident upon such a crystal, and therefore divides itself into two rays oppositely polarized, both rays are transmitted through the central parts of the crystal, which are bounded by paraliel planes, or by planes approaching to parallelism. But when the bounding planes of the crystal are much in- 
clined to each other, and therefore refract the light in the manner of a prism, the refractive indices of the rays may differ so much, that while one of them passes freely through such a prism, the other cannot pass at all, but suffers total internal reflexion, and is thereby dispersed; just as if the prism had a larger refracting angle with respect to that ray than to the other. Therefore if two oppositely polarized rays are presented successively to such a crystal, as in our experiment, one of them will be transmitted, and the other not. That this is the true explanation appears from this, that when the oblique planes are well formed and clearly defined by the microscope, the colour also is accurately limited by the same boundary : so that while this part analyzes the tints of a plate of sulphate of lime, the rest of the crystal is inactive.

It may be inferred by analogy, that the same cause produces the analyzing power of striated or fibrous surfaces, and of those in which the striæ are too minute to be discernible (as in No. 1, suprà, page 225) : for it is not the property of all crystals with striated surfaces to have the analytic power, but only of such as are doubly refractive in a high degrce.

I have said that the capillary crystals (No. 3) possess the analytic property, although their diameter is often evanescent even with a microscope. An important inference may be drawn from this, viz. that a ray of light immediately on entering one of these crystals, subdivides itself 
into two rays of different refractive indices, or at least that the thickness of crystal which is requisite to produce this effect is insensible to observation.

When nitre is made to crystallize in gum, it often shoots into prismatic crystals, which are very interesting objects, the more so, that they are of a permanent nature, and not liable to spontaneous change. When examined by polarized light, these prisms, in one position of their axis, frequently disappear completely. This arises from the refractive power of the gum being equal to that of one of the two rays in the crystal. Reverse the polarization of the ray, and the crystal appears, as it were, to start into existence, acquiring great strength and blackness of outline, and, not unfrequently, entire opacity. Again, when the sulphate of lime is interposed, this opacity disappears, and the crystal becomes brightly coloured. Since it is probable that many better methods may be found of obtaining this kind of crystal than have hitherto presented themselves, I have hopes that it will be possible to obtain large and permanent artificial crystals, which may possess the advantages of the tourmaline without the inconvenience resulting from its dark colour. 
No. 3.

\section{E X O R D I U M *}

By C. R. GORING, M.D.

The discovery of a set of objects for ascertaining the defining and penetrating powers of microscopes, has founded a new era in the history of those instruments. The thick aplanatic object-glass for diverging rays, and the Amician reflecting microscope, have in consequence been perfected. The substitution of diamond and sapphire lenses, for those made of glass, in the single microscope, with the ingenious apparatus for illumination contrived by Dr. Wollaston, may also in some measure be attributed to the same source. It may surely be affirmed that no improvements at all commensurate to these in magnitude and importance are likely to be made hereafter. Microscopes are now placed completely on a level with telescopes, and, like them, must remain stationary in their construction.

In the present work I have endeavoured to establish the mechanical part of the construction of microscopes,

* From First Edition, with corrections. By C. R. G. 
that is to say, their mountings, carriages, aud apparatus, \&c. on true and philosophical principles, and I fatter myself not totally without success, most of the better class of instruments, which have been made of late years, being more or less constructed according to the plans I have suggested. This, however, is a subject on which no man must pretend to dogmatize or dictate, for such is the spirit of contradiction, and of renitency against conviction, in mankind, that they will make it a point of honour to go tise wrong way if you urge them too forcibly on in the right one, just to shew that they will have their own way, and are determined to think and act for themselves.

Though it may savour somewhat of egotism, I cannot refrain from stating some of the difficulties which I experienced in making the drawings of the living objects, though I know very well that people of first-rate talent explode difficulties, and will hardly allow of their existence, except with bunglers and half-taught amateurs. I wish I had been one of those favoured individuals with whom the most arduous achievements of all sorts " are no more difficile,

Than for a blackbird to whistle."

Hudibras.

If any portrait painter had to execute a likeness of some person afflicted with chorea, who could not be prevailed upon to be quict for more than half a minute together, who was perpetually jigging about the apartment, and exhibiting his tail instead of his head, 
\&c. \&c., I think he would be compelled to admit that he had undertaken a task which would at least require time and patience for its completion; but if, in addition, the said person was to be removed to a distance, so that the artist could only see him with a powerful telescope, and had to follow his motions as well as he could, and be content to catch a glimpse of him crossing his field of view now and then, according to the lumour and good pleasure of the said individual, I think the worthy limner would begin to think that after all there was some difficulty to contend with.

Now this case I conceive to be an exact parallel to that of drawing living objects with a microscope.

Their incorrigible restlessness so baulks and baffles the artist, that he is frequently compelled to lay down his pencil to regain his lost temper, and fresh courage to proceed : in many cases his best resource is to study the object till he has got all its features by heart-then to set them down on paper-study again, and gradually correct them : by the time he has made half a dozen rough sketches he will get pretty near the truth : he may then commence a regular drawing. I can safely say that I have drawn many of my objects five or six times over before I could arrive at my portraiture. I have heard a great deal about shutting one's eyes after having made an observation, and drawing from the impression left on the retina. This, I suspect, is better in theory than in practice, and it is evident that, unless the object is stationary, 
the last impression must be so confounded with the preceding ones that no distinct image can be left.

But it will probably be asked, why I did not kill my object before $I$ drew it, instead of giving myself all this unnecessary trouble? I answer, that I never could make a drawing to my mind from a dead aquatic larva or insect. Such is the extreme delicacy of their organs, and so rapid their decomposition in water, that long before a drawing can be executed, the main and capital parts of the internal, and even external structure, in most subjects, will become confused and unintelligible. If they are removed out of the water, a still greater change is effected by their drying : their colours vanish, and their whole appearance is totally changed; to say nothing of the fact, that a dead aquatic insect so loses the peculiar distinctive character derived from its favourite attitude and position, that though the component parts might, in some instances, be correctly given, the tout ensemble would be scarcely recognized. Some of the proportions-leng th of the body and legs, \&c.-may, however, be measured from the dead subject; and this help I have always had recourse to when I could spare a specimen for destruction. All attempts to preserve these creatures in spirits, turpentine, \&c. are useless, from the excessive corrugation these liquids produce. I also made various attempts to confine them in a narrow compass, so as to preveut much latitude of motion; but was compelled to desist from the project, finding that they got 
into constrained and unnatural positions, and injured themselves by struggling.

At the period the drawings were made, it is proper for me to observe, that the happy method of preserving aquatic insects in Canada balsam or varnish was not discovered; still, however, a live subject is far superior to a dead one, under any circumstances whatever ; which proposition I consider so self-evident that I shall not set about proving it.

1 suspect that other individuals have met with the same. obstacles as myself in making drawings of living microscopic objects; for I think it may be affirmed, without any illiberality, that, with very few exceptions, those of my predecessors are proportionally more rude and incorrect than those of any other subjects of natural history whatever; their various lineaments and features being frequently false, and exaggerated to a degree amounting to caricature; nevertheless, they have been handed down from one bookmaker to another, ever since the days of Swammerdam, as if they needed no improvement whatever. I have made my drawings at that period of the growth of the larva or crysalis in which $I$ thought it made the best and most interesting object, and that they vary: greatly in their appearance, according to the degree of maturity to which they have arrived. There are also many varieties, very closely resembling each other, which it is not very easy to particularize; but I am quite confident, that when the genuine object is procured, in the 
state in which I drew it, the correctness of my execution will be recognised.

The specimens which I have selected are those which experience has shewn to excite the strongest emotions of pleasure and satisfaction in the great mass of observers of all ranks; whom I have always found to be most delighted by comparatively larye living objects, seen with medium powers. In fact, they seem to afford the same sort of gratification with a menagerie of living wild beasts on the large scale; and most certainly many of them wonderfully emulate the ferocity, voracity, cunning, and cruelty of the mammalia. They prey on each other, and fight with a degree of determined obstinacy not inferior to that of any beings whatever. They have likewise a thousand diverting pranks and humours, quite peculiar to themselves. In addition to these amiable and amusing qualities, they possess such a high degree of transparency, that their unique and beautiful internal machinery is as clearly perceptible as if they were made of glass; so that, without any dissection, we can unravel all the mysterious workings of their nature; such as the circulation of the blood, the pulsations of the heart, the peristaltic motion of the intestines, and the play of every muscular fibre. This property of transparency is not possessed by any other living beings with which $I$ am acquainted, except the animalcula infusoria. I may observe, that no perfect insects present so many facilities for adaptation to the microscope, or can be so easily preserved and managed; so that the larvæ, \&c. appear 
to me peculiarly and exclusively devoted to the consideration of microscopists.

Their natural history will be given by Mr. P., with every particular likely to interest the reader concerning their peculiar habits and instincts : such as their mode of locomotion, and of taking their prey; the food which they most affect ; their relative dispositions towards each other, and other beings with whom they associate; with full directions how, when, and where to procure thern; and how they may be preserved in health and vigour for observation, \&c. \&c.

I do not feel myself called upon to state more concerning the nature and object of this work; and I humbly hope that truth and justice to myself and partner, and our joint publication, does not require me to have said less.

I shall conclude this introduction by a vindication of microscopic science and its votaries, from the aspersions which have been cast upon them by the inconsiderate; many of whom have been pleased to assert, that microscopes have, of late, received a degree of patronage from the most illustrivus and distinguished savans, to which they are not legitimately entitled. Were they applicable to no other purposes than the dissection of blackguard vermin, the observation of stinking ditch-water, or the amorous passions of ants and worms, I should, perhaps, for argument's sake, admit that they were but the tools of a puny, pitiful pedant, whose passions and amusements were of a trifling, if not of a degrading complexion : but 
I would ask whether, in the hands of men like Bauer, they are not applied to the development of the most curious, important, and interesting details of anatomy and physiology, which, without their assistance, could never have been known? and whether the finest and most delicate parts of the structure of animals, in their extreme penetralia, are not rendered equally intelligible with the coarsest and most evident parts of their fabric, by means of these instruments?

None are apt to treat microscopists with more contempt than some astronomers, and even mere star-gazers.

I shall always possess the most profound veneration for astronomy, as the most sublime of all the sciences; but star-gazing is a distinct department, though frequently confounded with it; and is, in my opinion, little better than downright microsophizing. To the telescope certainly belongs the inspection of the great and sublime works of the creation; to the microscope belongs the petites and beautiful ones: if the former shews us the world above, the latter exhibits the world beneath us.

I must here positively chant the vast superiority of a microscope, as a hobby-horse, over a telescope, at least when the latter is used merely as a star-gazing instrument. Let us suppose you have, at a great expense, procured a very fine telescope. How many hours in the year will you be able to use it? Not above one hundred, says Sir W. Herschel, even if you lose not one in other avocations. How many colds and quinzies are you to get by exposure to the night air, when you 
might be much better employed in your warm bed? How many disappointments are you to endure from finding the wind suddenly shift into the wrong quarter, after you had counted on a good night's sport ? How many scoldings and curtain lectures from your wife? After all, when you have seen all the double stars, clusters, nebulæ, within reach of your instrument, together with the planets, mountains in the moon, and spots on the sun, \&c. together with any curious terrestrial objects about your habitation, and exhibited the same to your friends, what remains but to dispatch your charmer up to the garret, as of no further use ? You may, certainly, on high festivals, transport it down again, in order to convince people what a prodigiously scientific personage you are, even to be able to possess such an instrument, and to know the right end of it from the wrong one.

A microscope, on the other hand, is available at all times and seasons. There is no end to the number of objects it may investigate. In the solitude of the most dismal prison, you would only need a lamp, a microscope, and some vegetable infusions, to furnish you with an inexhaustible fund of amusenent, totally independent of other external objects. When employed in researches on animal and vegetable physiology, where are your investigations to terminate? Your life will not suffice to study sufficiently the wonders of the minutiæ of natural history.

The supreme Author of Nature has been pleased to bestow so exquisite a degree of finishing upon 
many of his works, that they can be only appreciated by man with the assistance of the microscope. Surely he who is but a work of God may be allowed to admire the works of his Creator, without incurring derision or ridicule, even though they are minutiæ. Trifles are said to take only with frivolous minds; but minutice are not ne. cessarily trifles, as it will be easy to prove. It is not only, in my own opinion, unscientific, but even swinish and ridiculous, to contemn any thing merely on account of its minuteness. To say nothing of the hackneyed argument, that greatness and littleness exist only by comparison, I will ask, if the Automaton Chess-player had been made on a scale of 1-20th of an inch to a foot, or even much less, it would, in consequence, become despicable as a work of art ?

Suppose some individual, greatly distinguished by his talents in ship-building, in making astronomical instruments, or steam engines, \&c., was also to evince a passion for making minute automata and watch-work, such as tarantula spiders, minute singing-birds, musical seals, or even such curiosities as a coach drawn by fleas, \&c. would it shew good breeding, or good taste, to despise or ridicule his minute labours, while we admired his grander and more imposing works?

Now it does appear to me, that the Supreme Being does, in some sense, resemble such an individual; for his power loves to display itself in every way in which it can be displayed, whether upon the minute or grand scale, in the creation of animalcules, as well as of fixed stars and I 
cannot help thinking myself, that those who spurn and scoff at the minute works of God, be they what they may, while they affect an admiration of his great wonders, are guilty of a species of impiety, and must be either liars, or hypocrites, or fools.

Men are perpetually wondering what can be the use of bugs, and fleas, and wasps, and such kind of vermin, and speak of them as absolute blots in the escutcheon of the Almighty. The use of these little insects is surely to teach man a perpetual lesson of hurnility. He is extremely apt to fancy himself the only being of real importance in this planet, and that every thing in it has been made for his exclusive use and accommodation : whereas a very little consideration must teach him that the said fleas, and bugs, and wasps, \&c. are intended to enjoy themselves in their own way just as he does; that is to say, without greatly considering the convenience, comforts, or happiness of other beings, I consider it as certain that bugs were intended to prey upon man, as that man and the other prædaceous mammalia were intended to destroy the weaker animals. If a bug (I beg pardon-a cimex lectularius) could reason, it would probably suppose that man was of no other use in the creation than to prepare its habitation and supply its food; and would think that no better evidence need be adduced to prove the immense importance of a bug than that such bountiful provision had been made for it, \&c.

If mere utility is to be made the standard of excellence, what a large part of that of most of the sciences consists 
in their effect as counterpoises to superstition and barbarism! and in this point microscopic science surely has its voice among the rest. All men are apt to despise their neighbours' pursuits, and to dignify their own as the only ones of real importance and value: but while the use of the microscope is sanctioned by the examples of Pond, of Amici, of Wollaston, of Herschel, and of Brewster, who disdain not to relax from their severer studies in such pursuits, he must be very hardy and fastidious indeed who dares to deride and condemn them.

Great disgrace has been brought on microscopic science by the manner in which it has been perverted to the support of preconceived opinions and hypothetical views, as well as to a spirit of wonder-making. I hope that a new and golden age of observation will now commence.

C. R. G.

March 1837 . 


\section{No. 4.}

Observations on Swammerdam's method of Dissecting and Preparing Objects for the Microscope**

Referred to at page 121.

In the preparation of objects, no man was more successful or more indefatigable than Swammerdam : in minutely anatomizing, in patient investigation, and in curiously exhibiting the minute wonders of creation, he stands unrivalled, far exceeding all those that preceded, as well as those that succeeded him. Deeply impressed and warmly animated by the amazing scenes that he continually discovered, his zeal in pursuit of truth was not to be abated by disappointment or alarmed by difficulty, and he was never contented till he had attained a rational and clear idea of the organization of the object whose structure he wished to explore.

We have only to regret that we are ignorant of the methods he employed. To discover these, the great Boerhaave examined with a scrupulous attention all the letters and manuscripts of Swammerdam, and has communicated the result of his researches, which, though but

* Adams's Essays on the Microscope, p. 134, from the Life of Swammerdain, by Boerhave, ed. 1758. 
small, may enable us to form some idea of this great labourer in the field of science.

His chief art seems to have been in constructing very fine scissars, and giving them an extreme sharpness; these he made use of to cut very minute objects, because they dissected them equally ; whereas knives and lancets, let them be ever so fine and sharp, are apt to disorder delicate substances, as in going through them they generally draw after and displace some of the filaments. His knives, lancets, and styles, were so very fine that he could not see to sharpen them without the assistance of a magnifying glass; but with them he could dissect the intestines of bees with the same accuracy and distinctness that the most celebrated anatomist does those of large animals. He was particularly dexterous in the management of small glass tubes, which were no thicker than a bristle, and drawn to a very fine point at one end, but thicker at the other. These he made use of to show and blow up the smallest vessels discoverable by the microscope-to trace, distinguish, and separate their courses and communications, or to inject them with very subtile liquors.

He used to suffocate the insects in spirits of wine, in water, or spirit of turpentine, and likewise preserved them some time in these liquids; by which means he kept the parts from decomposition, and consequently collapsing and mixing together; and added to them such strength and firmness as rendered the dissections more easy and agreeable. When he had divided transversely 
with his fine scissar's the little creature he intended to examine, and carefully noted every thing that appeared without further dissection, he theu proceeded to extract the viscera in a very cautious and leisurely manner, with other instruments of great fineness; first taking care to wash away and separate, with very fine pencils, the fat with which insects are very plentifully supplied, and which always prejudices the internal parts before it can be extracted. This operation is best performed while the insect is in the pupa or chrysalis state.

Sometimes he put into the water the delicate viscera of the insects he had suffocated; and then shaking them gently, he procured himself an opportunity of examining them, especially the air-vessels or trachæa, which by this means he could separate, from all the other parts, whole and entire, to the great admiration of all those who beheld them : as these vessels are not to be distinctly seen in any other manner, or, indeed, seen at all without damaging them, he often made use of water, injected by a syringe, to cleanse thoroughly the internal parts of his insects; then blew them up with air, and dried them, by which means he rendered them durable, and fit for examination at a proper opportunity. Sometimes he has examined with the greatest success, and made the most important discoveries in insects that he had preserved in balsam*, and kept for years in that

* It is probable that the beautiful plan now adopted of mounting and preserving insects in Canada balsam is the same as that here alluded to; notwithstanding it may be considered as a new discovery, because the 
condition. Again, he has frequently made punctures in other insects with a fine needle, and after squeezing out all their moisture through the holes made in this manner, he filled them with air, by means of very slender glass tubes; then dried them in the shade; and, last of all, anointed them with oil of spike, in which a little rosin had been dissolved, by which means they retained their proper forms for a long time. He had a singular secret whereby he could so preserve the nerves of insects that they used to continue as limber and perspicuous as ever they had been.

He used to make a small puncture or incision towards the tail ; and after having gently and with great patience squeezed out all their humours, and great part of their viscera, he then injected them with wax, so as to give and continue to them all the appearance of healthy, vigorous living creatures. He discovered that the fat of all insects was perfectly soluble in oil of turpentine: thus he was enabled to shew the viscera plainly, only after this operation he used to cleanse and wash them well and often in water. He frequently spent whole days in thus cleansing a single caterpillar of its fat, in order to discover the true construction of this insect's heart.

His singular sagacity in stripping off the skin of caterpillars that were on the point of spinning their cones, 
deserves particular notice. This he effected by letting them drop by their threads into scalding water, and suddenly withdrawing them; for by this means the epidermis peeled off very easily; and when this was done he put them into distilled vinegar and spirit of wine mixed together in equal proportions, which, by giving a proper firmness to the parts, afforded an opportunity of separating them, with very little trouble, from the exuviæ, or skins, without any danger to the parts; so that by this contrivance the pupa could be shewn to be wrapped up in the caterpillar, and the butterfly in the pupa. Those who look into the works of Swammerdam will be abundantly gratified, whether they consider his immense labour and unremitting ardour in these pursuits, or his wonderful devotion and piety. On one hand, his genius urged him to examine the miracles of the great Creator in his natural productions; while on the other, the love of that same All-perfect Being, rooted in his mind, struggled hard to persuade him that God alone, and not His creatures, was worthy of his researches, love, and attention.

THE END. 


\section{SUPPLEMEN T}

TO THE

\section{MICROSCOPIC ILLUSTRATIONS.}

\section{CHAPTER I.}

Memoir concerning the Verification of Microscopic Phenomena, with fruits of experience relative to the analysis of Test Objects, and the defining and penetrating powers of Microscopes and Engiscopes.

\section{By C. R. GORING, M.D.}

That there may be no disputes or mistakes concerning terms or words, it is necessary to determine accurately what I mean by defining and penetrating powers as distinct from each other. It will, I believe, be found, from the consideration of various passages in my writings, that, by defining power, I mean nothing more than a destitution of both kinds of aberration, considered independently of the aperture of the microscope or engiscope; and, by penetrating power, merely a large angle of aperture, which may or may not be associated with an aplanatic and achromatic construction. The union of these two properties of course constitutes the perfection of an instrument, and is, by some writers, resolved entirely into defining power, which is or is not accurate, according to the sense in which the word is used. As, however, by Sir W. Herschel, the 
powers of telescopes have been separated into two parts, and penetrating power considered distinct, from a power of shewing objects of difficult definition. I have acted in the same spirit relative to the less important instruments. Thus, a telescope, having a very large aperture, though of an erroneous figure, will shew nebulæ, and clusters of stars, totally invisible by a small telescope of the most perfect kind; and the latter again will, in its turn, shew double stars and other minutiæ, which the former would be utterly incompetent to render manifest. In the same manner, an engiscope of a small angle of aperture will define, and shew very exactly, an enamelled dial plate, the outline of the brilliant scales of a variety of beetles, animalcules, and an innumerable quantity of common objects, too tedious to mention; but it will utterly fail upon the lined objects; while another, having a large angle of aperture, though replete with aberration, will nevertheless shew many of these, (though not so well, of course, as if aplanatic and achromatic;) while, if tried, on a dial plate, or a piece of diamond beetle, \&c. it will exhibit its imperfections in a most glaring manner, and shew a total deficiency of what I call defining power. There are objects which at once serve to exhibit the perfection of a microscope, or engiscope, both as to defining and penetrating power, provided the manner in which they are shewn is duly attended to.

The following aphorisms will serve to express my views relative to the subjects of this memoir.

1. A test is an object which serves to render sensible both the perfection and imperfection of an instrument, as to defining and penetrating power.

2. Proof objects may be ranged under three heads: First, those which render manifest chromatic and spherical 
aberration; secondly, those which give evidence of the presence of a large angle of aperture; and thirdly, those which shew the union of the above properties, and consequently the greater or less approximation of an instrument to its most perfect condition.

3. Chromatic aberration is rendered sensible by almost any transparent object, when the light falls upon it obliquely; but more especially by such as are not transparent, but,only illuminated by intercepted light, of which a very good example may be seen in a piece of fine wire sieve, treated like a diaphanous object, also in a thin plate of metal, perforated by very small holes. The various colours are seen according to the order of their refrangibility, by putting the object both without and within the focus, as well as by viewing it at the focal point; all brilliant opaque objects also exhibit chromatic aberration strongly, when managed in the same way.

4. Spherical aberration is most sensibly felt in viewing opaque objects, especially if of the brilliant class; it shews itself in a variety of ways : first, as a diffused nebulosity over the whole field of view; secondly, as a confined nebulosity, extending only to a certain distance from the object; and thirdly, in a want of sharpness and decision in the outline caused by a penumbra or double image, which can never be made to lap perfectly over the stronger or true one. Aplanatism, or a destitution of the aberration of sphericity, is evinced by the absence of these appearances, and by the vanishing of the image immediately the object is put out of focus either way.

5. A deficiency of angular aperture is shewn by a want of light, producing unsatisfactory vision, which is rather increased than ameliorated, by augmenting the intensity 
of the artificial illumination,-by an incapacity of shewing lined objects, except such as are of the lowest class, and by giving very large spurious discs, with artificial stars; also by shewing easy test objects, with the lines faint, while the spaces between them are darker and more opaque than they ought to be.

6. When the spherical and chromatic aberration is small and faint, and the angle of aperture considerable, the lines on proof objects become fine, sharp, and dark, and the spaces between them clear and bright, (provided the illumination is properly conducted:) they moreover become visible in a very faint light; if the instrument is perfectly aplanatic, the outline and the lines are seen at once, and the spurious discs of all brilliant points are very sharp and small.

7. An instrument, possessing an aplanatic pencil of $\mathbf{5 5}$ degrees, shews all the easy lined objects anyhow; there is no management whatever required to bring them out; the light may be thrown through them as directly as possible, and still they will not disappear; for in this case the penetration of the optical part is so great as to get the better of all imperfections in the illumination, and to exhibit the object in a manner, in spite of the illumination, rather than by its assistance.*

8. Notwithstanding this fact, in order to obtain a maximum of distinctness and effect, it is in every case requisite that the illumination should be of the most exact kind; and if the instrument has only an aperture just sufficient to render a particular object visible, it is absolutely necessary that it should be so, to render it visible at all.

* Achromatic Illuminators, now so much admired by some observers, were first proposed in the Micrographia, page 86 . 
9. This illumination consists in causing the light to fall upon the object obliquely; moreover, the line of the said obliquity must traverse the system of lines intended to be brought out nearly at right angles, though there are some anomalies in this respect; and the intensity of the light must be such as to produce a maximum of blackness or darkness in the lines, for which purpose a faint illumination, whether the light is artificial or natural, invariably answers best. All condensations by concave mirrors and lenses are hurtful, and cause the lines to assume a faint nebulous appearance, as if drawn with a pencil instead of a pen and ink. There is also another false phenomenon produced, by condensing light on the plane of the object; for example, on the lozenges, on the scales of the podura, which I have sometimes seen exhibited by such illumination, just in the opposite way to which they ought to be shewn, namely, with the spaces between the lines dark, and the lines themselves faint; so that the scale somewhat resembled a sample of the moss hypnum. I have, moreover, seen this style of vision very much admired by connoisseurs.

10. There is an infinite number of ways in which lined objects may be illuminated, so as to fulfil the aforesaid indications more or less perfectly; but I am of opinion that there is nothing equal to a wax taper placed behind the stage, without any other apparatus whatever, both from its simplicity and its very manageable nature. It is sometimes advisable to put the slider-holder on the wrong way, that is, on the opposite side of the stage to that on which it is customary to fix it, so that there may be no aperture of any description behind the object, which is thus left perfectly exposed to the most oblique ray. This method, moreover, allows the candle to be brought extremely near 
to the object-an arrangement sometimes, though rarely necessary, with certain objects not of the lined kind. The objective end of the engiscope may then be introduced into the interior of the slider-holder. It is impossible to lay down rules concerning the angle of deviation from direct light, which it is most advisable to employ, in order to bring out any particular set of lines most satisfactorily; this must be left to the taste of the observer: neither can the distance of the candle from the object (on which the intensity of the illumination depends) be determined, so as to meet the views of every microscopist; from two to six inches may, however, be roughly stated. Whatever distance, and whatever degree of obliquity, brings out the lines darkest, and the spaces between them clearest, according to the vision of the individual who uses the instrument, is the best.*

The following rule will serve to shew when the light is direct, and when it is oblique. If the penumbra of the object, when put out of focus, appears stationary, and to go within and without the focus without changing its position, the light is direct, supposing the object-glass to be in adjustment; but if it seems to travel from one margin of the field of view to the other, then the light is oblique, and the direction of it is in the line in which the object seems to travel.

* In order to procure specimens of lined objects in the best possible state for observation, it is recommended to naturalists to steep the insects from which they are derived in sulphuric ather; this dissolves the grease which frequently tarnishes and clogs up their minute lines and markings, while it accumulates and licks up dust, \&c., thus rendering them unfit for observation; on removing the insect from the fluid, the æther will evaporate rapidly, and leave it dry, when the scales may be removed. Delicate scales can only be procured perfect from living specimens. 
11. When daylight is used vision is much improved by the use of diaphragms : these, however, are inert, unless the image of them in the visual pencil is less than that of the aperture of the object-glass, or magnifier, with which they are used : for example, if we put a diaphragm one-twentieth of an inch in diameter in the focus of a onetwentieth of an inch lens, having also one-twentieth of an inch of aperture, or, of course, in one of shorter focus, because the aperture of the lens, when vieved by a magnifier, will be found illuminated throughout its whole extent, just as if no diaphragm was used; but, when it is placed out of the plane of the focus, say half, or three-fourths of an inch off, then its effect will be very decided. In this case, it reduces the intensity of the illumination, and prevents faint objects from being drowned in an excess of light, while the darkness and strength of all the markings of the object are decidedly increased; it moreover seems to improve the oblique pencils of any instrument, and renders spherical aberration, if not very strong, almost insensible. In fact, the quantity of light in the visual pencil is reduced exactly in the same manner as if the aperture of the object-glass or magnifier was cut off to the standard. of the image of the diaphragm seen in it.

12. There is no modification of daylight illumination superior to that invented by Dr. Wollaston, provided it is used in a proper manner, whether the object is of the lined or proof kind, or not. In order to obtain an effective oblique light with it, it is necessary that the axis of the optical part of the instrument should not be in the same right line with the centre of the perforation, but deviating considerably from it, which gives oblique light in a line drawn from the centre of the aperture of the lens, or 
doublet, or visual pencil in an engiscope, to the centre of the image of the perforation in it. An engiscope, treated with this system of illumination, shews, in the margin of its visual pencil, a round image of the diaphragm, but, in plano-convex, single, or compound magnifiers, with their plane sides towards the object, this image assumes a semilunar figure. The intensity of the illumination is regulated by the distance of the image of the perforation, or of the focus of the illuminating lens, from the plane of the object; and if the light of a southern window, on a bright day, is employed, the instrument will be found to perform best, when it is made equal to about half or threefourths of an inch; the intercepted light in this method is divergent. The modification of Dr. W's illuminator, contrived by me, which has a real diaphragm, instead of the image of one, has an advantage over the original construction, in being more portable, and in adapting itself easily to any construction.

13. There are certain classes of objects which can never be seen completely well with artificial light of any kind, unless the instrument be perfect,-such are animalcules and aquatic insects, the hairs of a variety of animals, mosses, the tissue of conferva, and an infinite number of common objects. When it is necessary to exhibit them by candlelight, they are best seen with the flame very close to them, as already described; or if the construction of the instrument admits not of this arrangement, then, by rendering the illuminating rays parallel, by a bull's-eye lens, and afterwards reflecting them by a plane mirror, and using diaphragms under the stage, any condensation, by destroying the parallelism of the rays subverts the effect of the bull's-eye lens, and will 
be found prejudicial. I think, moreover, that when the construction of an instrument does not admit of the position of the flame of a taper behind the stage, this is, perhaps, the next best way of bringing out the lined objects; but the taste of mankind in such matters varies incessantly; every man may be said to see best in his own microscope, \&c., and in his own way too, be it what it may.

14. Single and compound magnifiers, as they exhibit the real object, instead of an image of it, do not require so exact an illumination as engiscopes, and are therefore more easily managed by the inexpert. An engiscope is always very fastidious and ticklish as to its illumination, no error in which can be committed without seriously injuring its performance. Thus, whatever illumination will suit an engiscope, will be sure to suit simple microscopes and doublets; but what will suit the latter pretty well, will by no means accord with the former.

15. Opaque objects sometimes require an illumination by means of cups, and sometimes only the natural light of the atmosphere, or of a small wax taper, or rushlight, placed before the stage, as near as may be to the object. With the latter species of illumination the lines on the scales of beetles and butterflies are, perhaps, best brought out; sometimes, however, a condensation, by means of a lens, is more effective. They can never be seen well with cups, which give an intense direct light; this, however, exhibits flies' feet, and other opaque objects of the same nature, with the highest effect.

16. The verification of the real nature, form, and construction of a vast variety of opaque objects, which elude the sense of touch by their extreme minuteness, can only be made out by an attentive study of their appearances 
under a variety of methods of illumination, conjointly with a consideration of the phenomena presented by bodies when seen in perspective, or, as painters term it, foreshortened. We are particularly perplexed in microscopic observations, by the circumstance that only a point of an object can be seen at a time, if the power used is considerable; we must, therefore, always begin to study them with low powers at first, and increase them gradually, so that we may always be able to recognize the particular part of the object we are looking at, otherwise all will be confusion. When we see an opaque object represented by a drawing, we see it as it never can be seen by a microscope, because, in the latter instrument, its various features can never be in focus at the same time, as before observed, and it would be impossible to represent it on paper exactly as seen at a variety of adjustments, without an infinite number of views of it.

I particularly recommend observers, in examining and verifying opaque objects too small to be dissected, to use the simple light of a candle before the stage, as its divergent rays bring out more strongly their various component features, and render them more intelligible than can be done by any other method. The oblique light of the taper plays over their various prominences and depressions like that of the evening sun over common objects, giving broad lights and shadows; and, if the observer has any knowledge of the operation of light, and the manner in which it is broken and intercepted by ordinary bodies, he will hardly fail to arrive at a tolerably clear idea of the nature of the minutiæ he is contemplating. The light of the sun must never on any account be used, as it gives rise to an infinity of indescribable deceptions, both as to 
- colour and form; it renders every opaque object a mass of confusion.

17. There are a variety of optical deceptions produced by microscopes and engiscopes, against which observers cannot be too strongly guarded, as inadvertent persons have brought great disgrace on microscopic science by trusting too much to the testimony of their instruments. It requires long and repeated observation to enable us to be quite certain of the nature of what we see : for-lst, we are seldom or never in the habit of viewing common objects by intercepted light; vision by it is therefore altogether new to us, and the phenomena presented by bodies subjected to its influence are totally different to what they assume as opaque bodies, which is the usual way in which we see common objects;-2dly, all microscopic vision may be considered as accomplished under very large angles, which is again a totally new .way of seeing to the uninitiated. The object is in a manner placed in a most unnatural state of proximity to the eye, and consequently assumes a totally different character to that produced by objects at our common visual distance, which must inevitably perplex us till we become habituated to it. There is one general law to which all transparent objects are subjected; namely, that those parts which appear brightest and clearest in them, are almost invariably the thinnest; a want of transparency nearly in every case argues thickness and substance. Much may be done towards their verification by examining sections of them as opaque objects, * where this is practicable; and care should

* Example. - In examining the eye of a libellula, which had been long kept, with the light of a taper behind the stage, I was much surprised to find that its lenses gave ercet images of the candle instead of inverted ones. I 
be taken never to view them both as opaque and transparent bodies at the same time, as this is sure to produce deception, and on this account they should be shaded from all incidental rays. Their true colours can never be seen properly by high powers : in order to ascertain them correctly, a low power should be employed, with the light of the sun reflected by a plaster of Paris disc.

Observers should study the effect of intercepted light on ordinary transparent bodies, of the real nature of which there can be no doubt, in order to be able truly to appreciate microscopic phenomena. There are a number of glass toys made, which will make very good subjects of this description; and so do ordinary glass tubes, and solid rods of glass - the former being filled with. other transparent objects, and afterwards with water. We frequently meet with bodies in transparent objects which operate like lenses on surrounding objects, of which they form miniature images, very remarkable to those who are not aware how the effect is produced.

In short, we must consider, that in all bodies viewed by intercepted light, there is, properly speaking, neither light nor shade, in the ordinary acceptation of these terms; there are only dark and light parts, which again assume new aspects as the light is more or less direct or oblique. Thus depressions on transparent objects are almost sure, under the action of oblique light, to assume the effect of prominences; but prominences seldom or never the sem-

therefore made a section of it, and examined it as an opaque body, and thought that I ascertained in this way that the lenses had become concave instead of convex, from collapse, or from the drying up of the substance between their exterior cases or laminæ. I have attempted to treat lined objects in this way, but could never succeed in developing their mysterious tissue, owing to their extreme minuteness. 
blance of depression. As almost all diaphanous bodies can be examined as opaque objects, a scrutiny of them in this way will generally be found greatly to assist our judgment concerning their nature, whether they admit of being cut into sections or not. It would be easy to write a volume on this subject only, if we commenced an illustration of particulars which could not be rendered clear and satisfactory without a vast number of figures. Long practice must after all determine our opinions, and scepticism should ever form a leading feature in them; we should suspect rather than believe.

18. Opaque objects are not upon the whole so liable to produce optical deceptions as transparent ones, because we are more in the habit of viewing ordinary bodies by reflected or radiated light. The most common illusion presented by them is that of shewing a basso-relievo as an alto-relievo; the reverse deception sometimes occur also, but more rarely. This effect occurs in ordinary objects viewed by the naked eyes, as well as in microscopes, especially if but one eye is employed.* Thus, if we look intently for some time at a basso-relievo (a die of a coin, for example), illuminated with very oblique light, it at first appears in its true character; but, after a little while, some point on which we more particularly direct our gaze will begin to appear in alt, the whole rapidly follows; in a

* The angle formed by the convergence of the two axes of our eyes directed to any particular object, the distance from eye to eye being the base of the triangle, enables us to judge pretty accurately of the distance of near objects ; but, if only one eye is used, of course our measure of distance is gone. Now, as the distance of a depression below or beyond a given plane must always be greater than that of an equal elevation above or within it (cæteris paribus), we are naturally less likely to be deceived when we use both eyes than when one is rendered inactive, as must be the case in all optical instruments not of a binocular construction. 
little time the effect wears off, and we again see it in basrelief; then again in alt; and so on, by successive fits. This deception arises from the simple circumstance that the lights and shades in bas-relief are very nearly like those of an alto-relievo of the same subject, illuminated from the opposite side; our understanding in this case instantly corrects the false testimony of the eye, when we consider from which side the light comes. (If we observe with an engiscope, we must always remember that its image is inverted, and that in consequence the light must be considered as proceeding from the side of the field of view opposite to that where the source of illumination actually exists.) It will also be highly advisable, when we are in doubt as to the manner in which an instrument shews prominences and depressions, to verify its vision by observing some known object with it, of the real state of which, as to inequality of surface, we have been previously informed by the sense of touch, to which it has been well said there is no fellow.*

19. Illumination, by cups or silver specula, does not produce these illusions, because they create no shade-the whole object is one mass of intense light ; other false perceptions are, however, occasioned by them. Thus, all globular bodies, having polished surfaces, reflect an image of the cups, and the pout, if there is one, appears as a dark spot in the centre. The eyes of insects, illuminated in this way, shew the semblance of a pupil in the centre of each lens, which deception may be verified by examining

* We usually see objects illuminated from above with the shadows below the prominences; now, unless the light is below an opaque object, when we view it in an engiscope, we shall see the shadows above, giving the prominences the appearance of depressions, and producing a very unnatural effect. -A. P. 
small globules of mercury in the same manner. Spherical bodies, with bright surfaces, will even, on some occasions, reflect an image of the object-glass and its setting, on the same principle; so that we must perpetually consider the laws of the refraction and reflection of light, in all the conclusions we draw from the evidence even of the very best instruments, used with every possible precaution.

20. Lastly, it must be observed, that in using engiscopes, we must never attempt to verify an object concerning which we are uncertain, by increasing the depth of the eye-glass immoderately, so as in this way to obtain a very high power. A negative eye-glass, of about one-fourth of an inch focus, is the deepest which should ever be employed, even with a short body; for an engiscope only shews a picture of an object, and the more it is amplified the more its imperfections are developed. It is, on this account, much safer to trust to moderate powers in these instruments, in preference to high ones, unless they are $o b$ tained through the medium of the depth and power of their objective part. It is the nature of deep eye-pieces to cause all luminous points to swell out into discs, and to render the image soft, diluted, and nebulous; at length all certain vision fades away, and the imagination is left to its uncontrolled operation. Single and compound magnifiers, having to deal with the real object, may be made of any power which can be used; and if our eyes are strong, and habituated to their use, we may place great reliance on their testimony; but we must never allow them to persuade us to believe marvels which are manifestly impossible, or contrary to the known laws of nature and right reason. 


\section{CHAPTER II.}

An exact Method of appreciating the Quality of Microscopes and Engiscopes, \&c.

BY C. R. GORING, M.D.

Ar the present epoch, it appears absolutely necessary that the public should be put in possession of some exact means of appreciating the excellencies and defects of microscopes and engiscopes. It is true that the proof objects originally discovered by me are sufficient for that purpose in honest hands, and when used with the precautions I have pointed out. But it is well known that they have been shamefully abused, owing to the various facilities of resolution which exist between different specimens of lined objects, the external characters of which closely resemble each other; so that it may be said that these are proof objects, to suit the capacities of all sorts of microscopes; nay, they are actually perverted to the purpose of deceiving the unscientific part of the public in a much more effectual manner than could possibly have been done without them; moreover, the works of superior artists, such as metals of the most exact figures, and aplanatic object-glasses, having their aberrations balanced with the most exquisite nicety, are totally unappreciated by the mass of observers, who nevertheless fancy themselves perfect judges of the merits of all sorts 
of instruments by the help of samples of spurious lined objects.

The art of working metals* and object-glasses is one of extreme delicacy,-I know of no parallel to it; it ought perhaps to be called one of the fine arts, for it ultimately consists in producing, though indirectly, the most exact pictures of objects which the imagination can possibly conceive. No injury, I think, can result to the interest of superior opticians by giving the public the power of perceiving the excellency of their productions. Inferior artists, however, who can produce nothing good, will naturally love darkness rather than light_-and for why?truly, because their works are evil. If the public had no certain means of knowing the exact rate of the going of chronometers, how could the makers of them expect to be remunerated for the better sorts according to their real value? and if a workman is not content to be paid for his instruments according to the quality of them, be it what it may, all that can be said, is, that he must be both a knave and a fool. Very fine optical instruments of all sorts are exceedingly scarce, and ought to be exceedingly valuable, as will be seen hereafter.

I shall now proceed to lay down certain self-evident propositions relative to the metals and object-glasses of engiscopes, which, simple as they are, will be found sufficient to place the reader in possession of a key to the knowledge of what is good and evil in these instruments.

1st. In all object-glasses and metals the main body of the light comes from the periphery, and not from the centre; so that if they are divided into a number of

* This is the technical term for concave speculums. 
annuli of equal breadth, those which are farthest removed from the centre must inevitably, from their greater size, reflect or refract the greatest quantity of light, (see 1, figure 1 , and the rings, $2,3,4,5)$; the outside rays, therefore, are by far the most important, and their condition must be particularly attended to in judging of the merit or demerit of any optical instrument. The inside rays, if taken very near the centre, exhibit no sensible aberration, however bad the object-glass or metal may be, as, for example the little disc in the centre of figure 1, marked 1.

Fig. 1.

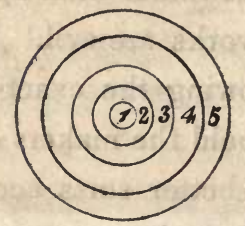

2dly. Every perfect object-glass and metal draws every pencil of light forming the image to a perfect point, see $\mathbf{F}$, figure 2; consequently the rays must be in the same state, and there will be the same degree of brightness and intensity of light, both within and without the focus, at any two given points, as $\mathbf{C}$ and $\mathbf{C}$, equidistant from the focus either way.*

3dly. Imperfect metals and object-glasses have their outside rays either shorter or longer than those which form the principal focus; in which case it is evident that if

* The reader must not suppose that I mean to assert that there is not exactly the same quantity of light at any point taken from the object-glass or metal, \&c. to an infinite distance from it, under every possible circumstance, both of aberration and of freedom from it. What is asserted relates only to the distribution of the rays, or to their state of condensation or diffusion. 
the marginal rays are too short the chief condensation of light will take place within the focus $\mathrm{F}$, figure 3 , at the points $\mathrm{fff}$ : if too long, then without the focus, at the points $f \mathrm{f} f$, figure 4 , beyond the principal focus $F$. With
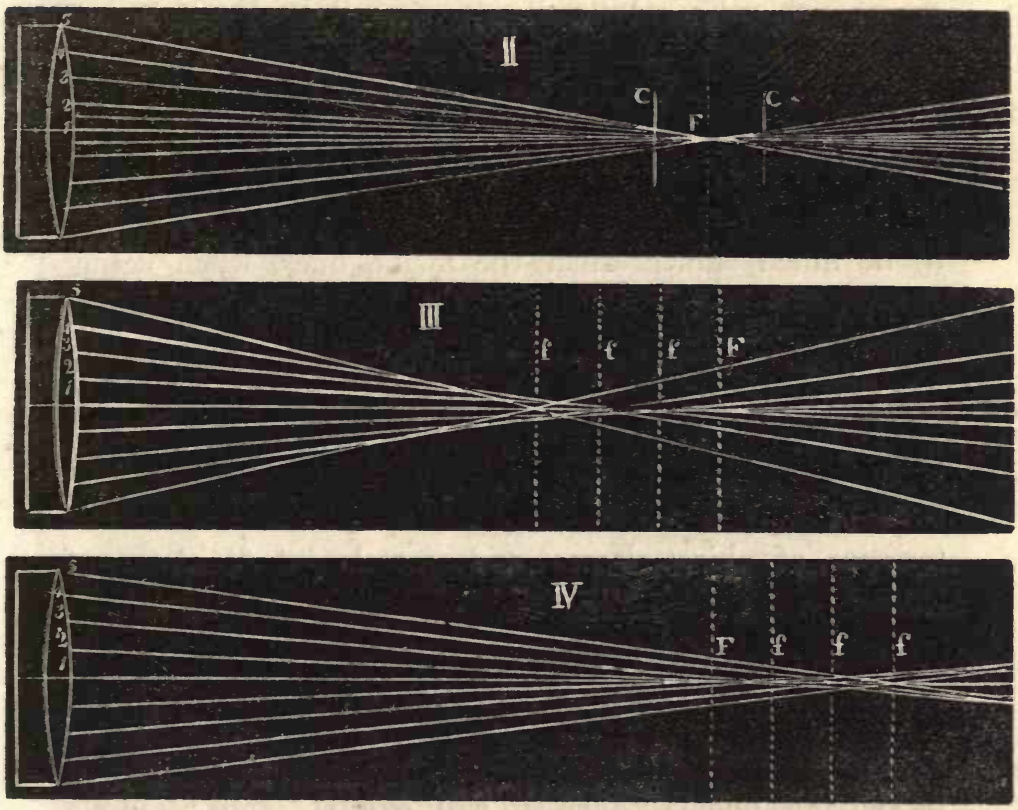

these defects may be associated inequalities produced by irregular working, frequently giving rise to two or more curves in their surfaces.

4thly. Object-glasses are subject to imperfections, arising from an imperfect correction of their chromatic aberration; for example, they may be under or over corrected; that is, the concaves of flint glass applied to them may be either of too shallow or too deep curvature to produce correction, both of which defects are nearly equally inju- 
rious to them ; nor can their colour, strictly speaking, ever be totally subdued, owing to what opticians call the irrationality of the coloured spaces in the prism producing what is termed the secondary spectrum; moreover, their component lenses may be imperfectly centered, and their curves not spherical; and, to crown all, they may be out of adjustment.

5thly. All spherical metals and common convex glasses, may of course be roughly considered as very much under corrected; accordingly their outside rays are well known to be much shorter than the inside ones, when acting either with parallel or diverging light; the colour of the glasses may also be considered as very much under corrected, being, indeed, in its primitive state of dispersion. Now this simple proposition will, in the sequel, conduct us to the knowledge of the discriminating characteristics of object-glasses and metals in all states of correction and aberration; for example, those of an objectglass over corrected both for sphericity and dispersion must inevitably possess exactly opposite characters to one under corrected, while one which is perfect will be neutral in the phenomena which it will exhibit, and resemble neither. In order to discover the state of the rays both within and without the focus, we must of course put the lens, object-glass, or metal, out of focus, and we shall discover the state of the rays both as they advance towards and recede from the focal point. We may confirm this method by using a common lens of large angular aperture, to form an image of the sun, or of a candle, on a piece of rubbed glass, and observing the state of the rays upon it as they approach or pass off from the focal image, when it will be found that the image within 

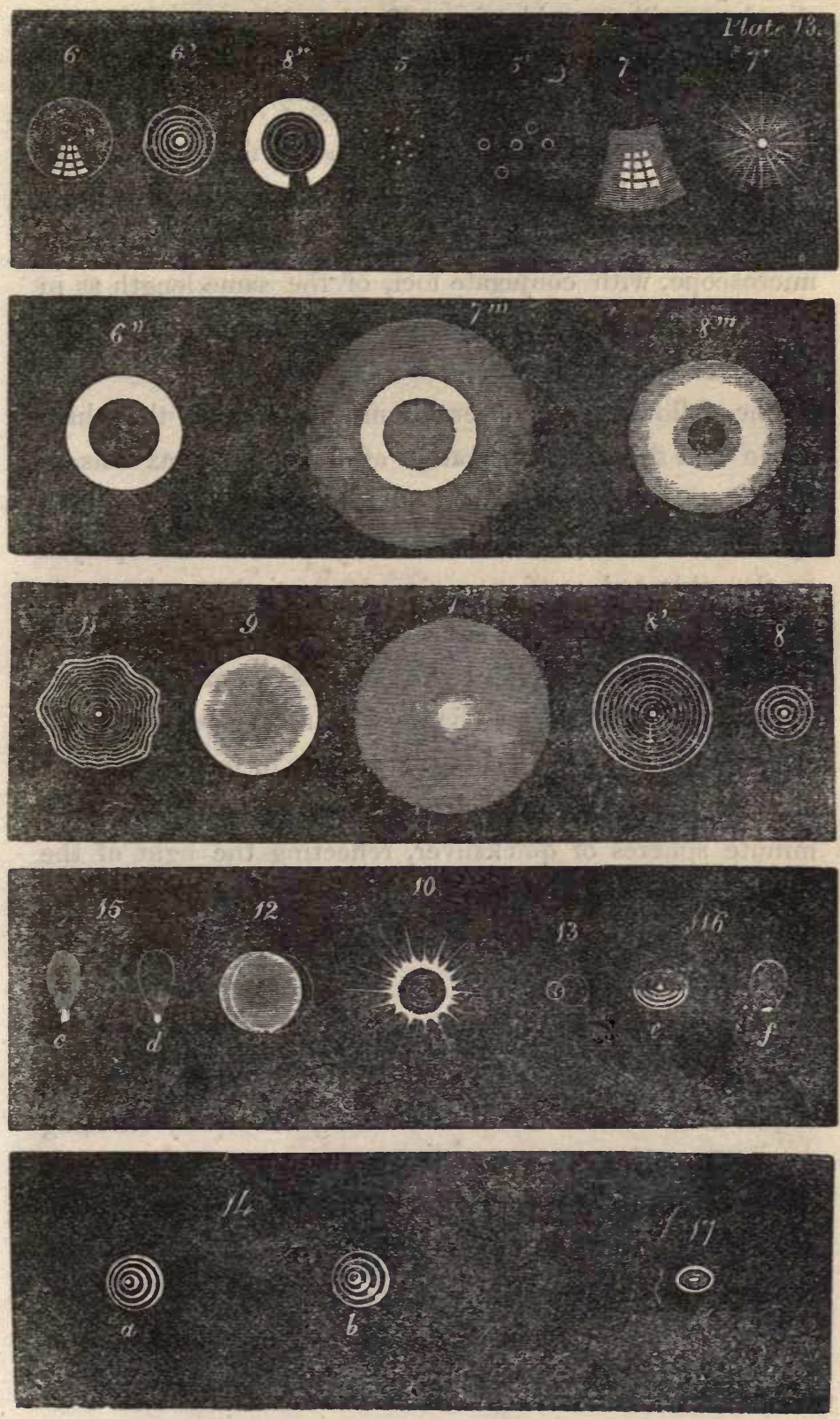
the focus will resemble figure 9 , plate 13 ,* with the addition of a luminous spot in the middle; that without it figure $7^{\prime \prime}$, and the focal one figure $7^{\prime}$. In this case parallel rays are of course employed, and the aberration of the lens will be greater with them than with diverging ones; but the image of a radiant point formed by a solar microscope, with conjugate foci, of the same length as in an engiscope, is a case in point, and will be found to present a very similar result.

The following are observations made upon the chromatic and spherical aberration of a plano-convex lens of nine-tenths of an inch focus and four-tenths of an inch aperture, with its plane side towards the radiant, employed as the object-glass of an engiscope, having an achromatic Huyghenian eye-piece. The objects used were, first a piece of watch-dial plate, with figures enamelled white, upon a black ground, see figure $5^{\prime}$; and secondly, artificial stars formed by crushing a globule of mercury with a piece of iron on a slip of black glass, so as to form very minute spheres of quicksilver, reflecting the light of the sun, a candle, or a window, at the pleasure of the observer, (see figures 5,6 , and $6^{\prime}$.)

\section{SPHERICAL ABERRATION.}

1st. Dial Plate.-There is a strong nebulosity diffusing itself around the borders of the white figures, and extending to a considerable distance from them, so that they are very ill defined, (see figure $7^{\prime \prime \prime}$ ), when put out of focus, the following phenomena present themselves. The prin- 
cipal condensation of light is not at the focal point, but within it; beyond the focus it is evidently much fainter than at the focus ; the field of view is manifestly brighter within the focus than anywhere else. Some still more remarkable peculiarities present themselves to the close observer, as the image vanishes both within and without the focus; - thus the object may be put a certain distance beyond the focus without disappearing, which, however, it ultimately does, enveloped in a strong fog; within the focus it may be said to disappear instantly, but quite in a different manner from what it did beyond the focus, for the white figures swell out at the edges, forming a penumbra, or well-defined border, without any nebulosity about it, (see figure $8^{\prime \prime \prime}$.) It is evident that there is no diffusion of light within the focus, for the black ground of the enamelled plate appears quite black.

On applying Sir D. Brewster's monochromatic lamp, the fringe of prismatic colour, which was mixed up with the foregoing phenomena, disappears, and allows them to be more distinctly seen.

2d. Artificial Star-used with the light of a window.

The appearances exhibited by the dial plate are confirmed, and rendered still more striking, by this brilliant object. In focus there is a strong coma surrounding the miniature image of the window seen in the globule, and extending to a considerable distance from it, so that the outline or figure of the globule cannot be seen (figure 7.) The globule may be put some distance beyond the focus without causing the spectrum of the window to disappear, which it does at last, in a diff used nebulosity, (see figure $7^{\prime \prime}$.) Within the focus the light of the window instantly swells out into a circular disc, the light of which is much more 
intense at the periphery than any where else, (see figures 8 and 9); it decreases as it approaches the centre, where there remains, however, a strong luminous point, (figure 8.) There is no diffusion of light, for the disc is perfectly well defined, and the black ground quite black close to it, continuing so for a long way within the focus.

On applying Sir D. Brewster's monochromatic lamp, the strong annuli of colour confounded with the spherical aberration, disappear, and leave a yellow disc; a new phenomenon now becomes visible, before hidden by the chromatic aberration, viz. the appearance of an infinite number of concentric annuli in the disc of light formed by the globule (figure 8 ); they are perfectly regular, and increase in brightness as they spread away from the centrical point of light.

On examining the aforesaid objects, in and out of focus, with a spherical metal of the same focus and aperture (used without a plane mirror, by merely placing the dial-plate and star in its focus), the same phenomena, as to spherical aberration, are seen much more distinctly, because, in this case, there is no chromatic confounded with it ; the aberration is, however, evidently far fainter. The spherical aberration of metals follows the same law as that of objectglasses, and is represented in figures 3,4 ; when too spherical, they have the condensation described within their focus ; but when too flat at the edges, or beyond their true figure (which is an ellipsis for the engiscope)-for example, supposing them to have become parabolical, hyperbolical, or ultra hyperbolical-then their outside rays will become too long; they may be considered as over corrected, and in this state present the same phenomena as an over corrected object-glass; that is, the principal strength and in- 
tensity of the light will be beyond the focus, and the diffusion will take place within it, as represented in figure 4. The indications of over correction will be more particularly dwelt upon hereafter. On cutting off the aperture of the nine-tenths plano-convex lens to three-fortieths of an inch the spherical aberration becomes insensible, unless the light of the sun is used, and the distinctness as perfect as the want of light will permit.

We may now obtain from it the characteristics of an object-glass of very small aperture, free from spherical error, which are as follow:-There is the same strength and intensity of light within and without the focus evinced both by its action on the dial-plate and on the artificial star. There is no diffusion of light either within or without the radiant point; the objects are perfectly well-defined without coma or nebulosity (see figures $6,6^{\prime}, 6^{\prime \prime}$ ) when in focus, and vanish, exhibiting alike a penumbra in the case of the dial-plate (figure $8^{\prime \prime \prime}$ ), and a circular disc (figure 9) in that of the artificial star when put out of focus either way.

\section{CHROMATIC ABERRATION}

Can never be seen in perfection until it is fairly separated from spherical. It is amusing to see how the two kinds of aberration mutually keep each other in countenance.

The same nine-tenths plano-convex lens, already described with the same aperture, is used in the following observations on the aberration of colour or refrangibility; the object is a rather large globule of quicksilver, and the illumination that of a southern window on a bright day (figure 6.) 
In focus.-The image of the window is seen tinged with orange light, which is encircled with a diffused disc, of a greenish yellow, extending to some distance from it. This halo is surrounded by a margin of a brighter and stronger green, which is succeeded by a blue, indigo, and purple annulet, gradually melting into each other, as in the prism, beyond which the black ground on which the globule of quicksilver was placed, becomes visible.

Phenomena beyond the focal point.-These may be rendered sufficiently intelligible by observing that on putting the globule beyond the focus, the colours already enumerated are still visible in the same order and arrangement as before, but fainter, because the discs or halos gradually swell out and become spread over a larger surface, and at length totally disappear in nebulosity.

Appearances within the focus.-On bringing the globule a little within the focus, the warm colours instantly present themselves; thus the image of the window is now of a bluish tint, and around it is a disc of bright yellow, succeeded by an annulet of orange, passing into one of strong crimson, which is again surrounded by nearly the same colours before described as visible at the focal point, viz. borders of bright green, blue, indigo, and purple, blended gradually together. If, however, the globule is brought considerably within the focus, then the following change takes place; the image of the window disappears altogether; in lieu of it is seen a central disc of purple, gradually shaded off into bright blue, which is contained within borders of colour, in the following order-green, yellow, orange, and red, which continue in the same state for a long way within the focus, until they disappear altogether. By cutting off the aperture to three-fortieths of an inch, 
the colour becomes insensible, unless the globule is illuminated by the light of the sun. The same phenomena are more faintly exhibited by a dial-plate, treated in the same manner as the globule, and indeed by all objects, more or less.

As it would be exceedingly difficult to give an exact pictorial representation of the phenomena of chromatic aberration, it has not been attempted.-The spherical and chromatic aberration of all single and compound magnifiers may be tried in the methods already pointed out, by merely looking through them at an artificial star or dial-plate, \&c., provided always that their focus is not so short as to preclude the illumination of the objects in the manner indicated, and that there is room to put an object sufficiently within their focus to cause the phenomena I have detailed to exhibit themselves. But this is an operation of extreme delicacy, and requires the sharpest and most practised eye to attain any certainty as to the result.

We thus obtain the characteristics of uncorrected and under-corrected object-glasses and lenses both with regard to spherical and chromatic aberration, and moreover those which denote the absence of both, constituting a state of aplanatism and achromatism.-What we now want to know are the distinguishing marks of objectives and lenses when over corrected both for sphericity and refrangibility, for this state must inevitably often occur, as it is quite as easy to cause the application of a correcting concave lens of flint glass to operate too strongly as too weakly, and exceedingly difficult to make it exactly neutralize the errors of one or more convex lens, without falling short of or surpassing the true mean.

First, then, with regard to spherical aberration, it must 
be evident, by a bare inspection of figure 4 , that, in the case of over correction for sphericity, the conditions before stated relative to an uncorrected lens or object-glass must be more or less reversed; that, as the main body of the light will be thrown beyond the focus $(F)$, where there will be no diffusion of light, as at the points ( $f f f$ ), but a certain diffusion within the point $F$, or principal focus; as it is known to be very easy to ascertain both the figure and focus of a concave of flint glass requisite to over correct a given convex of crown or plate, this method has been resorted to in order to procure data as to the phenomena which it will produce when in combination with a convex too weak for it, which are as follows :-First, there is a diffused nebulosity at the focus, (see plate 13, figure $\tau^{\prime \prime \prime}$, dial-plate); (figure 7 , image of a window in a globule of mercury); figure $7^{\prime}$, ditto, with the image of the sun), but not so extensive as in the case of the uncorrected lens; figures $8^{\prime}$ and $8^{\prime \prime \prime}$ now represent the appearances beyond the focus, and figure 10 those within it, consisting of a strong burr, with annuli in the centre, which are but barely visible in a small globule on a bright day, and not to be recognized at all in a large one in dull weather; all fully confirming the testimony of figure 4. The indications caused by over correction, for colour; will be rendered evident, by a consideration of the fact, that, if a prism of flint glass is made so powerful as completely to get the better of another of crown or plate applied to it, so that their refracting angles shall be opposed to each other, the dispersion of the flint one will alone be perceptible, and the colours will in consequence be refracted in the contrary order to that in which they would have appeared had the prism of plate or crown an equal mastery over the flint one. 
As the analogy between prisms and lenses is nearly perfect as to refrangibility, we may therefore assume that the same phenomena will be presented by lenses under similar circumstances, and the order of the colours already described will therefore be reversed within and without the focus, in cases where over correction has occurred; and this fact may be very easily verified, like that relative to spherical aberration, by applying a concave of such a focus and specific gravity to a convex as we know must infallibly prove an over-match for it; therefore we have only to repeat that the phenomena already stated under the head of chromatic aberration will apply more or less to all states of over correction, by reversing the appearances stated to exist in an. ordinary lens within and without the focus; that is, the warm colouring will be found beyond the focus, the cold tints within it; red, orange, and yellow, without; blue, indigo, and purple, within; \&c. As to achromatism, it must always speak for itself, being an absence of all colour (save that of the secondary spectrum, which is imperceptible in small object-glasses), both at the focus and within and without it.

\section{MISCELLANEOUS DEFECTS OF OBJECT-GLASSES AND} MFTALS, \&c.

These chiefly consist of inequalities produced by bad working and bad adjustment, all of which may be looked into by putting them out of focus. Thus fig. 11, plate 13, represents the appearance presented by a metal or objectglass, the figure of which has not been properly preserved in the working, though perhaps the spherical aberration may be but trifling. If we take an example of a metal, 
we shall suppose that its figure has been truly generated by the revolution of some conic section, but that it has afterwards been rendered unequal in different places, either in the polishing, from being kept too long on the tool, or made so on purpose, by abrading its surface in different places. In this case the contour of the disc is irregular, and the annuli correspond with it, but generally become truer as they approach the lucid point at the centre. But the reader must recollect, that, when a metal operates along with another, there will be a shadow of the small one, and its arm projected on the disc, as at figure $8^{\prime \prime}$, which represents the appearance of the Amician reflecting engiscope, shewing an artificial star out of focus : the same observation will apply to all discs generated by reflecting instruments.

By observing what part of the metal it is necessary to cover, in order to obliterate the image of some irregular part of it, the identical portion of its surface which is in fault may be discovered and amended.

These irregularities are chiefly observable in objectglasses and metals of small angles of aperture. It would be useless to specify all the varieties of error which may occur; but an oval disc is perhaps the most common.

Sometimes, in the process of working, two or more curves are generated in place of one, or it may be several curves of the same figure and focus which do not bear upon one focal point; in this case, the metal or objectglass shews two or more discs, which do not lap over each other, as at figure 12, and in this way give a false contour, but which may always be discriminated from figure 11 , by observing the direction of the annuli, and the outline of the overlapping discs. 
The figure of concave lenses may be tried upon the same principle as metals, for they will reflect enough light from a real or artificial star to allow us to judge of the nature of their curves. When a plain metal operates along with a concave one, as in the case of the Amician reflecting engiscope, an irregularity in the outline or contour of a disc out of focus is sometimes generated by an imperfection in the surface of the former, which may be known by trying the concave on a lucid point by itself, when, if the plain one only is in fault, of course the irregularity of the disc will disappear. The state of a plane reflecting surface as to exactitude may be known by observing the manner in which it reflects the image of some regular-shaped body (a right line is as good as anything), placed at a distance from it, the eye being also considerably removed from the metal; and still better by adjusting very exactly the focus of a telescope upon some distant body, and then reflecting an image of it by means of the plane metal to be tried (which is to be placed at some distance from the telescope), and viewing the same object again in the telescope, when, if the plane metal is perfect in point of figure, no difference of adjustment will be required to produce distinctness.

\section{IMPERFECTIONS IN CONCAVES OF FLINT GLASS, \&c.}

These rarely occur in the small lenses used for the objectglasses of engiscopes; they may be seen when they exist, by adjusting the instrument upon some lucid point, and then removing the eye-piece and looking at the objectglass with the naked eye, when the striæ in it will become 
manifest; also by holding it up and causing it to form an image of a candle, so close to the eye that the whole disc of the lens shall appear illuminated, which will be when the image of the candle falls on the cornea; defects of polish and impurities, and seediness, \&c. in the cement uniting glasses, will become evident by holding the lens so that the light of a candle shall fall obliquely upon it, and may be farther verified by examining it as a microscopic object.

A flat piece of flint glass may be examined by looking through it in the direction of its thickness, also by cementing a plano-convex lens of plate glass to it, so as to give it the power of refraction, as if the whole was a solid objectglass, and treating it accordingly.

\section{POLARIZATION OF GEMS AND JEWELLED MICROSCOPES.}

The polarization of precious stones may be seen by working a small portion of them flat, to which a small aperture may be cemented, through which a candle must be viewed in a dark room; when, if there is no polarization, but one image will be visible; but more than one, if it exists. A plano-convex lens may also be cemented to a plate formed from a precious stone, and the effect tried in this way, on a bat's or mouse's hair, which will present several images, if double refraction is present; or the whole may be made to form a miniature image of a candle, as the object-glass of a little telescope, which will give only one image of the taper, if the refraction is single. A plate of gem may moreover be tried as to polarization, by placing it between two tourmalines, which will be sure to 
exhibit the two or more polarizing axes, where they exist, as spots of light, surrounded by halos, \&c.

The polarization of lenses of gem may always be seen, by trying them on a bat's or mouse's hair, which will be sure to give more than one image, where it exists ; crystallizations and flaws are best seen by examining them as microscopic objects with oblique candle-light; they moreover produce a muddiness in the vision of all objects, but are not necessarily associated with polarization.

\section{CENTERING OF LENSES.}

The centering of a lens may be suspected of inaccuracy when it is impossible to bring an object-glass into which it enters as a constituent part into adjustment, (supposing that there is no fault in the turning of its setting); in which case its component annuli will not be concentric with each other, nor will the lucid point at the centre of the disc be truly in the middle of it, but give an appearance as at $a, 14$. Convex lenses are seldom ill-centered, but concaves frequently are. The former, in this state, have not their maximum of thickness-nor the latter their's of thinness at the centre.

\section{ADJUSTMENT OF OBJECT-GLASSES AND METALS.}

Bad centering may be confounded with, or mistaken for, bad adjustment, and vice versa. When an objectglass is out of adjustment, its component lenses are not so posited in their setting that their axes shall be in one right line, which must moreover coincide with the axis of the 
tube in which they are fixed. This defect is easily known, by observing the position of the luminous point in the centre of the discs they generate, which, if perfectly centrical, indicates perfect adjustment, while the degree of its eccentricity denotes the magnitude of the error in this particular : thus, (13) shews the phenomenon presented by a triple object-glass thrown violently out of adjustment ; and $(b, 14)$, another disc, of a similar description, but more out of focus. In observing for adjustment, it is especially necessary that the object employed should be placed exactly in the centre of the field of view, for it is impossible that an object-glass can be rigorously adjusted for more than one pencil. This may be either a direct or an oblique one, as we please; but it is impracticable to make a perfect adjustment for one pencil consist with a perfect adjustment of another; for whatever part of the field of view the adjustment has been effected, there the maximum of distinctness will be found. The state of adjustment may moreover be determined upon by using the rings $5^{\prime}$ on a dial-plate; if it is perfect, it will be well represented by $8^{\prime \prime \prime}$, where the penumbra goes off equally on all sides of the ring alike, leaving a dark centrical spot, and a true circular figure at the margins. The adjustment of metals with each other is denoted by precisely the same phenomena as that of object-glasses, always allowing for the effect of the shadow of the small metal and its arm.

N.B. The indications given by large globules of quicksilver frequently differ widely from those given by small ones, in all respects. We may term a globule large when it is visible to the naked eye, as at (5); small, when it is not. Thus, a large globule, giving an image of a window in focus, will, when put out, present only a disc, like (9), 
without annuli, growing gradually brighter towards its periphery, while a small one will give only a disc, as at $\left(6^{\prime}\right)$, in focus, and exhibit annuli and a centrical spot out of focus, as at (8) ; (9) will perhaps shew no difference of aspect, when put out of focus, either way, with some particular object-glass or metal, but (8) instantly will. The large globules are best to exhibit chromatic aberration, but for every other purpose it may be laid down as a maxim, that small globules, strongly illuminated, and put but very little out of focus, are most to be depended upon. Thus, an instrument will appear to be in perfect adjustment, if a globule is put a good way out of focus, but far from it if only very little.

There is sometimes a discrepancy between the evidence given by a dial-plate and an artificial star; an instrument will appear quite perfect, and destitute of aberration, when tried only by a dial-plate, but considerably in error when submitted to the ordeal of an artificial star. I believe, in such a case, it may be considered that it is perfect for all practical purposes, if it shews the dial-plate in a proper manner in and out of focus; for aberration and all other imperfection must be considered as of a relative nature. For example, an instrument may be said to aberrate when applied to some intensely luminous point; but not so when viewing an object of the ordinary degree of brightness; or it may aberrate with an opaque, but not with a diaphanous body; artificial stars must therefore rather be considered as a theoretical than practical test of the goodness of an instrument, which must always be considered as made not for viewing these fastidious niceties, but the ordinary run of natural objects. Telescopes have been made which have shewn stars, both natural and artificial, 
in the most exquisite manner, while their performance on the planets and other objects has been very indifferent, and by no means equal to that of other instruments of the same class, which failed in exhibiting stars in a satisfactory manner. Engiscopes are certainly to be met with which leave nothing to be wished for or desired in their performance on natural objects, which nevertheless show much imperfection in their operation on luminous points. We must never forget, that as man is an imperfect being himself, so all his works partake of the imperfection of his organization; that, in short, absolute perfection of any kind is a chimera.

I state it as the result of my own experience, that where instruments are not aplanatic, it is best for them to be a little under-corrected for spherical aberration; and, when not achromatic, they are most to my taste when overcorrected for colour.

\section{DEFECTS OF EYE-GLASSES.}

The state of these as to achromatism may be determined by trying them along with an object-glass previously known to be achromatic; when, if any colour appears, it is of course to be attributed to the eye-glass. When tried along with metallic objectives, the achromatism of an Huyghenian eye-piece should be absolute and perfect; as much so, in short, as if the vision was entirely accomplished by reflection. The imperfections of eye-glasses, such as seediness, bubbles, black specks, and the like, when visible to the eye in looking through them, will always revolve along with the revolution of the eye-piece, 
just as those arising from an object-glass will travel when it is turned round. By this rule the imperfections of the one may be distinguished from those of the other. In the vision of luminous points an eye-glass of a crystallized structure will often give an appearance of several points of light which do not exist; these, however, will always move as the eye-glass is turned about. Defects in the polish of eye-glasses may be tried by looking at them by oblique candle-light.

An inverting eye-piece cannot be made of more than two glasses, without causing a dimness or muddiness in the vision of opaque objects, and other deceptions, still more disagreeable, with diaphanous bodies: the first of these is a luminous spot in the centre of the field of view, which seems to be an image of the object-glass produced by reflection from the numerous surfaces. This is most perceptible when an object is placed in the centre of the field of view, which only partially fills it, and happens at the same time not to be very transparent in the middle. When a candle is placed behind the stage, an image of it may generally be seen in the axis of an engiscope, having an eye-piece consisting of more than two glasses, and not unfrequently a miniature image of the object viewed, if we look a little obliquely into the instrument. If an engiscope, with a triple or quadruple eye-glass, is made to form the image of a solar microscope, the aforesaid phenomena are rendered very striking, from the intensity of the illumination; but they are not very perceptible when daylight only is employed, and we merely look through the instrument.

Complicated eye-glasses, for the purpose of enlarging the field of view, will, I think, almost invariably be found 
to do more harm than good, and should be rejected on the same grounds, or nearly so, in engiscopes as in telescopes.

The juste milieu is the double eye-glass. The defects of eye-glasses as to the state of their oblique pencils, may be tried by a micrometer, or ivory scale; but recollect that you must not confound the aberration of the oblique pencils of the object-glass with those of the eye-piece, for the former are irremediable, or nearly so, by the latter. On this account it will be most advisable to use some objectglass which has the aberration of its oblique and centrical pencils nearly in the same state over the whole image, such as a grooved sphere, with which a pretty accurate estimation may be formed of the quantity of error produced by the edges of an eye-glass.

Positive achromatic eye-glasses for micrometrical measurements, composed of two double achromatics, may be examined as to their state of effectiveness by the rules already laid down for trying ordinary single and compound magnifiers.

\section{ABERRATION OF OBLIQUE PENCILS OF RAYS.}

The spherical aberration of the oblique pencils in double achromatic object-glasses is very violent when their angle of aperture is considerable; (15, plate 13), represents the burr produced by a globule of quicksilver in one of an inch focus, and a quarter of an inch of aperture, $c$ being the effect of a large, and $d$ that of a small globule placed near the edge of the field of view, and seen in focus ; (16) $e$ and $f$ represent the appearances out of focus, $e$ being that where the greatest condensation of light is found; 
while (17) shews the contrast of the pencil of a triple object-glass of nine-tenths of an inch focus, also of a quarter of an inch of aperture.

METHOD OF FINDING THE DOUBLE APLANATIC FOCI OF OBJECT-GLASSES HAVING THEIR INTERNAL CURVES IN CONTACT.

For the discovery of these, it will be advisable to have an engiscope constructed with a pull-out tube capable of considerable contraction and elongation; the rules already laid down will suffice for their detection, with the help of some extracts from the valuable paper of Mr. Lister in the Phil. Trans. for 1830, p. 187. Mr. L. says, p. 195, " in general an achromatic object-glass, of which the inner surfaces are in contact, or nearly so, will have on one side of it two foci in its axis, for the rays proceeding from which it will be truly corrected at a moderate aperture; that for the space between these two points its spherical aberration will be over corrected, and beyond them either way under corrected." Again, p. 196, "the longer aplanatic focus may be found when one of the plano-convex object-glasses is placed in a microscope, by shortening the tube, if the glass shews over correction; if under correction, by lengthening it, or by bringing the rays together, should they be parallel or divergent, by a very small good telescope.

"The shorter focus may be got at by sliding the glass before another of sufficient length and large aperture that is finely corrected, and bringing it forwards till it gives the reflection of a bright point from a globule of quicksilver sharp and free from mist, when the distance can be taken between the glass and the object. 
"The longer focus is the place at which to ascertain the utmost aperture that may be given to the glass, and where in the absence of spherical error its exact state of correction as to colour is seen most distinctly."

P. 197. "One other property of the double object-glass remains to be mentioned, which is, that when the longer aplanatic focus is used, the marginal rays of a pencil not coincident with the axis of the glass are distorted," ( $c$ and $d, 15$, plate 13,) "so that a coma is thrown outwards, while the contrary effect of a coma directed towards the centre of the field is produced by the rays from the shorter focus. These peculiarities of the coma seems inseparable attendants on the two foci, and are as conspicuous in the achromatic meniscus as in the plano-convex object-glass."

In the original paper will be found a number of curious particulars, which the reader cannot be too strongly recommended to consult.

METHOD OF MEASURING THE ANGLE OF APERTURE OF OBJECT-GLASSES, METALS, AND LENSES.

We have already seen that all object-glasses and lenses may have their outside rays cut off, and their apertures restricted, until they shew no sensible aberration, however bad their figures and quality may be; it therefore becomes of the last importance that we should know what aperture they really have, since that is the measure of their value and effectiveness when associated with aplanatism and achromatism. The apertures of lenses and object-glasses, used for microscopic purposes, must of course be determined by the size of the pencil of light they admit, since they operate on diverging rays; that is, we must measure 
the angle formed by the margin or edge of their acting aperture with the acting focal point.

There are a variety of methods of effecting this object thus, if we know the acting focus and the acting aperture, we have only to make a diagram on paper of them (which should be on a magnified scale for greater exactness), and measure the angle with a protractor. In general, it will perhaps be most advisable to calculate the angle of aperture for parallel rays, (and for magnifiers this method is the only correct one.) In this case the angle will always be a fixed one, whereas if it is taken for diverging rays, every alteration in the length of the body of the engiscope will cause some trifling alteration in the length of the anterior conjugate focus, so that the angle of aperture will always be less with a short than with a long body.

A very material point to be predetermined in this mode of measurement is the real focus of the lens, \&c. to be measured; and as few persons know precisely how to settle this in an effective practical way, the following method is given as pretty exact :-A triple object-glass must be procured, having a focus of some length, which may therefore be very exactly measured (reckoning from the middle of its thickness): it will be most convenient if its focus will come out in a round number, say twenty or thirty inches. The lens, whose focus we want to know, is to be applied to it as an eye-piece, and adjusted for distinct vision on a star, then with a good dynameter measure the power, which we will say turns out to be twenty, with a twenty-inch object glass.

It follows, therefore, that the focus of the eye-glass must be one inch.-N.B. If this method is too troublesome, get an optician to measure some particular lens for you. 
Having once got a lens whose focus we know for certain, that of all others may be easily obtained by converting them into the object-glasses of an engiscope, having a micrometer in its eye-piece, and measuring with them the size of the image of a division on another micrometer placed on the stage, which, if twice as large as that given by the inch lens, denotes a focus twice as long; if only half the size, one of half the length; if one-tenth, onetenth of the length, \&c.

Great care must be taken in these measurements to preserve the same length of body exactly with all the different lenses whose foci are to be measured; and the apertures must always be reckoned from the side of the lens next the eye-piece, taking care that it is not altered by the effect of stops in the body.

The following table serves to shew the angle of aperture of metals and object-glasses whose apertures bear the following proportions to their foci: the measurements were executed with a metal, in order that the thickness of glass lenses might not operate to occasion uncertainty and variation.

\begin{tabular}{|c|c|}
\hline $\begin{array}{c}\text { Aperture expressed in Terms of the } \\
\text { Focus for parallel Rays. }\end{array}$ & Angle of Aperture. \\
\hline$\frac{1}{10}$ & Degrees. \\
\hline$\frac{1}{8}$ & $5 \frac{1}{2}$ \\
$\frac{1}{4}$ & $6 \frac{1}{2}$ \\
$\frac{1}{3}$ & $13 \frac{3}{4}$ \\
$\frac{1}{2}$ & $18 \frac{1}{3}$ \\
$\frac{2}{3}$ & $27 \frac{1}{2}$ \\
$\frac{3}{4}$ & $36 \frac{2}{3}$ \\
1 & $41 \frac{1}{4}$ \\
& 55 \\
\hline
\end{tabular}


The angle of aperture of an object-glass is very difficult to be exactly found, on account of its thickness, and still more so, if several are combined together, by the methods already given; but Mr. Lister has discovered a very exact and satisfactory method of doing this, which he has given in the paper already alluded to, p. 191. The principle of it may be seen in figure 18. B represents the object-glass of an engiscope placed in a horizontal position, and C F its axis, directed so far on one side of a candle A, placed at a few yards distant, that the light of it shall bisect the field of view vertically, leaving half of it dark : then C being the focus of the object-glass, is to form a pivot, round

Fig. 18.

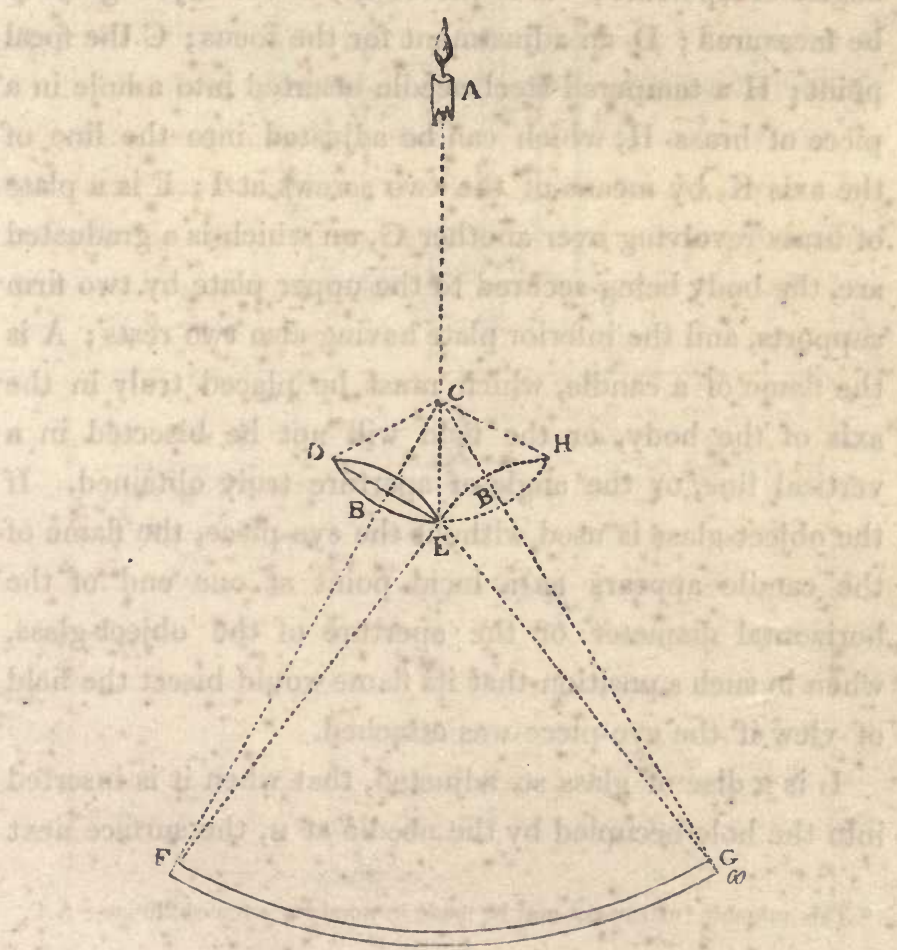


which the body is to revolve horizontally to the other side of the candle till the opposite half of the field is illuminated as before, and the object-glass has arrived at the position denoted by the dotted lines $B$, and the axis of the body into the line $\mathrm{C} \mathrm{G}$. The space travelled over by the body from $F$ to $G$ is the angle of aperture; in the present case equal to $60^{\circ}$, for it is evident by construction that the angles D C E and E C $\mathbf{H}$ are equal to the angle F C G made equal to $60^{\circ}$.

DESCRIPTION OF AN INSTRUMENT FOR MEASURING ANGLES OF APERTURE.

Figure 20 represents an elevation of an instrument for angles of aperture ;* $\mathrm{E}$ is the body ; $\mathrm{B}$ the object-glass to be measured; D an adjustment for the focus; $\mathbf{C}$ the focal point; $\mathrm{H}$ a tempered steel needle inserted into a hole in a piece of brass $\mathrm{H}$, which can be adjusted into the line of the axis $K$, by means of the two screws at $I ; F$ is a plate of brass revolving over another $\mathbf{G}$, on which is a graduated arc, the body being secured to the upper plate by two firm supports, and the inferior plate having also two rests; $\mathrm{A}$ is the flame of a candle, which must be placed truly in the axis of the body, or the field will not be bisected in a vertical line, or the angle of aperture truly obtained. If the object-glass is used without the eye-piece, the flame of the candle appears as a lucid point at one end of the horizontal diameter of the aperture of the object-glass, when in such a position that its flame would bisect the field of view if the eye-piece was attached.

$\mathrm{L}$ is a disc of glass so adjusted, that when it is inserted into the hole occupied by the needle at $\mathrm{H}$, the surface next

\footnotetext{
* This valuable instrument may be made in wood for a few shillings.-A.P.
} 
to the object-glass shall be exactly in the plane of the focus ; on this the scales of butterflies, \&c.may be placed,

Fig. 20.
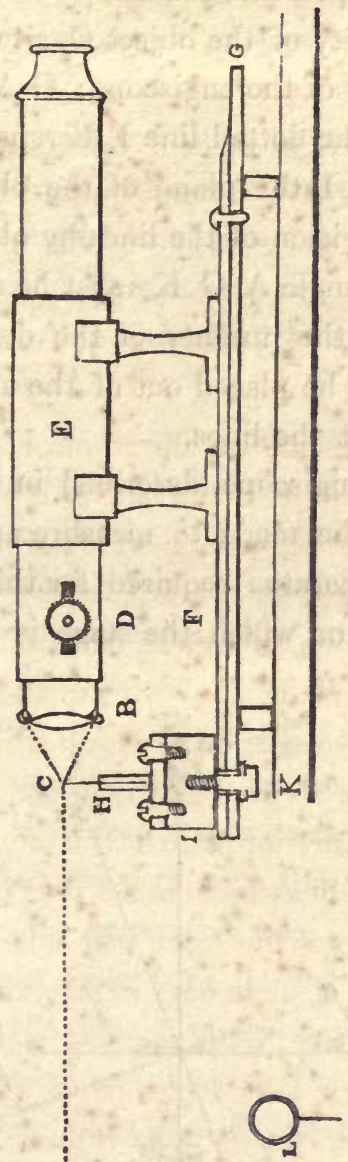
and the angle of deviation from direct incidence in the illumination (supposed to be the flame of a candle), found requisite to shew their lines most perfectly measured : thus, in figure $19, \mathrm{~A}$, represents the flame of the candle behind the stage, or locality of the object $\mathrm{C}$, situated in the plane D E; B the body of the engiscope; G A its axis adjusted for direct light; the dotted line $\mathbf{F} \mathrm{K}$ represents the axis of the body; and $\mathrm{H}$ I the plane of the object adjusted for the most perfect vision of the lines by oblique light. It is evident that the angle A C K must be equal to the angle F C G, which is the number of the degrees the axis of the engiscope will be placed out of the axis of direct light in order to exhibit the lines.

My aplanatic engiscope, described in chapter 9 of this work, may easily be made to measure angles of aperture. All the extra apparatus required for this purpose will be to cause the pin on which the stage is fixed to be truly

Fig. 19.

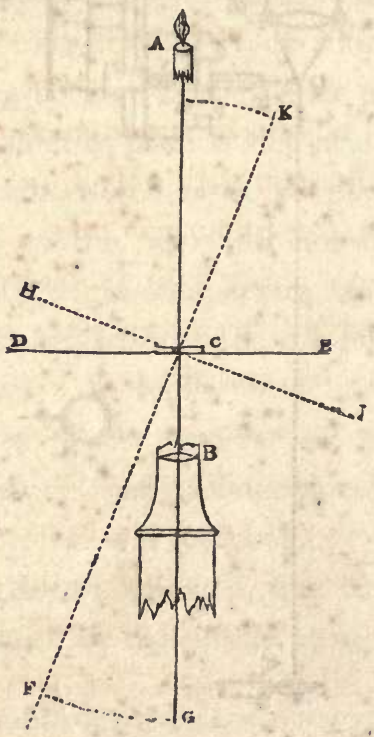


drilled, so as to receive the tempered steel pin, which will thus be in the line of the axis of the ball and socket, which will also be in that of the pillar, when the body is truly horizontal. The milled head, which lets down to steady the legs, must be removed, and in its place a piece of brass, armed with a point, screwed on, to mark the apex of the angle on a piece of paper placed under the instrument; the angle of aperture is then measured upon the same principle as in the instrument already described, by attaching the diagonal camera lucida to the eye-piece, and marking the legs of the angle on the paper to be afterwards measured with a protractor.

The method here given for appreciating the quality of microscopes applies also to all erecting eye-pieces having an external focus in front of the bottom glass, such eyepieces being in fact neither more nor less than compound microscopes, or engiscopes. I have called it exact, and prodigiously exact it must be, for it is quite capable of rectifying some of our modern optical theorists. No working optician can finish an instrument unless he is acquainted with it, and it will be seen whether erecting eye-pieces, \&c. can be made achromatic with only three lenses; whether their compensation for colour can take place any how, and whether it must not exist both in that part which forms the image, and in that which views it, to produce achromatism on the whole; and whether their spherical aberration can be reduced so low with the naked aperture of the bottom glasses as analysis would lead us to believe. If the curves of an object-glass are calculated falsely, and give an excess of aberration either to the concave or convex lenses, it will be instantly detected.-For details on Eye-pieces, see "Micrographia," Chapter 6. 
Just Published, Price Five Shillings,

\section{NOTES ON NATURAL HISTORY,}

\section{SERCTED FaOX}

"THE MICROSCOPIC CABINET;"

Illustrated by Ten Coloured Engravings.

BY ANDREW PRITCHARD, M.R.I.

Axso,

By the same Author, Price Five Shillings,

A

\section{GENERAL HISTORY OF ANIMALCULES,}

Illustrated by Five Hundred Engraved Figures.

Axso,

Price Thirty Shillings Coloured, and Twelve Shillings Uncoloured,

\section{A HISTORY $0 \mathrm{~F}$ INFUSORIA, LIVING AND FOSSIL.}

Note-This is the only complete Manual on this interesting branch of Natural History. It contains descriptions of all the known species, including those given in Dr. Ehrenberg's great work.

Anso,

Price Seven Shillings and Sixpence,

A LIST

or

\section{ALL THE PATENTS FOR INVENTIONS}

In the Arts, Chemistry, Manufactures, and Agriculture, from 1800 to 1840 , inclusire.

SLso,

Price Half-a-Crown for each Year,

E N G L I S H $\quad$ P A T E N T S

For 1841, 1842, and 1843.

LONDON :

WHITTAKER AND CO., AVE MARIA LANE. 



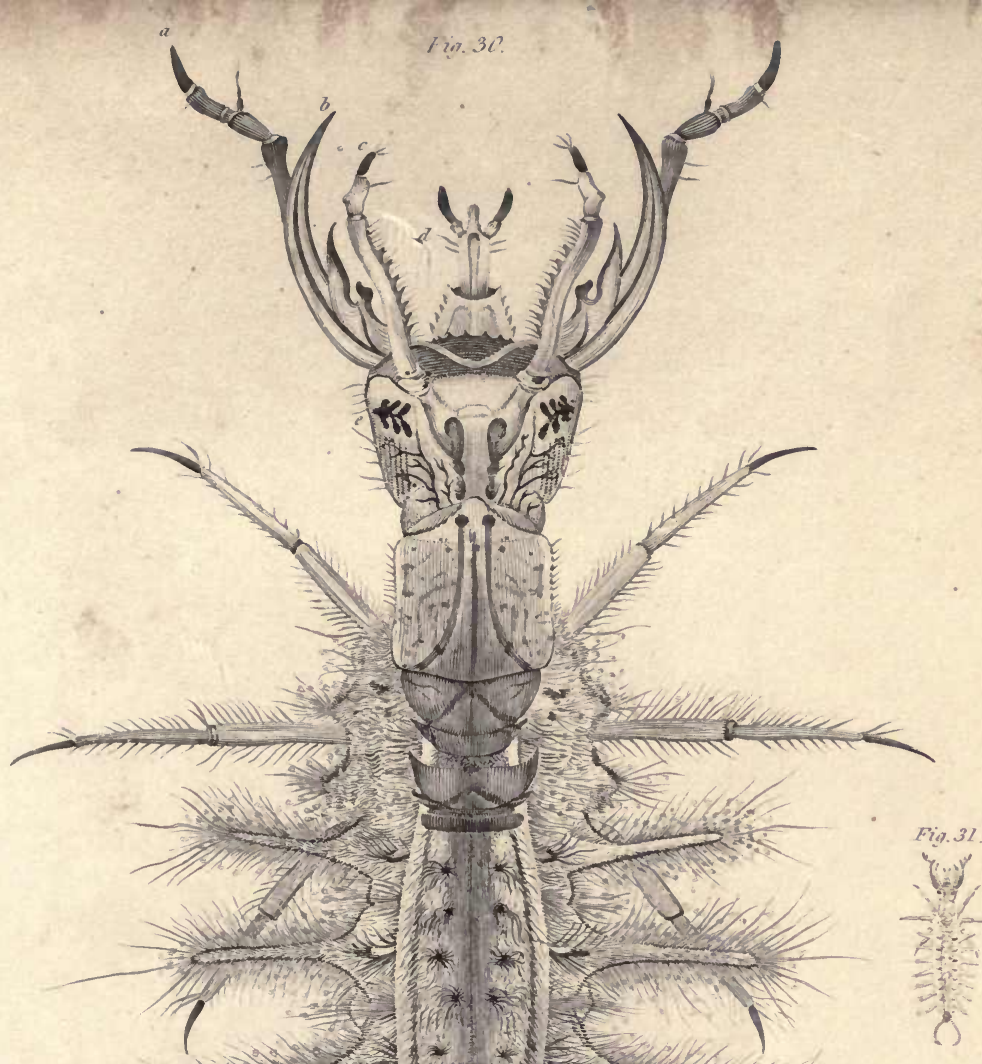

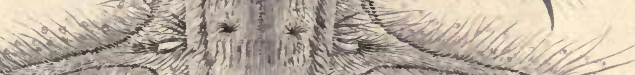

Fin. 31

(6)

s.t.

()

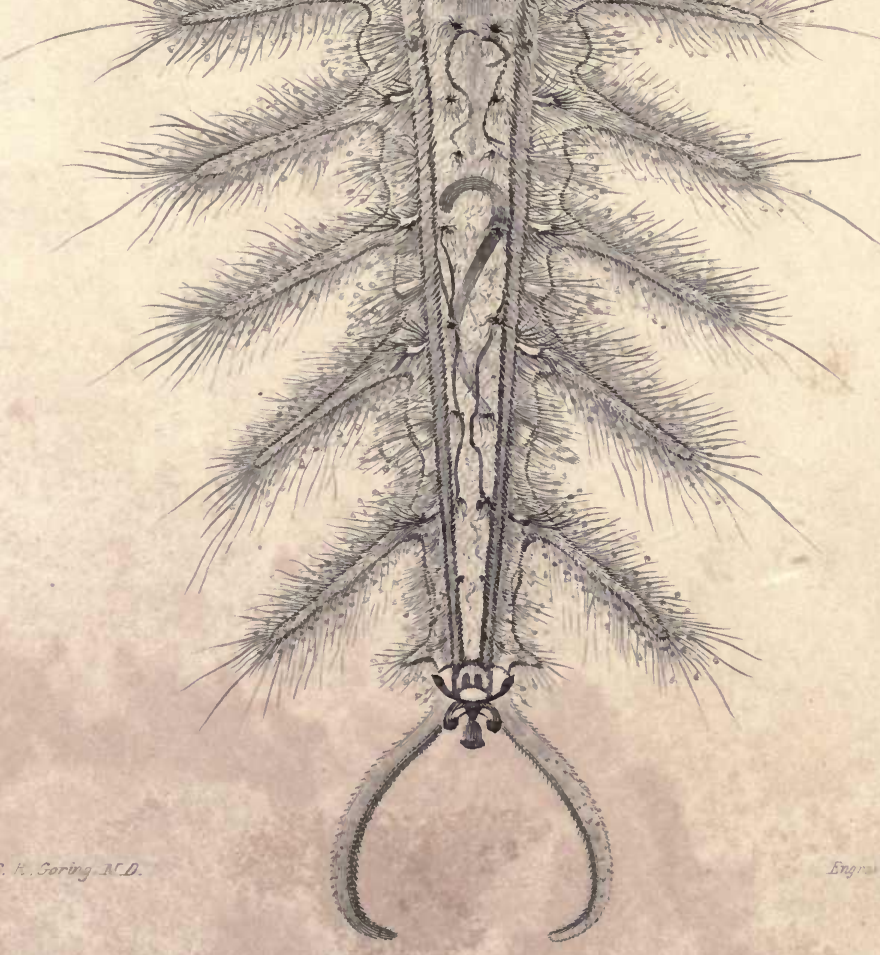


कर
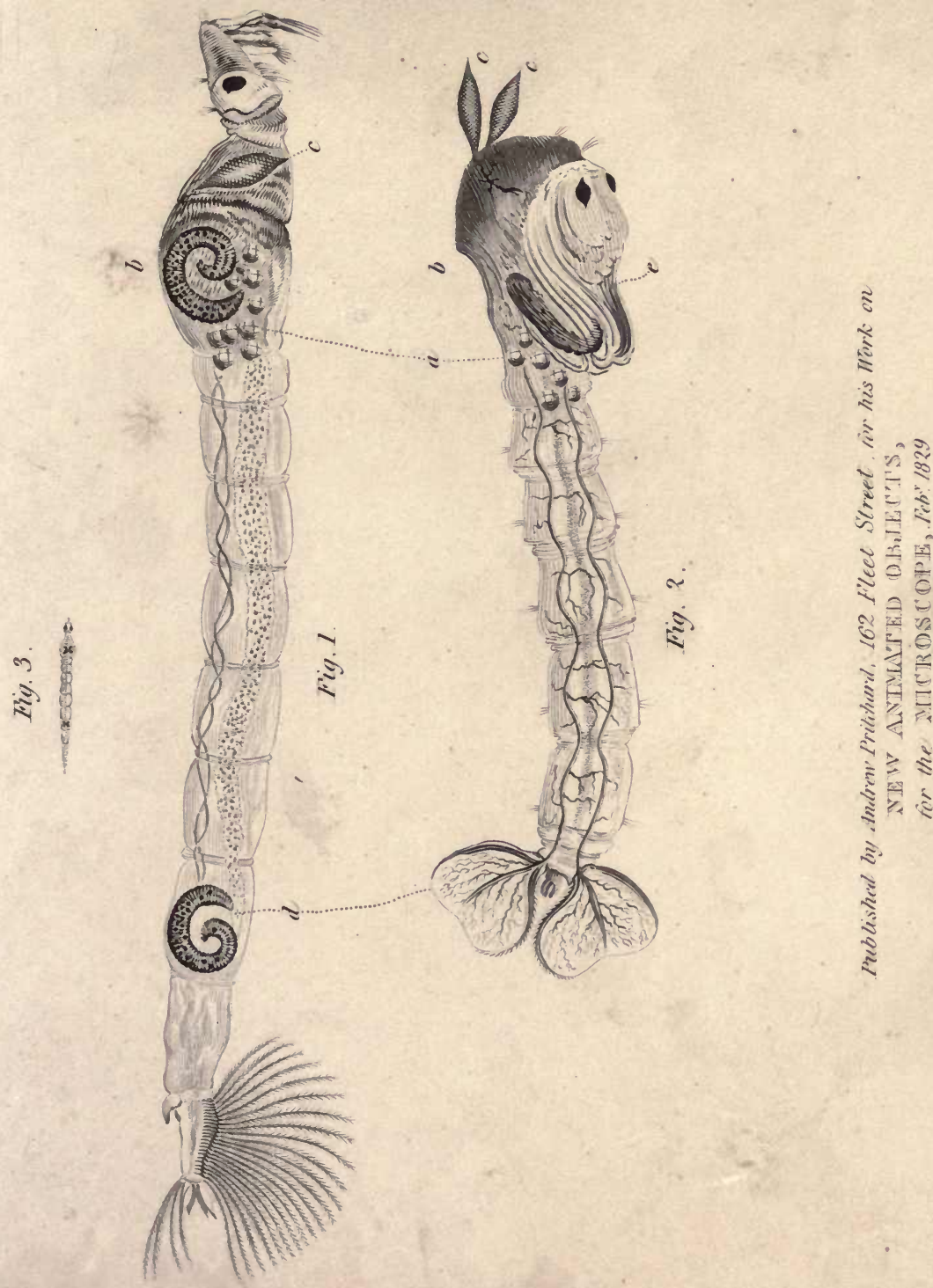


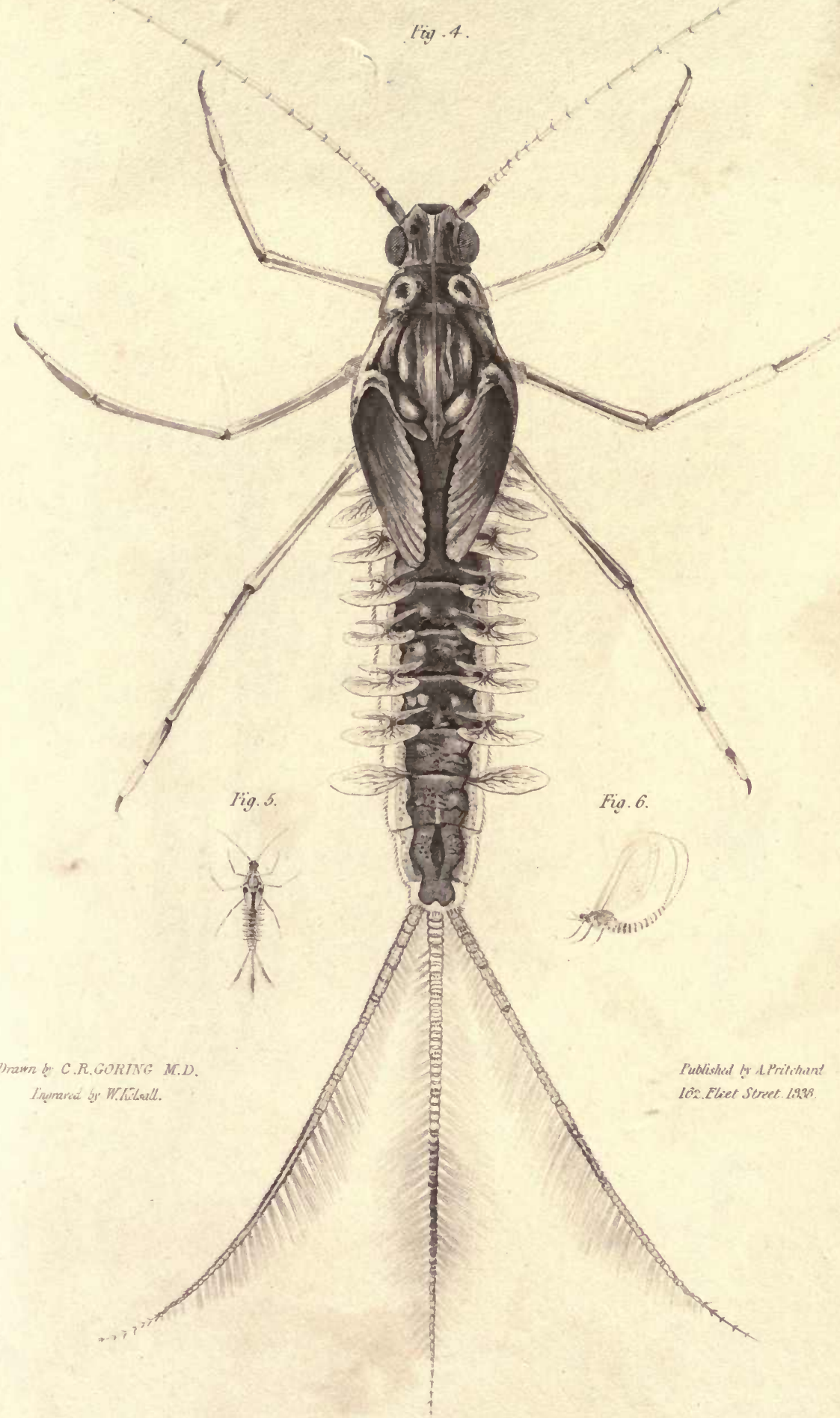






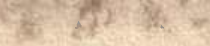

\&

$y^{2}$

a.

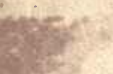

$\frac{28}{48}$

tog:

is

3is
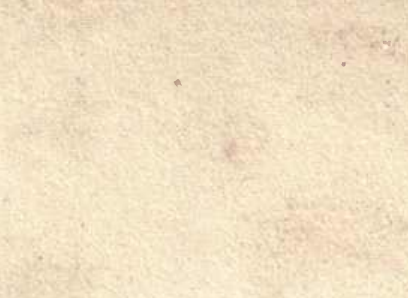

s. $\quad \therefore$

60.425:

tom

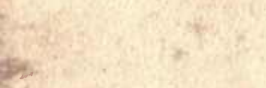



A-1 
